INSTITUTO DE PESQUISAS ENERGÉTICAS E NUCLEARES

Autarquia associada à Universidade de São Paulo

\title{
DETERMINAÇÃO DE ELEMENTOS ESSENCIAIS E TÓXICOS EM ALIMENTOS COMERCIAIS INFANTIS POR ANÁLISE POR ATIVAÇÃO COM NÊUTRONS E ESPECTROMETRIA DE ABSORÇÃO ATÔMICA
}

PRISCILA VALLINOTO

Dissertação apresentada como parte dos requisitos para obtenção do Grau de Mestre em Ciências na Área de Tecnologia Nuclear - Aplicações

Orientadora:

Dra. Vera Akiko Maihara

SÃO PAULO

2013 
Dedico à minha mãe Vera (in memorian)

e ao meu amor Victor Hugo por todo carinho, compreensão e incentivos. 
Mais Uma Vez

Renato Russo

Compositores: Flávio Venturini e Renato Russo

Mas é claro que o Sol

Vai voltar amanhã

Mais uma vez, eu sei

Escuridão já vi pior

De endoidecer gente sã

Espera que o Sol já vem

Tem gente que está do mesmo lado que você

Mas deveria estar do lado de lá

Tem gente que machuca os outros

Tem gente que não sabe amar

Tem gente enganando a gente

Veja nossa vida como está

Mas eu sei que um dia a gente aprende

Se você quiser alguém em quem confiar

Confie em si mesmo

Quem acredita sempre alcança

Mas é claro que o Sol

Vai voltar amanhã

Mais uma vez, eu sei

Escuridão já vi pior

De endoidecer gente sã

Espera que o Sol já vem

Nunca deixe que lhe digam

Que não vale a pena acreditar no sonho que se tem

Ou que seus planos nunca vão dar certo

Ou que você nunca vai ser alguém

Tem gente que machuca os outros

Tem gente que não sabe amar

Mas eu sei que um dia a gente aprende

Se você quiser alguém em quem confiar

Confie em si mesmo

Quem acredita sempre alcança 


\section{AGRADECIMENTOS}

A Deus, pelo dom da vida e por sempre olhar por mim.

À minha mãe (in memorian), por me ensinar a lutar pelos meus sonhos e ser o meu melhor exemplo de perseverança!

À Dra. Vera Akiko Maihara, pela orientação, carinho, dedicação, paciência e amizade. Por me fazer acreditar no meu potencial! Agradeço por confiar no meu trabalho e me ajudar a fazer um sonho virar realidade!

À Dra. Sônia Buongermino de Souza pela colaboração, disponibilidade e ensinamentos dados ao longo desse trabalho! Agradeço pela contribuição dada em cada um dos diversos encontros!

À Dra. Mitiko Saiki por todo o carinho e disponibilidade em todos os momentos que precisei! Agradeço por todo o incentivo e confiança! Uma pessoa que se tornou especial ao longo desse trabalho!

Ao Dr. Paulo Sérgio Cardoso da Silva pela paciência, ensinamentos e disponibilidade. Um apoio fundamental para o término desta dissertação!

Ao Dr. Edson Gonçalves Moreira, pelo carinho, amizade, e conhecimento! Sempre disponível em momentos importantes para a realização deste trabalho.

À Universidade de São Paulo (USP) e ao Instituto de Pesquisas Energéticas e Nucleares (IPEN-CNEN/SP), na pessoa do Sr. Superintendente Dr. José Carlos Bressiani, pela oportunidade concedida para executar esse trabalho.

À Comissão Nacional de Energia Nuclear (CNEN) pela concessão da bolsa de mestrado. 
Ao meu amor, Victor Hugo, por ser o meu porto seguro, me apoiar, ouvir ou simplesmente me abraçar em momentos difíceis! Agradeço por toda paciência, por me incentivar e por estar sempre ao meu lado!

À minha irmã, Paula, por estar sempre ao meu lado em todos os momentos. Por acreditar na minha capacidade e me incentivar sempre! Agradeço por todo incentivo e carinho!

Ao meu cunhado, Ney, por me aconselhar, orientar e estar presente em momentos muito importantes da minha vida! Por todas as conversas, ensinamentos e conselhos. Agradeço por ter se tornado um irmão!

Ao Roberto Hazenfratz-Marks por todo carinho, amizade, compreensão e solidariedade! Pelos ensinamentos e auxílio que foram essenciais para este trabalho. Por ser um amigo, companheiro, conselheiro! Agradeço por ser tão especial para $\operatorname{mim}$ !

Ao Diego Renan Tudela pela amizade, carinho e apoio em todos os momentos do mestrado! Por toda alegria que me proporcionou durante todo o tempo de convivência!

Aos amigos do Laboratório de Análise por Ativação com Nêutrons (LAN) do IPENCNEN/SP, Maria José Armelin (Tata), Guilherme Zahn, Daniele, Mychelle, Thalita, Rita, Elaine, Tassiane, Rogério, Kelly, Regina, Edson A., Eliane, Raphael, Vinicius, Karen, Cássio, Mauro, pela amizade, convivência, apoio sempre que preciso e por todos os bons momentos que passamos juntos.

E, finalmente, a todos aqueles que direta ou indiretamente contribuíram para concretização deste trabalho. 


\title{
DETERMINAÇÃO DOS ELEMENTOS ESSENCIAIS E TÓXICOS EM ALIMENTOS COMERCIAIS INFANTIS POR ANÁLISE POR ATIVAÇÃO COM NÊUTRONS E ESPECTROMETRIA DE ABSORÇÃO ATÔMICA
}

\author{
PRISCILA VALLINOTO
}

\author{
RESUMO
}

A Organização Mundial da Saúde recomenda que os bebês sejam amamentados de forma exclusiva, pelo menos, seis meses após o nascimento. Após este período, recomenda-se a introdução de alimentos complementares, a fim de atender as quantidades nutricionais, minerais e energéticas necessárias às crianças. Produtos alimentares destinados a lactentes formam uma parte importante da dieta de muitos bebês, por isso é muito importante que esses alimentos contenham quantidades suficientes de minerais. Alimentação complementar inadequada é uma das principais causas das altas taxas de desnutrição nos países em desenvolvimento. Neste estudo, níveis dos elementos essenciais: $\mathrm{Ca}, \mathrm{Cl}, \mathrm{Co}, \mathrm{Cr}, \mathrm{Fe}, \mathrm{K}, \mathrm{Mg}, \mathrm{Mn}, \mathrm{Na}$, Se e $\mathrm{Zn}$ e dos elementos tóxicos: As, Cd e Hg foram determinados em amostras de vinte e sete diferentes produtos alimentares por Análise por Ativação com Nêutrons Instrumental (INAA) e Espectrometria de Absorção Atômica (AAS). Para a validação da metodologia foram analisados os materiais de referência: INCT MPH-2 Mixed Polish Herbs e NIST - SRM 1577b Bovine Liver para INAA e NIST - SRM 1548a Typical Diet e NIST - SRM 1547 Peach Leaves para AAS. As vinte e sete amostras de alimentos para bebês foram adquiridas em supermercados e drogarias da cidade de São Paulo. Os elementos essenciais e tóxicos foram determinados e a maioria das concentrações obtidas dos elementos essenciais estava abaixo das recomendações da Organização Mundial da Saúde, enquanto as concentrações dos elementos tóxicos foram inferiores ao limite superior tolerável. As concentrações baixas dos elementos essenciais obtidas nessas amostras indicam que as crianças não devem ser apenas alimentadas com esses alimentos comerciais. 


\title{
DETERMINATION OF ESSENTIAL AND TOXIC ELEMENTS IN COMMERCIAL BABY FOODS BY INSTRUMENTAL NEUTRON ACTIVATION ANALYSIS AND ATOMIC ABSORPTION SPECTROMETRY
}

\author{
PRISCILA VALLINOTO
}

\begin{abstract}
The World Health Organization recommends that infants should be breastfed exclusively for at least six months after birth. After this period, it is recommended to start introducing complementary foods, in order to meet the child's nutritional, mineral and energy needs. Commercial food products for infants form an important part of the diet for many babies. Thus, it is very important that such food contains sufficient amounts of minerals. Inadequate complementary feeding is a major cause of high rates of infant malnutrition in developing countries. In this study, essential elements: $\mathrm{Ca}, \mathrm{Cl}, \mathrm{Co}, \mathrm{Cr}, \mathrm{Fe}$, $\mathrm{K}, \mathrm{Mg}, \mathrm{Mn}, \mathrm{Na}$, Se and $\mathrm{Zn}$ and toxic elements: As, $\mathrm{Cd}$, Hg levels were determined in twenty seven different commercial infant food product samples by Instrumental Neutron Activation Analysis (INAA) and Atomic Absorption Spectrometry (AAS). In order to validate both methodologies the reference material: INCT MPH-2 Mixed Polish Herbs and NIST - SRM 1577b Bovine Liver by INAA and NIST SRM 1548a Typical Diet and NIST - SRM 1547 Peach Leaves by AAS were analyzed. The twenty seven baby food samples were acquired from São Paulo city super markets and drugstores. Essential and toxic elements were determined. Most of the essential element concentrations obtained was lower than the World Health Organization requirements, while concentrations of toxic elements were below the tolerable upper limit. These low essential element concentrations in these samples indicate that infants should not be fed only with commercial complementary foods.
\end{abstract}




\section{SUMÁRIO}

Página

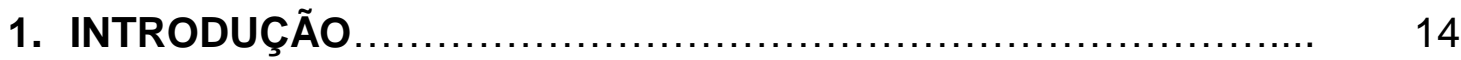

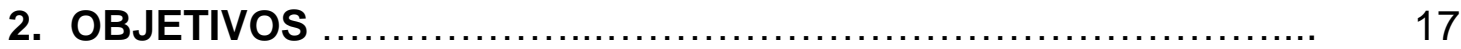

2.1. Objetivo geral............................................. 17

2.2. Objetivos específicos............................................ 17

3. ALIMENTAÇÃO INFANTIL......................................................... 18

3.1. Alimentação de crianças até seis meses................................ 18

3.2. Alimentação de crianças a partir de seis meses...................... 19

3.2.1. Introdução da alimentação complementar.......................... 21

3.2.2. Frequência da alimentação complementar........................ 21

3.2.3. Aceitação dos alimentos complementares......................... 22

3.2.4. Alimentos complementares............................................ 23

3.2.4.1. Tipos de alimentos complementares.............................. $\quad 26$

4. REVISÃO BIBLIOGRÁFICA....................................................... 28

5. MÉTODOS ................................................................ 32

5.1. Análise por Ativação com Nêutrons Instrumental (INAA)........... 32

5.2. Espectrometria de Absorção Atômica (AAS).............................. $\quad 35$

5.2.1. Espectrometria de Absorção Atômica com Atomização Eletrotérmica (ET AAS): Determinação de Cd........................... $\quad 36$

5.2.2. Espectrometria de Absorção Atômica com Geração de Vapor Frio (CV AAS): Determinação de Hg............................... $\quad 37$

5.3. Material de Referência Certificado (CRM) ................................... 37

6. PARTE EXPERIMENTAL....................................................... 38

6.1. Alimentos comerciais infantis............................................... 38

6.2. Preparação das amostras para análise ..................................... 39

6.3. Análise por Ativação com Nêutrons Instrumental (INAA)........... 41 
6.3.1. Preparação dos padrões sintéticos

6.3.2. Preparação e irradiação para a determinação dos radionuclídeos de meia-vida curta (meia-vida < 15 horas)...........

6.3.3. Preparação e irradiação para a determinação dos radionuclídeos de meia-vida longa (meia-vida $>1$ dia)

6.3.4. Medição das atividades dos radionuclídeos de meia-vida curta.

6.3.5. Medição das atividades dos radionuclídeos de meia-vida longa.

6.3.6. Medição das atividades e processamento dos espectros..

6.3.7. Identificação dos radionuclídeos.

6.4. Espectrometria de Absorção Atômica (AAS)

6.4.1. Preparo das amostras e dos materiais de referência certificados para análise.

6.4.2. Preparo das soluções-padrão......................................... 46

6.4.3. Parâmetros de análise..................................................... 47

6.4.4. Soluções complementares............................................... 48

7. RESULTADOS E DISCUSSÃO..................................................... 49

7.1. Análise dos materiais de referência certificados....................... 49

7.2. Concentração dos elementos nas amostras de alimentos comerciais infantis pelo método INAA.

7.3. Concentração dos elementos nas amostras de alimentos comerciais infantis pelo método AAS.

8. TRATAMENTO ESTATíSTICO ................................................... 93

8.1. Análise de agrupamento..................................................... 93

8.2. Coeficiente de correlação...................................................... 95

8.3. Análise de variância.................................................................. 97

9. CONSIDERAÇÕES FINAIS ................................................... 99

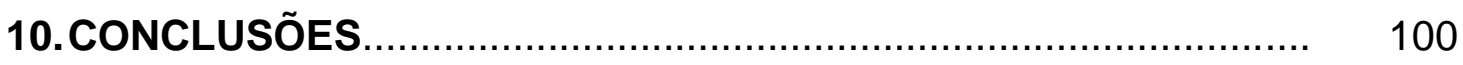

11. REFERÊNCIAS BIBLIOGRÁFICAS ........................................ 101 


\section{LISTA DE FIGURAS}

Página

Figura 1 Princípio da Análise por Ativação com Nêutrons................... 34

Figura 2 Esquema de um espectrômetro de Absorção Atômica.......... 36

Figura 3 Amostras no liofilizador................................................... 40

Figura 4 Amostra doce antes e após o processo de liofilização........... 40

Figura 5 Esquema das principais etapas do método INAA.................. 41

Figura 6 Esquema das principais etapas do método AAS ................... $\quad 45$

Figura 7 Fluxograma da digestão ácida para o método AAS............... 46

Figura 8 Dendrograma da análise de agrupamento para os elementos analisados nas amostras de alimentos comerciais infantis. $\quad 94$ 


\section{LISTA DE TABELAS}

Página

Tabela 1 Grupos de alimentos que devem ser oferecidos às crianças a partir dos seis meses de idade.

Tabela 2 Esquema de alimentação para crianças em amamentação.................. 25

Tabela 3 Esquema de alimentação para crianças não amamentadas................. 25

Tabela 4 Classificação dos alimentos comerciais infantis segundo as especificações do fabricante.

Tabela 5 Dados das amostras com seus códigos, principais ingredientes e classificação em etapas.

Tabela 6 Tempo de meia-vida e energia dos raios gama dos radionuclídeos......

Tabela 7 Dados utilizados para construção da curva analítica para a determinação de $\mathrm{Hg}$......

Tabela 8 Dados utilizados para construção da curva analítica para a determinação de $\mathrm{Cd}$

Tabela 9 Parâmetros para a determinação de $\mathrm{Hg}$.

Tabela 10 Parâmetros para a determinação de Cd

Tabela 11 Concentrações dos elementos no Mixed Polish Herbs (INCT-MPH-2) em base seca analisados por INAA.

Tabela 12 Concentrações dos elementos no Bovine Liver (NIST-1577b) em base seca analisados por INAA

Tabela 13 Concentrações dos elementos no Typical Diet (NIST-1548a) em base seca analisados por AAS.

Tabela 14 Concentrações dos elementos no Peach Leaves (NIST-1547) em base seca analisados por AAS

Tabela 15 Limites de detecção dos elementos determinados por INAA. 
Tabela 16 Concentrações dos elementos essenciais nas amostras em base seca (média \pm desvio padrão)...................................................................... 56

Tabela 17 Concentrações dos elementos essenciais nas amostras in natura (média \pm desvio padrão).

Tabela 18 Massas dos elementos essenciais presentes em $100 \mathrm{~g}$ de amostra (média \pm desvio padrão)

Tabela 19 Massas dos elementos essenciais por frasco comercial de amostra (média \pm desvio padrão)

Tabela 20 Comparação entre as massas dos elementos essenciais por frasco comercial de amostra obtidas neste estudo com as informações presentes no rótulo (média \pm desvio padrão).

Tabela 21 Comparação entre os valores dos elementos essenciais obtidos neste trabalho com os valores publicados por outros autores por $100 \mathrm{~g}$ de amostra (média \pm desvio padrão)

Tabela 22 Limites de detecção dos elementos determinados por AAS

Tabela 23 Concentrações dos elementos tóxicos nas amostras em base seca (média \pm desvio padrão).

Tabela 24 Concentrações dos elementos tóxicos nas amostras in natura (média \pm desvio padrão).

Tabela 25 Massas dos elementos tóxicos presentes em $100 \mathrm{~g}$ de amostra (média \pm desvio padrão)

Tabela 26 Massas dos elementos tóxicos por frasco comercial de amostra (média \pm desvio padrão).

Tabela 27 Coeficientes de correlação para os elementos analisados por INAA...

Tabela 28 Análise de variância para as médias dos elementos entre as diferentes etapas de alimentos comerciais infantis. 


\section{LISTA DE GRÁFICOS}

\section{Página}

Gráfico 1 Massa de Ca presente por frasco comercial e em $100 \mathrm{~g}$ de amostra. $\quad 63$

Gráfico 2 Massa de $\mathrm{Cl}$ presente por frasco comercial e em $100 \mathrm{~g}$ de amostra. $\quad 64$

Gráfico 3 Massa de Co presente por frasco comercial e em $100 \mathrm{~g}$ de amostra. 66

Gráfico 4 Massa de Cr presente por frasco comercial e em $100 \mathrm{~g}$ de amostra. $\quad 68$

Gráfico 5 Massa de Fe presente por frasco comercial e em $100 \mathrm{~g}$ de amostra. $\quad 70$

Gráfico 6 Massa de K presente por frasco comercial e em $100 \mathrm{~g}$ de amostra. $\quad 71$

Gráfico 7 Massa de Mg presente por frasco comercial e em $100 \mathrm{~g}$ de amostra. 73

Gráfico 8 Massa de Mn presente por frasco comercial e em $100 \mathrm{~g}$ de amostra. $\quad 74$

Gráfico 9 Massa de Na presente por frasco comercial e em $100 \mathrm{~g}$ de amostra. 76

Gráfico 10 Massa de Se presente por frasco comercial e em $100 \mathrm{~g}$ de amostra. 78

Gráfico-11 Massa de Zn presente por frasco comercial e em $100 \mathrm{~g}$ de amostra. 80

Gráfico 12 Massa de Cd presente por frasco comercial e em $100 \mathrm{~g}$ de amostra. 91

Gráfico 13 Massa de $\mathrm{Hg}$ presente por frasco comercial e em $100 \mathrm{~g}$ de amostra. 91 


\section{INTRODUÇÃO}

A alimentação infantil é motivo de muitas preocupações, dado que, no início da vida, fatores nutricionais e metabólicos têm efeito de longo prazo na saúde da vida adulta (Brasil, 2006). Após o nascimento, tem-se o período caracterizado por rápido crescimento e desenvolvimento, quando há necessidade elevada de energia, exigindo consumo maior de alimentos em relação ao peso da criança. A necessidade de nutrientes no período pós-nascimento, em relação ao peso, em média é muito maior do que em crianças mais velhas (Kazi et al., 2010). O período entre os 6 e 24 meses de idade é considerado crítico para a promoção de nutrição adequada. É nesse período que ocorre maior prevalência de desnutrição e deficiência de certos micronutrientes. Deste modo, é necessário ter grande preocupação com os alimentos que são oferecidos às crianças (Giugliani e Victora, 2000).

Nos primeiros anos de vida, é essencial para o crescimento e desenvolvimento da criança uma alimentação qualitativa e quantitativamente adequada, pois ela proporciona ao organismo a energia e os nutrientes necessários para o bom desempenho de suas funções e para a manutenção de um bom estado de saúde. As práticas alimentares são adquiridas durante toda a vida, destacando-se os primeiros anos como um período muito importante para o estabelecimento de hábitos alimentares que promovam a saúde do indivíduo (Philippi et al., 2003).

Uma nutrição inadequada ou incorreta pode afetar diretamente o crescimento da criança e pode ter consequências em longo prazo sobre o desenvolvimento dos órgãos e funções, que pode resultar em efeitos adversos para a saúde na vida adulta (Brasil, 2006).

O alimento é a fonte primária de elementos essenciais para os seres humanos e é uma importante fonte de exposição a elementos prejudiciais à saúde. Conhecer os níveis dos elementos essenciais e elementos tóxicos em alimentos é bastante importante, pois além de influenciar na saúde da criança, a carência dos essenciais 
ou excesso de tóxicos e/ou essenciais, pode trazer consequências, algumas vezes irremediáveis, para a vida toda (Nardi et al., 2009). Elementos-traço desempenham importante papel na biologia humana, e possuem grande variedade de funções bioquímicas em todos os organismos vivos. Embora os elementos-traço sejam essenciais, quando estes se apresentam em excesso, podem ser tóxicos (Saracoglu et al., 2007).

A ingestão de alguns minerais pode constituir grande risco à saúde, quando consumidos acima do limite superior tolerável por um longo período. Nesse sentido, a Organização Mundial da Saúde tem feito recomendações de ingestões diárias de minerais para bebês e crianças (Melo et al., 2008). A exposição de crianças a elementos essenciais em suas dietas deve ser considerada, já que durante o primeiro ano de vida há um rápido crescimento e desenvolvimento, resultando em uma necessidade energética, logo consumo alimentar relativamente muito mais alto, em relação a crianças mais velhas, quando comparado ao seu peso corporal (Saracoglu et al., 2007).

Deve-se salientar que para as crianças, principalmente, deve-se tomar cuidado com a alimentação, pelo fato de ocorrer a incorporação de novos hábitos alimentares que implicam no conhecimento de novos sabores, texturas e cores, experiências sensoriais que irão influenciar diretamente o padrão alimentar a ser adotado (Barbosa et al., 2005). O consumo inadequado, muitas vezes em excesso, pode comprometer a saúde da criança e do adulto. Muitos alimentos industriais são ricos em gorduras, carboidratos refinados e sódio, apresentando elevado teor energético. Além disso, os hábitos adquiridos com o aumento do consumo de alimentos industrializados podem reduzir o consumo de alimentos "in natura" (PAHO/WHO, 2003).

Os hábitos alimentares da população mudaram muito nesses últimos anos. A substituição de alimentos caseiros e naturais por alimentos industrializados com elevado grau de processamento tem se tornado cada vez mais frequente. Tais mudanças foram influenciadas por diversos fatores, dentre eles a influência do mercado publicitário, a globalização, o ritmo acelerado de vida nas grandes cidades e o trabalho da mulher fora do lar (Aquino, 2002; Toloni et al., 2011). 
O oferecimento de alimentos altamente energéticos e de baixo valor nutricional, assim como o abandono precoce da amamentação, contribuem para o comprometimento do crescimento e desenvolvimento da criança. É necessária uma preocupação com a alimentação complementar, dado que dietas hiperenergéticas, com excesso de açúcares simples, gorduras animais, ácidos graxos saturados, gorduras trans e sódio podem levar ao surgimento precoce de doenças crônicas não transmissíveis (Toloni et al., 2011).

A rotulagem nutricional é importante aliado para permitir às mães que façam escolhas alimentares mais saudáveis (Monteiro et al., 2005). Os rótulos disponibilizam dados sobre o conteúdo nutricional e podem relacionar o consumo do alimento com benefícios para a saúde. No entanto, o nível de compreensão que os consumidores têm sobre os rótulos é de fundamental importância para uma escolha alimentar mais criteriosa (Coutinho, 2007; Marins et al., 2008).

No Brasil, a Agência Nacional de Vigilância Sanitária (ANVISA) elaborou, nos anos de 2000 e 2001, a legislação que determina as informações nutricionais obrigatórias a serem veiculadas nos rótulos de alimentos (BRASIL, RDC nํㅜ, 2001; BRASIL, RDC no-40, 2001). Essa legislação, juntamente com as leis anteriores que estabeleciam padrões de qualidade, serve como base para as atividades de educação para o consumo saudável (Monteiro et al., 2005). Segundo a ANVISA, os nutrientes a serem declarados nos rótulos dos alimentos:

"Devem ser declarados, obrigatoriamente, o valor energético e os seguintes nutrientes: carboidratos, proteínas, gorduras totais, gorduras saturadas, gorduras trans, fibra alimentar e sódio" (BRASIL, RDC nํ360, 2003;).

O único elemento cuja concentração deve ser informada no rótulo, segundo a legislação imposta pela ANVISA é o sódio. A informação sobre a quantidade dos outros elementos presentes nos alimentos fica a critério do fabricante. Devido à essa escassez de informações no rótulo, é importante saber o conteúdo nutricional dos alimentos, principalmente quando estes são destinados às crianças. Com base nessas informações, verificou-se a importância de identificar e quantificar alguns elementos essenciais e tóxicos presentes em alimentos comerciais infantis. 


\section{OBJETIVOS}

\subsection{Objetivo geral}

Determinação de elementos essenciais como $\mathrm{Ca}, \mathrm{Cl}, \mathrm{Co}, \mathrm{Cr}, \mathrm{Fe}, \mathrm{K}, \mathrm{Mg}, \mathrm{Mn}$, $\mathrm{Na}$, Se e $\mathrm{Zn}$ e dos tóxicos As, $\mathrm{Cd}$ e $\mathrm{Hg}$ em alimentos comerciais infantis oferecidos às crianças a partir do sexto mês de idade.

\subsection{Objetivos específicos}

- Comparar os resultados obtidos com os valores fornecidos pela Organização Mundial da Saúde e outros órgãos de saúde, como o Institute of Medicine;

- Verificar se os alimentos comerciais infantis atendem às recomendações de ingestão diária para cada nutriente estudado;

- Verificar se os alimentos comerciais infantis contêm elementos tóxicos em sua composição. Se a presença desses elementos for detectada, analisar se a concentração encontrada está abaixo do limite superior permitido pelas legislações nacional e internacional. 


\section{ALIMENTAÇÃO INFANTIL}

\subsection{Alimentação de crianças até seis meses}

A Organização Mundial da Saúde recomenda amamentação exclusiva até os seis meses de idade. Amamentação exclusiva é definida como o oferecimento exclusivo de leite materno ao bebê, sem adição de outros líquidos ou sólidos (Ladomenou et al., 2010; Kramer e Kakuma, 2012).

O leite materno é especialmente adequado para as necessidades do bebê. Além de ser a melhor fonte de nutrição para a criança, o leite materno oferece proteção contra infecções, doenças autoimunes, disfunções gastrointestinais e promove o desenvolvimento cognitivo (Chezem, 2012; Huntes et al., 2012). O leite possui diversos fatores de defesa, dentre eles agentes antimicrobianos, imunomoduladores e anti-inflamatórios que combatem infecções e estimulam o sistema imune. O recém-nascido é mais vulnerável às infecções, devido à imaturidade do seu sistema imunológico, por isso a amamentação se torna essencial na proteção do bebê (Nick, 2011).

O leite humano é composto por diversos nutrientes, como proteínas, lipídeos, carboidratos, minerais, elementos-traço que são de extrema importância para atender às necessidades nutricionais e para garantir o crescimento e desenvolvimento normal do lactente (Anatolitou, 2012).

A dieta materna pode ter uma influência significativa sobre a produção e/ou composição do leite. O leite proveniente de mães desnutridas tem aproximadamente a mesma proporção de proteínas, carboidratos e gorduras do leite oriundo de mães bem nutridas, a diferença é a menor quantidade de leite produzido por mães desnutridas (Agostoni et al., 2009).

A partir dos seis meses, as necessidades nutricionais da criança não podem ser supridas apenas pelo leite humano. Nesta fase, a maioria das crianças atinge um 
estágio de desenvolvimento geral e neurológico, incluindo mastigação, deglutição, digestão e excreção, tornando possível o oferecimento de outros alimentos em complemento ao leite materno (Monte e Giugliani, 2004).

\subsection{Alimentação de crianças a partir de seis meses}

A partir dos seis meses de idade, alimentos complementares devem ser oferecidos às crianças em adição à amamentação, a qual deve ser mantida até os dois anos ou mais (Arabi et al., 2012).

Segundo Monte e Giugliani (2004), alimentos complementares são definidos como qualquer alimento, líquido ou sólido, oferecido à criança em adição ao leite materno, durante o período definido como período de alimentação complementar.

A introdução oportuna de alimentos complementares durante a infância é necessária tanto por razões nutricionais e desenvolvimento quanto por permitir a transição da amamentação para os alimentos familiares (Agostoni et al., 2008).

A introdução de práticas inadequadas de alimentação complementar pode resultar em vários danos para o crescimento e desenvolvimento da criança. $A$ introdução precoce de alimentos complementares reduz a duração da amamentação, interfere na absorção de importantes nutrientes existentes no leite materno, como o ferro e o zinco, além de aumentar a taxa de morbimortalidade infantil, isso porque há uma queda na ingestão dos fatores de proteção existentes no leite materno. Os alimentos complementares são considerados importante fonte de contaminação das crianças (Monte e Giugliani, 2004).

Assim como a introdução precoce da alimentação complementar oferece vários riscos à criança, a introdução tardia desses alimentos também é desfavorável, dado que o leite materno sozinho, a partir do sexto mês, não satisfaz as necessidades energéticas e nutricionais da criança, resultando na diminuição ou estagnação do crescimento, aumentando o risco de desnutrição e de deficiências de micronutrientes (Monte e Giugliani, 2004; Torigoe et al., 2012).

O período de introdução de alimentos complementares é muito importante, visto os efeitos que podem ocorrer com a introdução precoce ou tardia desta alimentação. Outro fator importante com relação aos alimentos complementares é a 
sua adequação nutricional. Uma alimentação complementar nutricionalmente adequada auxilia na prevenção da morbimortalidade na infância, incluindo a desnutrição e o sobrepeso (Dias et al., 2010).

Para a alimentação complementar ser considerada adequada, é necessário que exista composição equilibrada de alimentos, os quais devem conter quantidades adequadas de macro e micronutrientes, estar livres de qualquer tipo de contaminação, seja ela física, química ou biológica, ser de fácil consumo e aceitação e, finalmente, preparados com a utilização de alimentos consumidos habitualmente pela família (Caetano et al., 2010).

Crianças até os dois anos de idade se encontram em um período denominado "janela crítica de oportunidade" para a prevenção do crescimento vacilante e desnutrição e para o desenvolvimento cognitivo ideal (Arabi et al., 2012).

Alimentos complementares de baixa qualidade, com baixa densidade de nutrientes e práticas alimentares inadequadas foram identificados como uma das principais causas de desnutrição em crianças pequenas. Em países em desenvolvimento, além da introdução da alimentação complementar precoce ou tardia, ainda há o problema dos alimentos complementares oferecidos em quantidade e qualidade insuficientes, levando a grande risco de doenças nutricionais (Owino et al., 2008).

A maioria dos alimentos complementares habitualmente utilizados em países em desenvolvimento é à base de grãos de cereais fortificados, caracterizados por baixa densidade energética e, nutricional e são frequentemente inadequados em zinco, ferro e piridoxina, e podem ainda ser deficientes em cálcio, riboflavina, niacina, tiamina, ácido fólico, ácido ascórbico e vitamina A (Owino et al., 2008).

A promoção da amamentação passou por consideráveis avanços nos últimos anos, porém o mesmo não ocorreu com a alimentação complementar. A maneira como a alimentação complementar deve ser introduzida, bem como quais alimentos devem ser oferecidos ainda é um assunto pouco discutido frente às discussões sobre aleitamento (Dias, 2010; Santos, 2010).

Estudos recentes sobre alimentação infantil têm mostrado que alguns conceitos e recomendações utilizados por muitas décadas se tornaram 
ultrapassados. Estudos da década de 70 e 80 recomendavam o oferecimento de água, considerando-a como fonte de alimento e sucos nos intervalos das mamadas para crianças com idade entre 1 e 4 meses. A introdução de papas deveria ser feita a partir do $5^{\circ}$ mês, iniciando pela papa de hortaliças e oferecendo a papa de fruta como sobremesa (Kubota et al., 1980). Embora essas recomendações estejam ultrapassadas e existam estudos nessa área que implicaram em modificações a respeito desses conceitos, uma parcela da população, incluindo profissionais da área, desconhecem o avanço científico a respeito desse tema e continuam seguindo as orientações antigas (PAHO-WHO, 2003).

Segundo Lopez e Brasil (2004), aos seis meses as crianças devem receber, além do leite materno, os alimentos complementares, os quais devem ser compostos por frutas na forma de papas ou sucos. A partir dos seis meses e meio, devem ser introduzidas as papas salgadas.

\subsubsection{Introdução da alimentação complementar}

O Ministério da Saúde, através do Guia Alimentar para Crianças Menores de Dois Anos, recomenda que as frutas sejam o primeiro tipo de alimento complementar oferecido à criança. Em seguida, recomenda-se que os alimentos complementares sejam oferecidos nesta sequência: gema de ovos, cereais, tubérculos e hortaliças, leguminosas e carnes (Brasil, 2005). A dieta deve ser variada e a consistência deve progredir até chegar nos alimentos sólidos. Alimentos complementares na forma de papas ou amassados devem ser utilizados ao invés da forma líquida, dado que este último pode ser prejudicial ao processo de desenvolvimento da mastigação (Bernardi et al., 2009).

\subsubsection{Frequência da alimentação complementar}

A frequência da alimentação complementar varia se a criança ainda está em amamentação ou se não recebe mais o leite materno. No Guia Alimentar para Crianças Menores de Dois Anos (Brasil, 2005), recomenda-se que crianças amamentadas recebam três porções de alimentos complementares, enquanto crianças não amamentadas devem receber cinco refeições. 


\subsubsection{Aceitação dos alimentos complementares}

Até a última década, na literatura científica, não havia muitas pesquisas baseadas em evidências sobre quais os alimentos complementares mais apropriados e os métodos para a introdução destes alimentos. Consequentemente, muitas práticas de alimentação complementar são baseadas nas crenças dos pais, tradições familiares ou conhecimento médico (Mennella e Trabulsi, 2012).

Segundo o Ministério da Saúde (Brasil, 2005), para garantir uma alimentação nutricionalmente adequada para a saúde e desenvolvimento da criança, é necessário o consumo de alimentos variados. Uma dieta variada é essencial para o crescimento infantil, bem como para a formação dos hábitos alimentares.

Os diferentes tipos de alimentos não possuem o mesmo grau de aceitação pela criança. A aceitação de vegetais verdes, por exemplo, é mais difícil do que a de frutas e legumes (Nicklaus, 2009). Normalmente, crianças costumam rejeitar alimentos desconhecidos, comportamento conhecido como neofobia alimentar. Algumas mães interpretam erroneamente esta rejeição como uma aversão permanente ao alimento. Nesse momento, é importante que a mãe se concentre na vontade da criança de comer a comida em vez de suas expressões faciais, e continuar a oferecer repetidas oportunidades para a criança provar a comida, bem como outros alimentos do mesmo grupo (Mennella e Trabulsi, 2012).

A exposição repetida ao alimento aumenta a chance de aceitação pelo bebê, por isso as mães não devem desistir de oferecê-lo nas primeiras rejeições da criança. Para que uma criança aceite um novo alimento em sua dieta, são necessárias, em média, de oito a dez repetições. A preferência por determinados alimentos é um processo de aprendizagem, portanto crianças tendem a preferir alimentos aos quais foram expostas com maior frequência (Dias et al., 2010).

Os bebês podem discriminar os sabores de diferentes frutas e vegetais. A exposição a uma variedade de sabores promove a vontade de comer alimentos variados. As mães devem expor seus bebês repetidamente a uma variedade de frutas e vegetais, ricos em nutrientes, dentro e entre as refeições; isto ajuda as 
crianças a se acostumarem com os novos alimentos e os alimentos da família (Mennella e Trabulsi, 2012).

O reconhecimento alimentar se inicia no útero, onde o feto começa a ser exposto a diferentes sabores transmitidos através do líquido amniótico. Alimentos consumidos pela mãe durante a amamentação são mais facilmente aceitos pelas crianças. Bebês expostos a uma variedade de alimentos são mais propensos a aceitarem novos alimentos em comparação com bebês expostos a uma dieta monótona, com pouca variação de sabores (Santos, 2010; Mennella e Trabulsi, 2012).

A variedade de sabores está associada à variedade no conteúdo nutritivo dos alimentos. A preferência por sabores variados deve aumentar a gama de nutrientes consumidos, aumentando a probabilidade de obtenção de dieta bem equilibrada (Mennella e Trabulsi, 2012).

\subsubsection{Alimentos complementares}

A alimentação complementar, a partir dos seis meses de idade, deve ser dividida em 3 refeições por dia, sendo duas refeições compostas por papa de fruta e uma refeição composta por papa salgada. O Ministério da Saúde recomenda através do livro Dez Passos para uma Alimentação Saudável para Crianças Brasileiras Menores de Dois Anos (Brasil, 2010), que a criança com seis meses receba um alimento de cada grupo na refeição salgada e uma fruta na refeição doce. Portanto, na refeição salgada a criança deve receber um cereal ou tubérculo, um legume e/ou uma verdura, feijões e uma carne ou ovo. A cada dia deve ser oferecido um alimento diferente de cada grupo para a criança ir se acostumando com os diferentes sabores. Os diferentes grupos de alimentos, sugeridos pelo Ministério da Saúde (Brasil, 2010) se encontram na Tabela 1.

Aos sete meses, a criança deverá receber duas papas de fruta e duas papas salgadas. A partir do oitavo mês, a criança pode começar a receber a alimentação da família, desde que esses alimentos não possuam excesso de temperos (Lofgren, 2008; Brasil, 2010). Ao completar 12 meses, a criança deve receber 3 refeições principais (café-da-manhã, almoço e jantar) e dois lanches (frutas ou cereais ou 
tubérculos). Na Tabela 2 e na Tabela 3 estão apresentadas as maneiras como as refeições devem ser oferecidas às crianças amamentadas e não amamentadas, respectivamente, de acordo com a idade, segundo as recomendações apresentadas no guia Dez Passos para uma Alimentação Saudável para Crianças Brasileiras Menores de Dois Anos (Brasil, 2010).

Tabela 1 - Grupos de alimentos que devem ser oferecidos às crianças a partir dos seis meses de idade

\begin{tabular}{c|c|c|c}
\hline $\begin{array}{c}\text { Cereais e } \\
\text { Tubérculos }\end{array}$ & $\begin{array}{c}\text { Hortaliças e } \\
\text { Frutas }\end{array}$ & Carnes e Ovos & Grãos \\
\hline $\begin{array}{c}\text { Arroz, mandioca, } \\
\text { batata, batata- } \\
\text { doce, } \\
\text { mandioquinha, } \\
\text { Folhas verdes, } \\
\text { abóbora, } \\
\text { beterraba, quiabo, } \\
\text { tomate, cenoura, } \\
\text { e inhame. }\end{array}$ & $\begin{array}{c}\text { Frango, codorna, } \\
\text { peixes, pato, boi e } \\
\text { laranja, banana, } \\
\text { abacate, mamão, } \\
\text { melão, melancia e } \\
\text { manga. }\end{array}$ & & $\begin{array}{c}\text { Feijões, lentilha, } \\
\text { ervilha-seca, soja } \\
\text { e grão-de-bico. }\end{array}$ \\
& & & \\
\hline
\end{tabular}

Fonte: Ministério da Saúde (Brasil, 2010) 
Tabela 2 - Esquema de alimentação para crianças em amamentação

\begin{tabular}{c|c|c}
\hline A partir de 6 meses & A partir de 7 meses & A partir de 12 meses \\
\hline Leite materno à vontade & Leite materno à vontade & $\begin{array}{c}\text { Leite materno e fruta ou } \\
\text { cereal ou tubérculo }\end{array}$ \\
\hline Papa de fruta & Papa de fruta & Fruta \\
\hline Papa salgada & Papa salgada & $\begin{array}{c}\text { Refeição básica da } \\
\text { família }\end{array}$ \\
\hline Papa de fruta & Papa de fruta & $\begin{array}{c}\text { Fruta ou pão } \\
\text { simples ou tubérculo ou } \\
\text { cereal }\end{array}$ \\
\hline Leite materno & Papa salgada & $\begin{array}{c}\text { Refeição básica da } \\
\text { família }\end{array}$ \\
\hline
\end{tabular}

Obs.: Após o oitavo mês, a criança pode receber gradativamente a alimentação da família, desde que esta não seja composta por alimentos muito temperados.

Fonte: Ministério da Saúde (Brasil, 2010)

Tabela 3 - Esquema de alimentação para crianças não amamentadas

\begin{tabular}{c|c|c}
\hline $\mathbf{4}$ a $\mathbf{8}$ meses & A partir de 8 meses & A partir de 12 meses \\
\hline Leite & Leite & $\begin{array}{c}\text { Leite e fruta ou cereal ou } \\
\text { tubérculo }\end{array}$ \\
\hline Papa de fruta & Fruta & Fruta \\
\hline Papa salgada & $\begin{array}{c}\text { Papa salgada ou refeição } \\
\text { da família }\end{array}$ & $\begin{array}{c}\text { Refeição básica da } \\
\text { família }\end{array}$ \\
\hline Papa de fruta & Fruta & $\begin{array}{c}\text { Fruta ou pão } \\
\text { simples ou tubérculo ou } \\
\text { cereal }\end{array}$ \\
\hline Papa salgada & Papa salgada ou refeição & Refeição da família \\
\hline Leite & da família & Leite \\
\hline
\end{tabular}

Obs.: Após o oitavo mês, a criança pode receber gradativamente a alimentação da família, desde que esta não seja composta por alimentos muito temperados.

Fonte: Ministério da Saúde (Brasil, 2010) 
Embora a criança com seis meses ainda não esteja com a dentição formada, é importante oferecer a ela alimentos complementares espessos, de maneira a estimular a mastigação e a trituração pela gengiva, que já se encontra bastante dura nesta fase. Segundo o Ministério da Saúde (Brasil, 2010), no início, o alimento complementar deve ser pastoso, sob a forma de papas ou purês. Gradativamente, esta consistência deve ser aumentada até chegar à alimentação da família. Os alimentos complementares devem ser cozidos e amassados com garfo. A utilização de liquidificadores e peneiras é contraindicada, pois nesta fase a criança está aprendendo a distinguir consistências, sabores e cores dos alimentos.

Não é recomendado que a criança até um ano receba alimentos muito misturados, já que ela está aprendendo a reconhecer os diferentes alimentos. Portanto, recomenda-se que estes alimentos sejam amassados e colocados em porções separadas no prato da criança (Brasil, 2010).

\subsubsection{Tipos de alimentos complementares}

\section{Papa de cereais}

As papas de cereais são largamente utilizadas como alimentos complementares, devido à sua enorme praticidade. Tradicionalmente, cereais em forma de farinha são um dos primeiros alimentos a serem introduzidos na dieta da criança após os seis meses. Estes alimentos podem estar isentos de glúten, quando são preparados a partir de milho ou arroz, ou podem possuir glúten em sua composição, quando são preparados a partir de mistura de cereais. O glúten deve ser oferecido entre $\circ 6^{\circ}$ e $7^{\circ}$ mês, para auxiliar na redução do risco de doença celíaca e alergia ao glúten. O oferecimento de cereais enriquecidos com ferro deve ser feito até os dois anos de idade, dado que a anemia é bastante comum até este período (Silva e Aguiar, 2011; Guerra et al., 2012).

\section{Frutas}

As frutas devem estar sempre presente na alimentação complementar. Desde os seis meses, crianças devem receber frutas como alimento complementar, pois 
estas são importante fonte de vitaminas, minerais e fibras. A utilização de frutas maduras e cruas é aconselhável (Silva e Aguiar, 2011; Guerra et al., 2012).

\section{Carne}

A introdução e o consumo de carne no primeiro ano de vida da criança auxiliam na proteção contra a anemia. A biodisponibilidade do ferro e do zinco existente na carne torna este alimento a melhor fonte desses minerais. Além do ferro e do zinco, a carne é uma excelente fonte de proteínas (Bortolini e Vitolo, 2012; Guerra et al., 2012).

\section{Legumes}

A utilização de legumes como alimentos complementares é bastante importante, dado que estes alimentos representam uma importante fonte nutricional, devido ao alto teor de proteína vegetal e carboidratos complexos. Os legumes também são considerados importante fonte de minerais, vitaminas e fibras, confirmando a importância da presença dessa classe de alimentos na composição da alimentação complementar (Silva e Aguiar, 2011; Guerra et al., 2012). 


\section{REVISÃO BIBLIOGRÁFICA}

O período ideal para a introdução de alimentos complementares concentra grande parte dos estudos com relação a este assunto. Entretanto, não existem muitas pesquisas sobre determinação de elementos essenciais e tóxicos em alimentos do período de alimentação complementar.

A nutrição adequada é garantida pelo leite materno até os seis meses, porém a partir do $6^{\circ}$ mês a introdução da alimentação complementar é necessária. Os alimentos produzidos industrialmente representam uma parte importante da dieta de muitos bebês e crianças pequenas, por isso é muito importante que esses alimentos contenham quantidades suficientes de minerais. Baseados nessas informações, pesquisadores noruegueses realizaram análise sobre a concentração de minerais e elementos-traço presentes em alimentos comerciais infantis. Os pesquisadores analisaram 76 tipos diferentes de amostras englobando fórmulas infantis e alimentos comerciais infantis de três indústrias diferentes encontrados nos mercados noruegueses. Para a determinação dos elementos $\mathrm{Al}, \mathrm{Ca}, \mathrm{Co}, \mathrm{Cr}, \mathrm{Cu}, \mathrm{Fe}, \mathrm{K}, \mathrm{Mg}, \mathrm{Mo}$, $\mathrm{Na}$, Ni e Zn foi utilizada a técnica de espectrometria de massa com plasma indutivamente acoplado (ICP-MS). Este estudo demonstrou que uma dieta baseada em alimentos comerciais cumpre as necessidades do lactente para os minerais analisados, sem exceder o limite superior tolerável (Melo et al., 2008).

Alguns alimentos infantis são enriquecidos com elementos essenciais para assegurar que as necessidades nutricionais da criança sejam supridas. Porém, esta exposição deve ser analisada dado que durante o primeiro ano de vida, há um rápido crescimento e desenvolvimento infantil, o que leva a grandes necessidades energéticas e, consequentemente, um grande consumo de alimentos, com uma média em relação ao peso do corpo muito maior do que em adultos e crianças mais velhas. Tendo em vista essas informações, pesquisadores determinaram a concentração dos elementos-traço $\mathrm{Cu}, \mathrm{Mn} \mathrm{Fe}, \mathrm{Zn}$, Se, Cr, Al, Ni e Co em dezenove 
amostras diferentes de alimentos infantis consumidos na Turquia. Para a análise desses elementos, os pesquisadores utilizaram a técnica de Espectrometria de Absorção Atômica (AAS). As concentrações determinadas em todos os elementos estavam abaixo do limite superior tolerável para as amostras analisadas (Saracoglu et al., 2007).

A composição de alimentos comerciais infantis pode ser bastante diferente dos alimentos caseiros preparados por diversas famílias. Portanto, a informação sobre os níveis de diversos elementos presentes nesses alimentos industrializados é importante. Muitos dos elementos podem estar presentes nos alimentos naturalmente ou através de processamentos, tais como armazenamento agrícola e procedimentos industriais. É bem estabelecido que $\mathrm{Pb}, \mathrm{Cd}, \mathrm{As}, \mathrm{Al}, \mathrm{Sn}$ e $\mathrm{Hg}$ são tóxicos e os bebês são mais sensíveis a estes elementos que os adultos. Elementos considerados essenciais, $\mathrm{Fe}, \mathrm{Cu}, \mathrm{Zn}, \mathrm{Na}, \mathrm{Ca}, \mathrm{Mg}$, podem ser tóxicos quando ingeridos em excesso. Levando em conta esses conceitos e as poucas informações adequadas sobre alguns elementos presentes em alimentos infantis na Arábia Saudita, Al Khalifa e Ahmad (2010) determinaram os níveis de elementos essenciais $\mathrm{Ca}, \mathrm{Na}, \mathrm{Mg}, \mathrm{Fe}, \mathrm{Cu}$ e $\mathrm{Zn}$ e os não essenciais $\mathrm{Al}, \mathrm{As}, \mathrm{Cd}, \mathrm{Hg}, \mathrm{Pb}, \mathrm{Sb}$ e Sn em 56 amostras compreendendo fórmulas infantis e alimentos comerciais infantis, coletados em diferentes áreas da capital da Arábia Saudita, Riad. Para a determinação da concentração destes elementos os autores optaram pela técnica de espectrometria de emissão ótica com plasma indutivamente acoplado (ICP-OES). As concentrações de $\mathrm{Ca}, \mathrm{Cu}$ e $\mathrm{Fe}$ nos alimentos complementares eram superiores às concentrações desses elementos nas fórmulas infantis, mas estavam abaixo do limite superior tolerável, bem como as concentrações dos elementos tóxicos.

Muitos problemas de desenvolvimento em bebês e criança têm sido diretamente relacionados com a exposição a elementos tóxicos. Excesso de alumínio pode inibir diversas atividades enzimáticas importantes e contribuir para a insuficiência do desenvolvimento mental e mineralização óssea. O corpo das crianças possui alta capacidade cumulativa de chumbo, exibindo grande toxicidade deste elemento, mesmo em níveis mais baixos de exposição. A ingestão de cádmio por meio da respiração é mínima para a população em geral, tornando praticamente 
exclusiva a ingestão deste elemento através da alimentação. Pesquisadores do Paquistão determinaram o teor de elementos tóxicos: $\mathrm{Al}, \mathrm{Cd}$, $\mathrm{Ni}$ e Pb presentes em oito marcas diferentes de alimentos comerciais infantis mais consumidos pela população deste país aplicando o método de AAS. Os níveis de elementos tóxicos nas amostras analisadas estavam abaixo do limite superior tolerável, exceto para os alimentos que apresentavam arroz em sua formulação. Estes alimentos apresentaram alto nível de Cd (Kazi et al., 2010).

Atualmente, alimentos comerciais infantis se tornaram uma parte importante da dieta de muitos bebês e crianças. No Reino Unido, muitos pais estão cada vez mais optando por alimentos infantis comerciais, prontos para o consumo. Embora este consumo esteja em ascensão, há muito debate sobre o suprimento das necessidades nutricionais da criança através da ingestão desses alimentos. Uma série de nutrientes importantes pode ser limitada ou em excesso em algumas marcas, afetando sua qualidade nutricional e adequação para as crianças. É, portanto, necessário examinar o valor nutritivo da composição de alimentos para determinar se as crianças estão recebendo o nível correto de nutrientes. A rotulagem dos alimentos comerciais infantis não traz informações sobre o conteúdo mineral, dado que a declaração de micronutrientes não é obrigatória no Reino Unido. Com base nessas informações, pesquisadores do Reino Unido analisaram os níveis de elementos essenciais e traços, como $\mathrm{Ca}, \mathrm{Cu}, \mathrm{Mg}, \mathrm{Fe}, \mathrm{Zn}, \mathrm{K}, \mathrm{Na}$ e Se em alimentos comerciais infantis através das técnicas ICP-OES e ICP-MS. Os resultados das análises indicaram uma considerável variabilidade entre as amostras no que diz respeito ao teor de minerais. Isto está relacionado com a proporção de diferentes ingredientes que entram na composição desses alimentos. Os pesquisadores concluíram que os alimentos comerciais infantis do Reino Unido não contêm os níveis recomendados dos minerais analisados (Zand et al., 2011).

Crescimento e desenvolvimento infantil dependem do fornecimento de uma alimentação adequada. Há dois aspectos importantes que podem levar a um desequilíbrio nutricional: o baixo consumo de nutrientes, resultando em deficiências, e o elevado consumo, que resulta em uma toxicidade potencial. Atualmente, há uma escassez de dados sobre o valor nutricional dos alimentos infantis comerciais no 
Reino Unido. Para avaliar estes dois aspectos, Zand et al. (2012) analisaram oito diferentes amostras de alimentos comerciais infantis "prontos para o consumo" a base de aves e peixes de quatro marcas. Os pesquisadores analisaram os elementos essenciais: $\mathrm{Ca}, \mathrm{Fe}, \mathrm{Mg}, \mathrm{K}, \mathrm{Na}$ e $\mathrm{Zn}$ por meio de ICP-OES. A determinação dos níveis de seis elementos-traço: $\mathrm{Se}, \mathrm{Mo}, \mathrm{Co}, \mathrm{Cu}, \mathrm{Cr}, \mathrm{Mn}$ e oito elementos não essenciais potencialmente tóxicos: $\mathrm{As}, \mathrm{Ba}, \mathrm{Ni}, \mathrm{Cd}, \mathrm{Sb}, \mathrm{Pb}, \mathrm{Hg}$ e Al foi feita por ICPMS. Na maioria das amostras a ingestão diária total de elementos determinados não atingiu o valor de Ingestão Diária Recomendada (DRI), porém Mg e K ultrapassaram esse valor, o que deveria ser investigado.

Embora, os elementos $\mathrm{Cu}, \mathrm{Zn}, \mathrm{Fe}, \mathrm{Mn}, \mathrm{Ca}$ e Se sejam micronutrientes essenciais e possuam uma variedade de funções bioquímicas nos organismos, estes elementos podem ser tóxicos quando ingeridos em excesso. A exposição de altos níveis de Mn pode resultar em uma síndrome neurotóxica que afeta o equilíbrio de dopamina e de controle comportamental. O Se possui funções estruturais e enzimáticas, o Ca pode ser uma estratégia de prevenção eficaz para reduzir os níveis circulantes de $\mathrm{Pb}$. Em posse dessas informações, Pandelova et al. (2012) determinaram as concentrações dos elementos: $\mathrm{Ca}, \mathrm{Cd}, \mathrm{Cu}, \mathrm{Fe}, \mathrm{Hg}, \mathrm{Mn}, \mathrm{Ni}, \mathrm{Pb}, \mathrm{Se}$ e Zn presentes em amostras de alimentos infantis consumidos na Europa, através das técnicas ICP-OES e ICP-MS. Estes pesquisadores encontraram níveis altos de Mn, Ca e Zn, os quais, porém, não superavam o limite superior tolerável, bem como foi observado com os elementos tóxicos.

A determinação de elementos essenciais e tóxicos em alimentos complementares é bastante importante devido aos diversos problemas que podem ter início nesta fase da vida da criança. No Brasil, há poucas publicações sobre alimentação complementar, principalmente sobre a concentração de elementos essenciais e tóxicos presentes nesse tipo de alimento. Por isso, um trabalho que determine essas concentrações em alimentos comerciais infantis é de extrema importância e de interesse para o público em geral. 


\section{MÉTODOS}

No presente trabalho, foram utilizadas as técnicas de Análise por Ativação com Nêutrons Instrumental (INAA) e Espectrometria de Absorção Atômica (AAS), para a determinação de elementos essenciais e tóxicos presentes em alimentos comerciais infantis.

\subsection{Análise por Ativação com Nêutrons Instrumental (INAA)}

A Análise por Ativação com Nêutrons Instrumental é um método para a avaliação qualitativa e quantitativa dos elementos em diversos tipos de amostras. Esta técnica é muito utilizada para a análise de macro, micro e elementos-traço nos campos da arqueologia, biomedicina, bioquímica, ambiental, geologia, geoquímica, nutrição dentre outros. Este método baseia-se na medição da radiação característica de radionuclídeos formados diretamente ou indiretamente por irradiação neutrônica do material (Gaikwad, 2011; Chung et al., 2012).

A Análise por Ativação com Nêutrons Instrumental é um método bastante atrativo, fornecendo resultados muito precisos e exatos. A preparação da amostra para a análise é relativamente simples, já que não necessita de dissolução. Outras vantagens deste método são: a possibilidade de fornecer resultados de vários elementos simultaneamente e, por não necessitar de dissolução das amostras, ser um método não destrutivo e não sofrer contaminação de reagentes nem perda durante o preparo da amostra (Di Piero et al., 2008; Park et al., 2011).

O método de INAA é baseado no bombardeamento da amostra com nêutrons. Os nêutrons interagem com o núcleo do elemento da amostra por meio de choque inelástico tornando a amostra radioativa. Esta radioatividade é medida usando-se a espectrometria dos raios gama emitidos por cada radionuclídeo formado. A emissão de cada radionuclídeo produzido no processo de ativação possui características 
próprias, com relação à meia-vida e a radiação gama emitida, o que permite as determinações quantitativas da concentração do elemento na amostra por comparação com padrões, através da Equação 1 (De Soete et al., 1972).

$$
C_{a}^{i}=\frac{\left(A a^{i} m_{p} C_{p}^{i}\right) e^{\lambda\left(t_{a}-t_{p}\right)}}{A_{p}^{i} m_{a}}
$$

Onde:

$\mathbf{C a}^{\mathrm{i}}=$ concentração do elemento i na amostra

$C p^{i}=$ concentração do elemento i no padrão

$\mathrm{Aa}^{\mathrm{i}}$ = atividade do radioisótopo i na amostra

$A p^{i}=$ atividade do radioisótopo i no padrão

$\mathrm{m}_{\mathrm{a}}=$ massa da amostra

$\mathrm{m}_{\mathrm{p}}=$ massa do elemento no padrão

$\lambda=$ constante de decaimento do radioisótopo $\left(\lambda=0,693 / t_{1 / 2}\right)$, sendo $t_{1 / 2}=$ meia-vida

$\mathrm{t}_{\mathrm{a}}=$ tempo de decaimento da amostra

$t_{p}=$ tempo de decaimento do padrão

O método comparativo é bastante utilizado na Análise por Ativação com Nêutrons, porque diversos parâmetros da análise podem ser descartados, já que as amostras e os padrões são irradiados ao mesmo tempo sob as mesmas condições. Além do método comparativo, há o método de análise absoluta, que é baseado na determinação da concentração dos elementos com base no conhecimento exato do fluxo dos nêutrons incidentes, da calibração de eficiência do detector e na utilização das constantes físicas dos elementos a serem analisados, como abundância isotópica, seção de choque e porcentagem de emissão gama por decaimento. Outro método existente para a Análise por Ativação com Nêutrons é o método do $k_{0}$, que consiste na substituição das constantes físicas por uma constante $\mathrm{k}_{0}$, obtida a partir 
de repetidas determinações experimentais. Esta técnica pode ser bastante útil em análises rotineiras de elementos com $\mathrm{k}_{0}$ pré-determinado, além de garantir maior precisão e exatidão para alguns elementos, quando comparada à análise por método comparativo. Porém, o método $\mathrm{k}_{0}$ possui implantação complexa, já que necessita de um grande esforço para a determinação das constantes para a determinação do $\mathrm{k}_{0}$. Este método necessita de condições uniformes de irradiação e boa infraestrutura computacional (Zagatto, 2000).

Sendo os nêutrons eletricamente neutros na natureza, não apresentam qualquer força coulômbica de atração ou repulsão, atingindo diretamente o núcleo do elemento (Gaikwad, 2011), como observado na Figura 1.

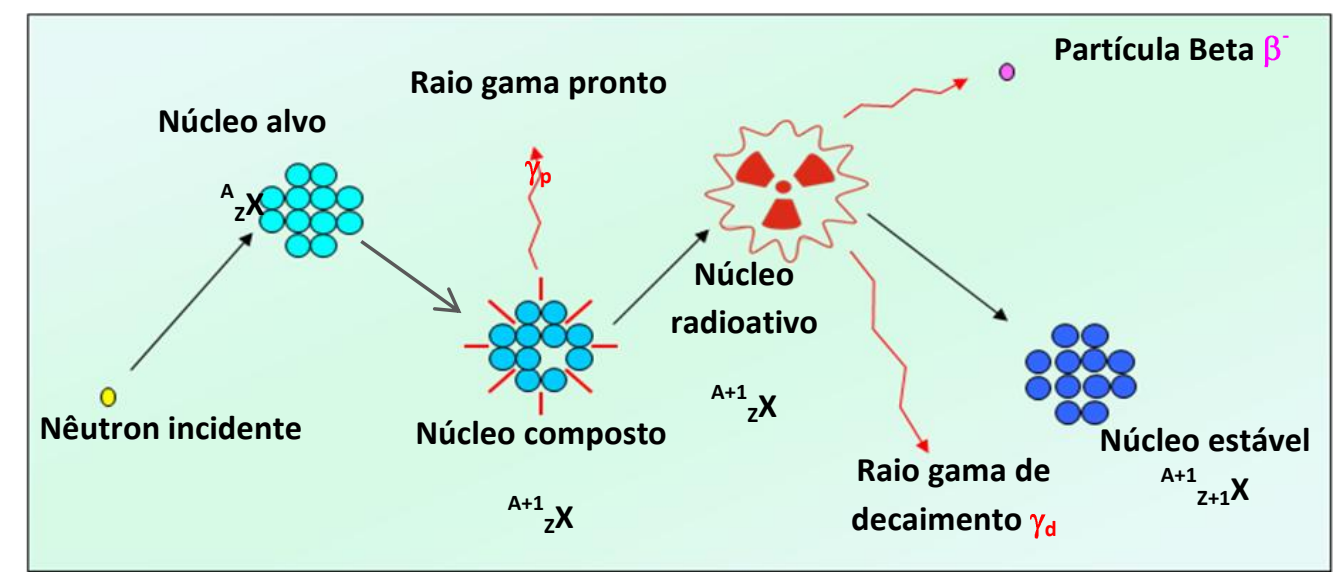

Figura 1 - Princípio da Análise por Ativação com Nêutrons

Fonte: Adaptado de IAEA, 1990.

Além das vantagens citadas anteriormente, a INAA apresenta alta sensibilidade e aplicabilidade na determinação de diversos elementos, incluindo os traços em uma ampla gama de matrizes e alta especificidade. Porém as desvantagens deste método são: não fornecer a forma química do elemento, o tempo necessário para a análise de alguns elementos é longo (semanas), não é possível a determinação de elementos como $\mathrm{O}, \mathrm{N}$ e $\mathrm{Pb}$, a necessidade de uma fonte de nêutrons, o custo de manutenção da instalação e a exposição do analista à radiação (Gaikwad, 2011). 


\subsection{Espectrometria de Absorção Atômica (AAS)}

A Espectrometria de Absorção Atômica é um método de análise quantitativo muito utilizado para determinar a concentração de elementos em amostras ambientais, tecidos biológicos, alimentos, materiais geológicos, dentre outros (Amorim et al., 2008).

O princípio da Espectrometria de Absorção Atômica é que átomos livres em estado gasoso absorvem luz. O comprimento de onda no qual ocorre a absorção da luz é específico para cada elemento. Esta absorção está diretamente relacionada ao número de átomos no estado fundamental no percurso óptico, seguindo a lei de Lambert-Beer (Borges et al., 2005; Gomes et al., 2006) dada pela Equação 2.

$$
A=\log \left(I_{0} / l\right)=a b c
$$

(Equação 2)

Onde:

A = absorbância

$\mathrm{I}_{0}=$ intensidade da radiação monocromática que incide na amostra

$\mathrm{I}$ = intensidade da radiação que emerge da amostra

$\mathrm{a}=$ absortividade molar, que caracteriza a espécie absorvente

$\mathrm{b}=$ caminho ótico, que é a distância percorrida pela radiação através da amostra $\mathrm{c}=$ concentração do analito na amostra

Os principais componentes de um espectrômetro de Absorção Atômica são: fonte (as três principais são lâmpada de catodo oco, fontes de espectros contínuos e lâmpadas de descarga sem eletrodo), sistema de modulação de sinal (utilizado para eliminar interferências causadas por emissão de radiação pela chama), sistema de atomização (as principais formas de atomização do analito são por chama ou por atomização eletrotérmica), monocromador (remove grande parte da radiação emitida pela chama) e detector (Holler et al., 2009), conforme ilustrado na Figura 2. 


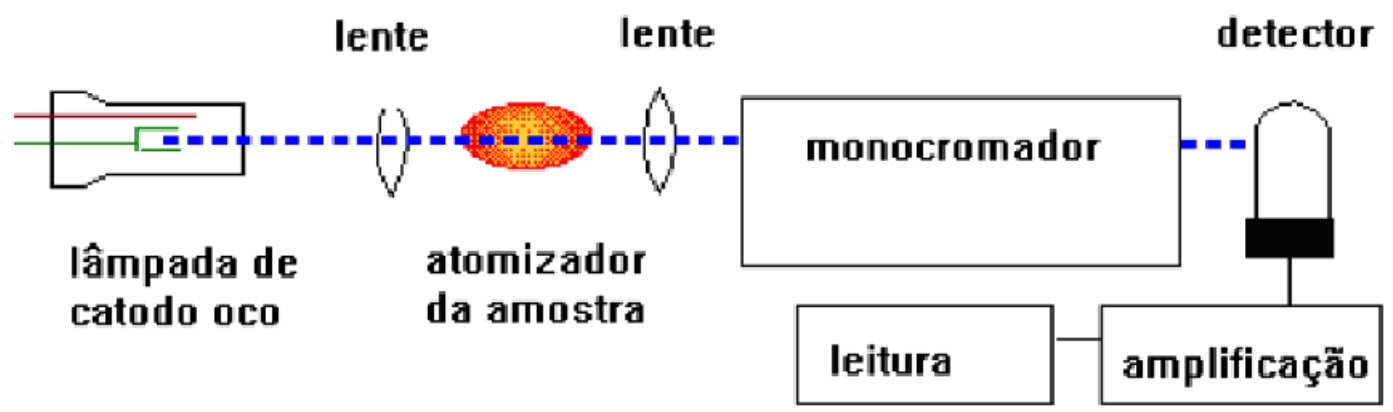

Figura 2: Esquema de um espectrômetro de Absorção Atômica

Fonte: Oliveira Filho e Oliveira, 2011

Para a determinação de elementos-traço, a Espectrometria de Absorção Atômica é um dos métodos mais utilizados, pois permite a determinação de elementos em diversas matrizes, é específica, altamente sensível, bastante rápida e fornece resultados confiáveis (Borges et al., 2005).

Este método é bastante vantajoso, pois possibilita a determinação da maioria dos elementos ao nível de $\mu \mathrm{g} / \mathrm{L}$, além de necessitar de pequenos volumes de amostra e possuir um limite de deteç̧ão baixo. Porém, a Espectrometria de Absorção Atômica pode sofrer interferências de matriz além de ser bastante vulnerável a efeitos de contaminação durante a digestão da amostra (Ceotto, 2009).

\subsubsection{Espectrometria de Absorção Atômica com Atomização Eletrotérmica (ET} AAS): Determinação de Cd

Para a determinação de $\mathrm{Cd}$ foi utilizado o método de Espectrometria de Absorção Atômica com Atomização Eletrotérmica. Esta técnica segue os mesmos princípios descritos anteriormente, onde a atomização é realizada em forno de grafite pirolítico. Geralmente é monoelementar, porém é adequada para a determinação de baixas concentrações de metais e semimetais. Dentre as vantagens, se destacam alta sensibilidade, alta seletividade, necessidade de pequenos volumes de amostras e baixos limites de deteç̧ão (Ribeiro et al., 2002). 


\subsubsection{Espectrometria de Absorção Atômica com Geração de Vapor Frio (CV} AAS): Determinação de $\mathrm{Hg}$

Para a determinação de $\mathrm{Hg}$ foi utilizado o método de Espectrometria de Absorção Atômica do Vapor Frio (CV AAS), cujo princípio baseia-se, como no método de absorção atômica convencional, na absorção da radiação pelos átomos de mercúrio. Diferente do método convencional, o método CV AAS não necessita de chama, pois o mercúrio é altamente volátil à temperatura ambiente. No processo de análise, os íons de $\mathrm{Hg}$ são reduzidos à forma elementar e carregados por um gás até o caminho óptico, onde ocorrerá a interação dos átomos com a radiação. Este método só é capaz de analisar $\mathrm{Hg}$ na forma elementar, por isso, em algumas análises é necessária uma etapa de redução do mercúrio antes da detecção (Micaroni et al., 2000).

\subsection{Material de Referência Certificado (CRM)}

Segundo o Vocabulário Internacional de Termos Fundamentais e Gerais de Metrologia (VIM 5.14; 2012), define-se como material de referência certificado:

"Material de referência, acompanhado por um certificado, com um ou mais valores de propriedades, e certificados por um procedimento que estabelece sua rastreabilidade à obtenção exata da unidade na qual os valores da propriedade são expressos, e cada valor certificado é acompanhado por uma incerteza para um nível de confiança estabelecido."

O material de referência deve ser homogêneo, estável, os valores de propriedade do material de referência certificado devem ter uma incerteza suficiente que permita sua utilização (VIM 5.14; 2012).

Os materiais de referência certificados podem ter diversos usos, como a validação do método utilizado, a verificação do uso correto de um método, calibração, controle de qualidade e garantia de qualidade (VIM 5.14, 2012).

No presente estudo os materiais de referência certificados utilizados tiveram como função a validação dos métodos, ou seja, verificar a precisão e exatidão dos resultados das duas metodologias utilizadas. 


\section{PARTE EXPERIMENTAL}

\subsection{Alimentos comerciais infantis}

Para a realização deste trabalho, foram adquiridas amostras de alimentos comerciais infantis em redes de supermercados da cidade de São Paulo durante os anos de 2010 e 2011. Foram analisadas 27 amostras, englobando alimentos de todas as etapas existentes, tanto do sabor doce quanto do salgado.

Os alimentos comerciais infantis existem apenas na forma de purês e atualmente apenas uma marca comercial é responsável pela produção e comercialização destes alimentos no país, por isso não foi possível fazer comparação entre marcas. Este fabricante divide os alimentos comerciais infantis em 4 etapas, de acordo com a idade mínima que a criança deve ter para consumi-los, conforme apresentado na Tabela 4. Esta informação da idade adequada, bem como a etapa a qual pertence o alimento, encontra-se no rótulo da embalagem.

Tabela 4 - Classificação dos alimentos comerciais infantis segundo as especificações do fabricante

\begin{tabular}{c|c}
\hline Etapa & Idade \\
\hline Etapa 1 & A partir de 6 meses \\
\hline Etapa 2 & A partir de 6 meses \\
\hline Etapa 3 & A partir de 8 meses \\
\hline Etapa Jr & A partir de 12 meses \\
\hline
\end{tabular}

$\mathrm{Na}$ Tabela 5 estão identificados os principais ingredientes declarados pelo fabricante para cada amostra codificada e analisada no presente estudo. 
Tabela 5 - Dados das amostras com seus códigos, principais ingredientes e classificação em etapas

\begin{tabular}{|c|c|c|}
\hline $\begin{array}{l}\text { Código da } \\
\text { Amostra }\end{array}$ & Principais Ingredientes & Etapa \\
\hline $1 \mathrm{a}$ & Ameixa & Etapa 1 \\
\hline $2 a$ & Caju & Etapa 1 \\
\hline $3 a$ & Maçã & Etapa 1 \\
\hline $4 a$ & Maracujá & Etapa 1 \\
\hline $5 a$ & Uva & Etapa 1 \\
\hline $1 b$ & Banana e leite & Etapa 2 \\
\hline $2 \mathrm{~b}$ & Goiaba e leite & Etapa 2 \\
\hline $3 b$ & Maçã, mamão e laranja & Etapa 2 \\
\hline $4 b$ & Manga, banana, abacaxi e laranja & Etapa 2 \\
\hline $5 b$ & Maçã e banana & Etapa 2 \\
\hline $6 b$ & Manga e pera & Etapa 2 \\
\hline $7 \mathrm{~b}$ & Pêssego e leite & Etapa 2 \\
\hline 1c & Carne, batata, cenoura e gema de ovo & Etapa 2 \\
\hline 2c & Carne, batata, cenoura, brócolis e abóbora & Etapa 2 \\
\hline $3 c$ & $\begin{array}{l}\text { Feijão, batata, mandioquinha, cenoura e } \\
\text { beterraba }\end{array}$ & Etapa 2 \\
\hline $4 \mathrm{c}$ & Frango, batata, cenoura e macarrão & Etapa 2 \\
\hline $5 c$ & Peito de frango, batata, couve e espinafre & Etapa 2 \\
\hline $6 \mathrm{c}$ & Carne, batata, cenoura e mandioquinha & Etapa 2 \\
\hline 7c & $\begin{array}{c}\text { Peito de peru, batata, mandioquinha e } \\
\text { chuchu }\end{array}$ & Etapa 2 \\
\hline 1d & $\begin{array}{l}\text { Carne, arroz, feijão, batata, cenoura, } \\
\text { brócolis e abóbora }\end{array}$ & Etapa 3 \\
\hline $2 d$ & Batata, cenoura, chuchu e carne & Etapa 3 \\
\hline $3 d$ & Peito de frango, batata, cenoura e chuchu & Etapa 3 \\
\hline $4 d$ & Batata, cenoura, carne, chuchu e macarrão & Etapa 3 \\
\hline $1 e$ & $\begin{array}{c}\text { Macarrão com carne moída e polpa de } \\
\text { tomate }\end{array}$ & Etapa Jr \\
\hline $2 \mathrm{e}$ & Carne, legumes e polpa de tomate & Etapa Jr \\
\hline $3 e$ & Galinha, arroz e polpa de tomate & Etapa Jr \\
\hline $4 \mathrm{e}$ & Strogonoff de carne com arroz e batata & Etapa Jr \\
\hline
\end{tabular}

\subsection{Preparação das amostras para análise}

Inicialmente, esses alimentos foram liofilizados por 24 horas a uma temperatura de $-50^{\circ} \mathrm{C}$ e $50 \mu \mathrm{bar}$ de pressão no liofilizador Modulyo da Thermo Electron Corporation, conforme ilustrado na Figura 3. Posteriormente, as amostras foram homogeneizadas em um liquidificador cujas facas comuns foram trocadas por 
facas de titânio para evitar a contaminação. As amostras salgadas foram completamente secas, ficando sob a forma de pó. As amostras doces não foram completamente secas, provavelmente devido à higroscopia da frutose presente nesses sabores, como pode ser observado na Figura 4.

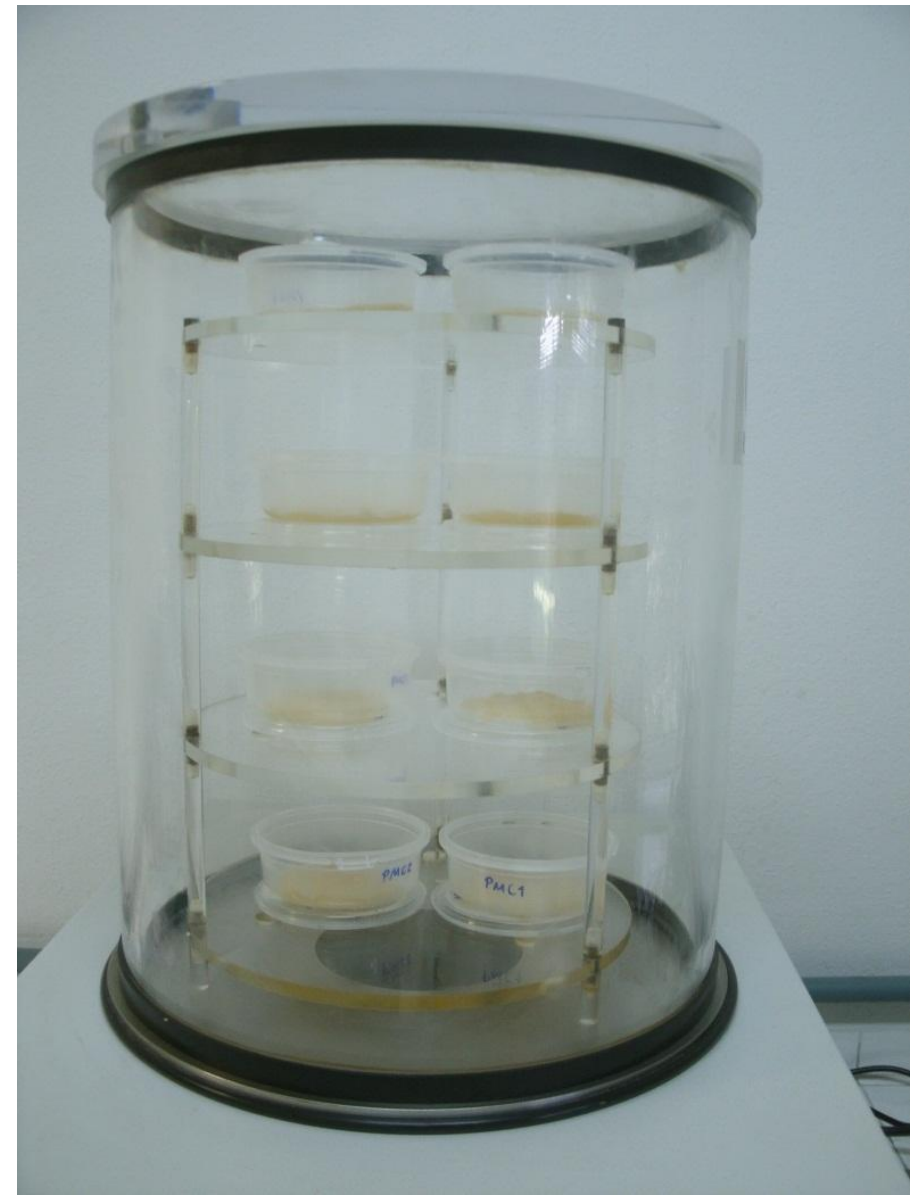

Figura 3 - Amostras no liofilizador

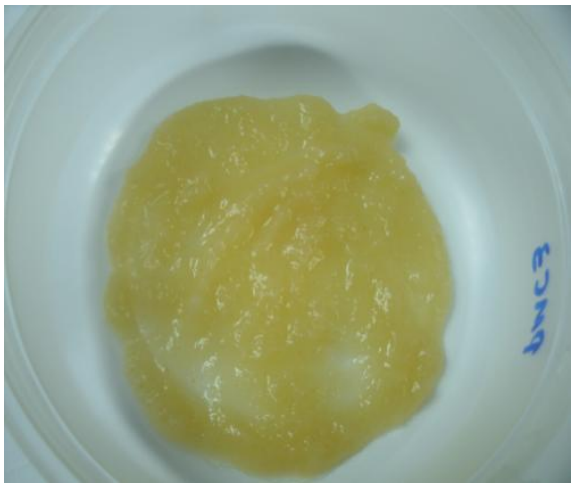

Antes da liofilização

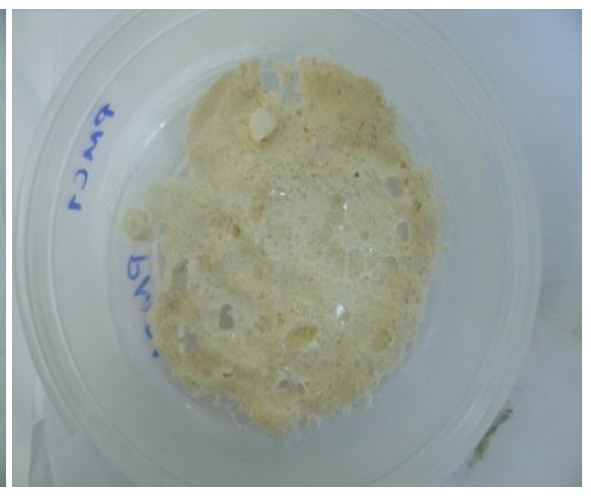

Após a liofilização

Figura 4 - Amostra doce antes e após o processo de liofilização 


\subsection{Análise por Ativação com Nêutrons Instrumental (INAA)}

A determinação dos elementos $\mathrm{As}, \mathrm{Ca}, \mathrm{Cl}, \mathrm{Co}, \mathrm{Cr}, \mathrm{Fe}, \mathrm{K}, \mathrm{Mg}, \mathrm{Mn}, \mathrm{Na}$, Se e $\mathrm{Zn}$ nas amostras comerciais infantis foi realizada pelo método INAA.

A Figura 5 mostra o fluxograma das etapas principais da análise por este método.

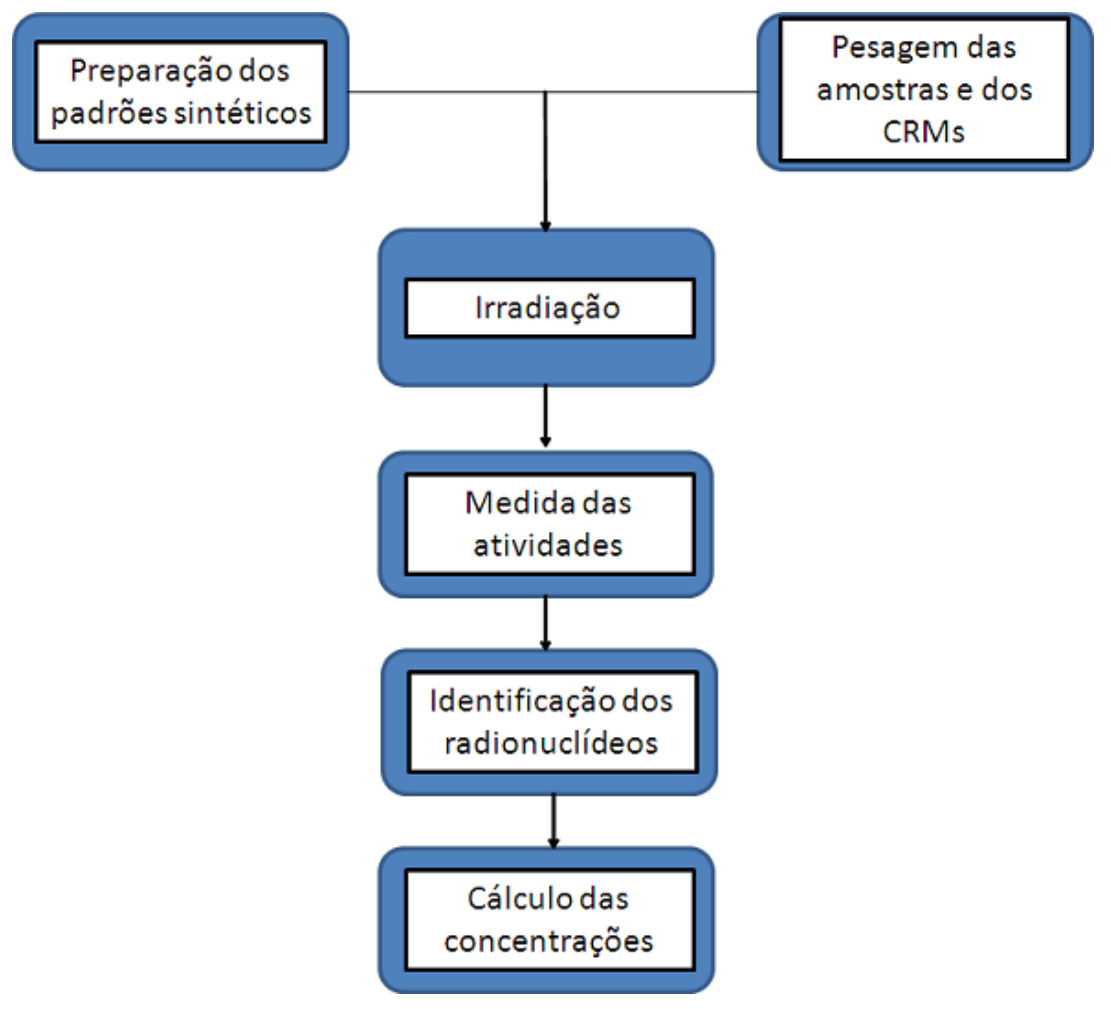

Figura 5 - Esquema das principais etapas do método INAA

\subsubsection{Preparação dos padrões sintéticos}

No método comparativo, a Análise por Ativação com Nêutrons Instrumental requer a utilização de padrões, com a finalidade de comparar suas atividades após a irradiação, com as atividades medidas da amostra.

Padrões de As, $\mathrm{Ca}, \mathrm{Cl}$, Co, $\mathrm{Cr}, \mathrm{Fe}, \mathrm{K}, \mathrm{Mg}, \mathrm{Mn}$, Na, Se e $\mathrm{Zn}$ foram preparados a partir de diluições apropriadas de suas soluções-padrão estoque Spex Certiprep. Alíquotas $(25-100 \mu \mathrm{L})$ dessas soluções foram pipetadas em tiras de papel de filtro Whatman 40 e secas sob o aquecimento de uma lâmpada infravermelho. Os padrões de $\mathrm{Cl}$ e de As foram secos em dessecador, onde ficaram armazenados por uma noite. Após a secagem completa desses padrões, essas tiras de papel foram 
colocadas dentro de pequenos invólucros de polietileno previamente limpos com água deionizada e solução $\mathrm{HNO}_{3} 10 \%$ em volume.

\subsubsection{Preparação e irradiação para a determinação dos radionuclídeos de meia- vida curta (meia-vida $<15$ horas)}

Aproximadamente $100 \mathrm{mg}$ de cada uma das amostras de alimentos comerciais infantis foram pesados na balança analítica Modelo: Shimadzu (Libor AEL 40SM) nos invólucros de polietileno previamente limpos com água deionizada e solução $\mathrm{HNO}_{3} \quad 10 \%$ em volume. Posteriormente à pesagem, as amostras de alimentos comerciais infantis foram acondicionadas, duas a duas, em dispositivos de plástico juntamente com os padrões de $\mathrm{Cl}, \mathrm{K}, \mathrm{Mg}, \mathrm{Mn}$ e $\mathrm{Na}$ e um material de referência certificado. As amostras e os padrões foram irradiados por $20 \mathrm{~s}$ a um fluxo de nêutrons térmicos da ordem de $6,6 \times 10^{12} \mathrm{~cm}^{-2} \mathrm{~s}^{-1}$ por meio de um sistema pneumático do reator de pesquisa, IEA-R1 do IPEN-CNEN/SP.

\subsubsection{Preparação e irradiação para a determinação dos radionuclídeos de meia- vida longa (meia-vida $>1$ dia)}

Aproximadamente $200 \mathrm{mg}$ de cada uma das amostras de alimentos comerciais infantis foram pesados na balança analítica Modelo: Shimadzu (Libor AEL 40SM) nos invólucros de polietileno previamente limpos com água deionizada e solução $\mathrm{HNO}_{3} \quad 10 \%$ em volume. Posteriormente à pesagem, as amostras de alimentos comerciais infantis foram acondicionadas, três a três, em dispositivos de alumínio juntamente com os padrões de $\mathrm{As}, \mathrm{Ca}, \mathrm{Co}, \mathrm{Cr}$, Fe, Se e $\mathrm{Zn}$ e dois materiais de referência certificados. As amostras e os padrões foram irradiados por $8 \mathrm{~h}$ a um fluxo de nêutrons térmicos da ordem de $4,5 \times 10^{12} \mathrm{~cm}^{-2} \mathrm{~s}^{-1}$ no núcleo do reator de pesquisa, IEA-R1 do IPEN-CNEN/SP.

\subsubsection{Medição das atividades dos radionuclídeos de meia-vida curta}

A determinação dos radionuclídeos ${ }^{38} \mathrm{Cl}$ e ${ }^{27} \mathrm{Mg}$ foi feita logo após a irradiação no sistema pneumático. O período de medição para estes radionuclídeos foi de $300 \mathrm{~s}$ tanto para os padrões quanto para as amostras e material de referência certificado. A 
segunda medição foi feita após um tempo de decaimento de $3300 \mathrm{~s}$, onde foram determinados os radionuclídeos ${ }^{42} \mathrm{~K},{ }^{56} \mathrm{Mn}$ e ${ }^{24} \mathrm{Na}$. O período de medição para estes radionuclídeos foi de $900 \mathrm{~s}$ para os padrões e $2400 \mathrm{~s}$ para as amostras e material de referência certificado.

\subsubsection{Medição das atividades dos radionuclídeos de meia-vida longa}

A primeira medição dos radionuclídeos de meia-vida longa foi feita após um período de decaimento de 5 dias. Com este tempo de decaimento foram determinados os radionuclídeos de ${ }^{76} \mathrm{As} \mathrm{e}^{47} \mathrm{Ca}$. Os padrões foram medidos durante $1800 \mathrm{~s}$, enquanto as amostras e os materiais de referência certificados tiveram um período de medição de 7200 s. A segunda medição foi realizada após um período de decaimento de 15 dias. Nesta medição foram medidos os radionuclídeos ${ }^{60} \mathrm{Co},{ }^{51} \mathrm{Cr}$, ${ }^{59} \mathrm{Fe},{ }^{72} \mathrm{Se} \mathrm{e}{ }^{65} \mathrm{Zn}$. Os padrões, assim como na primeira medição, foram medidos por $1800 \mathrm{~s}$, enquanto as amostras e os materiais de referência certificados tiveram um período de medição de 50000 s.

\subsubsection{Medição das atividades e processamento dos espectros}

As atividades dos raios gama dos radionuclídeos das amostras, materiais de referência certificados e padrões irradiados foram medidas em um espectrômetro constituído de um detector de Ge Hiperpuro da EG\&G ORTEC com 20\% de eficiência e 1,9 keV de resolução para o pico de $1332,49 \mathrm{keV}$ do ${ }^{60} \mathrm{Co}$. O detector está acoplado a um sistema eletrônico composto por um analisador multicanal, fonte de alta tensão, amplificador e um microcomputador compatível. Os espectros de raios gama foram processados utilizando o software VISPECT2.

\subsubsection{Identificação dos radionuclídeos}

As concentrações dos elementos de interesse foram calculadas utilizando a Equação 1 apresentada no item 5.1. Na Tabela 6 estão identificados o tempo de meia-vida e a energia do fotopico utilizada para cada radionuclídeo de interesse para este estudo. 
Tabela 6 - Tempo de meia-vida e energia dos raios gama dos radionuclídeos

\begin{tabular}{c|c|c}
\hline Radionuclídeo & Tempo de meia-vida & Energia (keV) \\
\hline${ }^{76} \mathrm{As}$ & 26,32 dias & 559,10 \\
\hline${ }^{47} \mathrm{Ca}$ & 4,54 dias & 1297,09 \\
\hline${ }^{38} \mathrm{Cl}$ & 37,24 minutos & 1642,69 \\
${ }^{60} \mathrm{Co}$ & 5,27 anos & 1332,50 \\
\hline${ }^{51} \mathrm{Cr}$ & 27,7 dias & 320,08 \\
\hline${ }^{59} \mathrm{Fe}$ & 44,5 dias & 1099,25 \\
\hline${ }^{42} \mathrm{~K}$ & 12,36 horas & 1524,58 \\
\hline${ }^{27} \mathrm{Mg}$ & 9,46 minutos & 843,76 \\
\hline${ }^{56} \mathrm{Mn}$ & 2,58 horas & 846,76 \\
\hline${ }^{24} \mathrm{Na}$ & 14,96 horas & 1368,60 \\
\hline${ }^{75} \mathrm{Se}$ & 119,77 dias & 264,66 \\
\hline${ }^{65} \mathrm{Zn}$ & 243,9 dias & 1115,55 \\
\hline
\end{tabular}

Fonte: IAEA (1990)

\subsection{Espectrometria de Absorção Atômica (AAS)}

Os elementos $\mathrm{Cd} \mathrm{e} \mathrm{Hg}$ foram determinados por meio da técnica de AAS. Para a determinação de $\mathrm{Hg}$ foi utilizado o método Espectrometria de Absorção Atômica com Geração de Vapor Frio (CV AAS) através do espectrômetro FIMS (Flow Injection Mercury System) da marca Perkin Elmer. O Cd foi determinado por Espectrometria de Absorção Atômica com Atomização Eletrotérmica (ET AAS) utilizando-se o espectrômetro Analyst 800 da marca Perkin Elmer.

A Figura 6 mostra o fluxograma das etapas principais da análise por este método. 


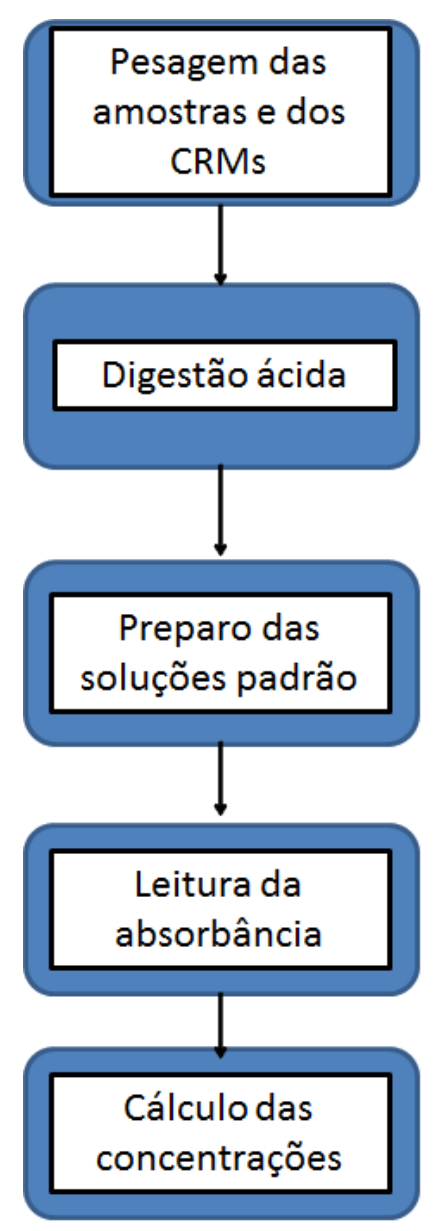

Figura 6 - Esquema das etapas principais do método AAS

\subsubsection{Preparo das amostras e dos materiais de referência certificados para análise}

Aproximadamente $1 \mathrm{~g}$ de cada uma das amostras de alimentos comerciais infantis foi pesado em balança analítica (Ohaus AR2140 Adventurer), bem como foram pesados cerca de $1 \mathrm{~g}$ dos materiais de referência certificados.

As amostras e os CRMs foram submetidos à digestão ácida, que consistiu na

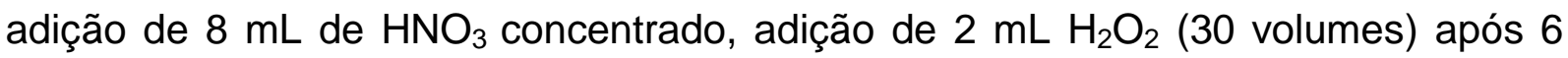
horas. Essas amostras dissolvidas permaneceram em repouso durante a noite e foram digeridas no dia seguinte, por três horas, em um bloco digestor a $90^{\circ} \mathrm{C}$. Ao final da digestão ácida, as soluções foram diluídas a um volume final de 25,3 mL. Para cada rodada de análise foi preparado um branco analítico, que consistia de um 
frasco sem amostra, porém com todos os reagentes utilizados. Este branco analítico passou por todo o processo de digestão e foi medido na determinação de $\mathrm{Cd}$ e $\mathrm{Hg}$. O fluxograma desta digestão ácida está apresentado na Figura 7.

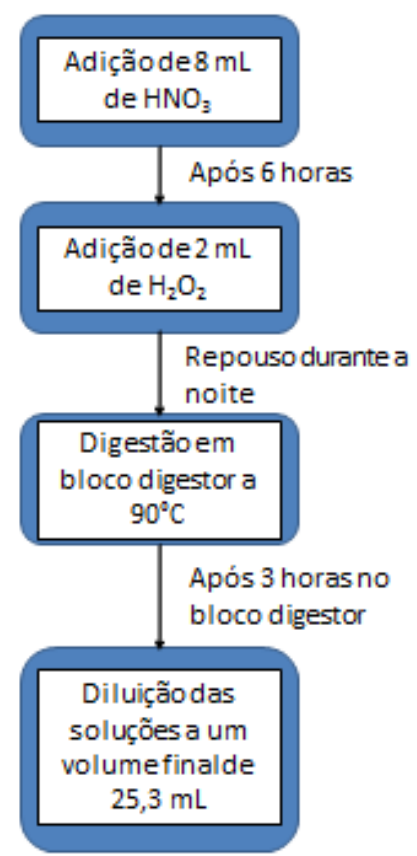

Figura 7 - Fluxograma da digestão ácida para o método AAS

\subsubsection{Preparo das soluções-padrão}

Para o preparo das soluções-padrão de $\mathrm{Hg}$ partiu-se de uma solução estoque 1 com concentração de $1,158 \mathrm{mg} \mathrm{mL}^{-1}$, previamente preparada para outras análises dos grupos de pesquisa do laboratório. Pipetaram-se $100 \mu \mathrm{L}$ desta solução e o volume foi completado para $100 \mathrm{~mL}$, formando a solução estoque 2, com concentração de $1158 \mathrm{ng} \mathrm{mL}^{-1}$. Pipetou-se $1 \mathrm{~mL}$ da solução estoque 2 e completouse o volume para $10 \mathrm{~mL}$, formando a solução estoque 3 com concentração de 116 $\mathrm{ng} \mathrm{mL} \mathrm{m}^{-1}$. Para alcançar as concentrações apropriadas, diferentes volumes da solução estoque 3 foram pipetados nos frascos de PFA Savilex. Essas soluções sofreram a mesma digestão ácida que as amostras. Desta maneira, foram obtidas as soluções de $\mathrm{Hg}$ para obtenção da curva analítica para a leitura do espectrômetro, conforme dados da Tabela 7. 
Tabela 7 - Dados utilizados para construção da curva analítica para a determinação de $\mathrm{Hg}$

\begin{tabular}{c|c|c|c}
\hline Solução & $\begin{array}{c}\text { Volume pipetado } \\
(\boldsymbol{\mu L})\end{array}$ & Volume final $(\mathbf{m L})$ & $\begin{array}{c}\text { Concentração } \\
\text { final }\left(\mathbf{n g} \mathbf{~ m L}^{-\mathbf{1}}\right)\end{array}$ \\
\hline $\mathrm{Hg} \mathrm{1}$ & 100 & 25,3 & 0,46 \\
\hline $\mathrm{Hg} \mathrm{2}$ & 300 & 25,3 & 1,38 \\
\hline $\mathrm{Hg} \mathrm{3}$ & 500 & 25,3 & 2,29 \\
\hline $\mathrm{Hg} \mathrm{4}$ & 700 & 25,3 & 3,21 \\
\hline
\end{tabular}

Para o preparo das soluções-padrão de Cd partiu-se de uma solução estoque 1 com concentração de $1004 \mu \mathrm{g} \mathrm{mL}^{-1}$, previamente preparada para outras análises dos grupos de pesquisa do laboratório. $O$ equipamento fez a diluição automática e previamente estabelecida a partir da solução estoque 1, formando as soluções estoques 2, 3, 4 e 5. Desta maneira, foram obtidas as soluções de Cd usadas para a obtenção da curva analítica para a leitura do espectrômetro, conforme ilustrado na Tabela 8.

Tabela 8 - Dados utilizados para construção da curva analítica para a determinação de Cd

\begin{tabular}{c|c}
\hline Solução & $\begin{array}{c}\text { Concentração final } \\
\text { (ng mL }^{-1} \text { ) }\end{array}$ \\
\hline Cd 1 & 1,41 \\
\hline Cd 2 & 2,81 \\
\hline Cd 3 & 4,22 \\
\hline Cd 4 & 5,62 \\
\hline Cd 5 & 7,03 \\
\hline
\end{tabular}

\subsubsection{Parâmetros de análise}

Nas Tabelas 9 e 10 são descritos, respectivamente, os parâmetros utilizados para a determinação de $\mathrm{Hg}$ com o espectrômetro FIMS e de Cd com o espectrômetro Analyst800. 
Tabela 9 - Parâmetros para a determinação de $\mathrm{Hg}$

\begin{tabular}{c|c}
\hline Volume de injeção & $500 \mu \mathrm{L}$ \\
\hline Fluxo do carregador & $10 \mathrm{~mL} \mathrm{~min}^{-1}$ \\
\hline Fluxo do redutor & $6 \mathrm{~mL} \mathrm{~min}^{-1}$ \\
\hline Fluxo de argônio (gás de arraste) & $50 \mathrm{~mL} \mathrm{~min}^{-1}$ \\
\hline
\end{tabular}

Tabela 10 - Parâmetros para a determinação de Cd

\begin{tabular}{c|c}
\hline Lâmpada de Cd & EDL \\
\hline Comprimento de onda utilizado & $228,8 \mathrm{~nm}$ \\
\hline Abertura da fenda & $0,7 \mathrm{~nm}$ \\
\hline Corrente da lâmpada & $230 \mathrm{~mA}$ \\
\hline Volume de injeção da amostra & $20 \mu \mathrm{L}$ \\
\hline Volume de injeção do modificador \\
químico & $10 \mu \mathrm{L}$ \\
\hline
\end{tabular}

\subsubsection{Soluções complementares}

Para a construção da curva de calibração de $\mathrm{Cd}$ foi utilizada como diluente uma solução $\mathrm{HNO}_{3}$ 0,2\% (v/v). Esta solução também foi utilizada como branco analítico. A solução de modificador químico era composta por $\mathrm{NH}_{4} \mathrm{H}_{2} \mathrm{PO}_{4} 0,5 \%(\mathrm{~m} / \mathrm{v})$ e $\mathrm{Mg}\left(\mathrm{NO}_{3}\right)_{2} \quad 0,03 \% \quad(\mathrm{~m} / \mathrm{v})$. Essas soluções foram preparadas seguindo as recomendações do fabricante do espectrômetro.

Para a determinação de $\mathrm{Hg}$ foi preparado um carregador constituído por solução de $\mathrm{HCl} 3 \%(\mathrm{v} / \mathrm{v})$. Uma solução de $\mathrm{SnCl}_{2} \cdot 2 \mathrm{H}_{2} \mathrm{O} 3 \%(\mathrm{~m} / \mathrm{v})$ em $\mathrm{HCl} 3 \%$ foi preparada para ser utilizada como redutor, para fazer a redução de $\mathrm{Hg}^{2+}$, presente nas soluções, $\mathrm{a} \mathrm{Hg}^{0}$. 


\section{RESULTADOS E DISCUSSÃO}

\subsection{Análise dos materiais de referência certificados}

Para validação da metodologia INAA utilizada para a determinação de As, Ca, $\mathrm{Cl}$, Co, $\mathrm{Cr}, \mathrm{Fe}, \mathrm{K}, \mathrm{Mg}, \mathrm{Mn}, \mathrm{Na}$, Se e $\mathrm{Zn}$, dois materiais de referência certificados foram analisados: INCT MPH-2 Mixed Polish Herbs, produzido no Institute of Nuclear Chemistry and Technology, localizado na cidade de Varsóvia, na Polônia, e NIST SRM 1577b Bovine Liver, produzido no National Institute of Standards and Technology, localizado na cidade de Gaitersburgo, nos Estados Unidos.

Nas Tabelas 11 e 12 são apresentados os resultados experimentais obtidos para os valores certificados de As, $\mathrm{Ca}, \mathrm{Cl}, \mathrm{Co}, \mathrm{Cr}, \mathrm{Fe}, \mathrm{K}, \mathrm{Mg}, \mathrm{Mn}, \mathrm{Na}$ e $\mathrm{Zn}$, para o INCT MPH-2 Mixed Polish Herbs e NIST - SRM 1577b Bovine Liver, respectivamente. A maioria dos resultados está concordante com os valores certificados, como mostram os resultados dos erros relativos, o que resulta em uma boa exatidão do método utilizado. Os valores encontrados para desvio-padrão relativo ficaram abaixo de $9,2 \%$, o que mostra uma boa precisão do método utilizado. Os cálculos para desvio-padrão relativo e erro relativo foram feitos para os elementos analisados que apresentavam valores certificados com suas respectivas incertezas.

O desvio-padrão (DP) foi determinado para avaliar a reprodutividade dos resultados obtidos. A Equação 3 indica o cálculo para a determinação do desviopadrão:

$$
\left.\mathrm{DP}=\left[\sum \overline{(\mathrm{X}}-\mathrm{X}_{\mathrm{obtido}}\right)^{2} / \mathrm{n}-1\right]^{1 / 2}
$$

Onde:

DP = desvio-padrão;

$\bar{X}=$ média aritmética dos valores obtidos;

$\mathrm{X}_{\text {obtido }}=$ valor obtido;

$\mathrm{n}=$ número de determinações. 
Para analisar a precisão do método utilizado, foi calculado o desvio-padrão relativo percentual (DPR). A Equação 4 indica o cálculo para a determinação do desvio-padrão relativo:

$$
\mathrm{DPR}=\frac{(\mathrm{DP}) \times 100}{\mathrm{x}}
$$

Onde:

$\mathrm{DPR}=$ desvio-padrão relativo percentual;

DP = desvio-padrão;

$\overline{\mathrm{X}}=$ média aritmética dos valores dos obtidos.

Para analisar a exatidão do método utilizado, foi calculado o erro relativo percentual (ER). A Equação 5 indica o cálculo para a determinação do erro relativo:

$$
E R=\frac{\mid X_{\text {obtido }}-V_{\text {non. certificado }}}{V_{\text {non. certificado }}} \underline{I \times 100}
$$

Onde:

$\mathrm{X}_{\mathrm{obtido}}=$ valor obtido;

$\mathrm{V}_{\text {non. certificado }}=$ valor nominal ou valor certificado;

Para o controle de qualidade dos resultados obtidos pelas técnicas INAA e AAS, utilizou-se o critério Z-score (Thompson, 2000), apresentado na Equação 6, apenas para os elementos com valor certificado e para os elementos com valor informativo. Todos os valores obtidos ficaram abaixo de 3 , o que garante que os resultados estão dentro do intervalo de confiança de $99 \%$ do valor verdadeiro ou aceito. 


$$
\begin{aligned}
& \mathrm{DP}=0,22 \mathrm{C}, \text { se } C<1,2 \times 10^{-7} \\
& \mathrm{DP}=0,02 \mathrm{C}^{0,8495}, \text { se } 1,2 \times 10^{-7} \leq \mathrm{C} \leq 0,138 \\
& \mathrm{DP}=0,01 \mathrm{C}^{0,5}, \text { se } C>0,138 \\
& Z_{\text {score }}=\left(X_{\text {obtido }}-V_{\text {non. certificado }}\right) / \mathrm{DP}
\end{aligned}
$$

Onde:

$\mathrm{DP}=$ desvio padrão

$\mathrm{C}=$ concentração

DP e C são expressos em razão de massa admassionais $\left(1 \mu \mathrm{g} / \mathrm{g} \equiv 10^{-6}\right)$

$\mathrm{X}_{\text {obtido }}=$ valores obtidos;

\begin{tabular}{|c|c|c|c|c|c|}
\hline \multirow[b]{2}{*}{ Elemento } & \multirow[b]{2}{*}{$\begin{array}{l}\text { Este estudo } \\
{\text { (Média } \pm D P)^{a}}^{\text {M }}\end{array}$} & \multicolumn{4}{|c|}{ Mixed Polish Herbs (INCT-MPH-2) } \\
\hline & & $\begin{array}{c}\text { DPR }^{b} \\
(\%)\end{array}$ & $\begin{array}{l}E^{c} \\
(\%)\end{array}$ & |z-score| & $\begin{array}{c}\text { Valores do } \\
\text { Certificado(INCT- } \\
\text { MPH-2) }\end{array}$ \\
\hline As $n g g^{-1}$ & $176 \pm 16$ & 9,1 & 7,9 & 0,42 & $191 \pm 23$ \\
\hline $\mathrm{Ca} \mu \mathrm{g} \mathrm{g}^{-1}$ & $10842 \pm 241$ & 2,2 & 0,39 & 0,09 & $10800 \pm 700$ \\
\hline $\mathrm{Cl} \mu \mathrm{g} \mathrm{g}^{-1}$ & $2790 \pm 136$ & 4,9 & 1,8 & 0,37 & $2840 \pm 200$ \\
\hline Co $n g g^{-1}$ & $225 \pm 16$ & 7,1 & 7,1 & 0,55 & $210 \pm 25$ \\
\hline $\mathrm{Cr} \mu \mathrm{g} \mathrm{g}^{-1}$ & $1,692 \pm 0,068$ & 4,0 & 0,12 & 0,07 & $1,69 \pm 0,13$ \\
\hline Fe $\mu g^{-1}$ & $487 \pm 36$ & 7,4 & & & $(460)^{d}$ \\
\hline $\mathrm{K} \mu \mathrm{g} \mathrm{g}^{-1}$ & $19176 \pm 1083$ & 5,7 & 0,40 & 0,11 & $19100 \pm 1200$ \\
\hline $\mathrm{Mg} \mu \mathrm{g} \mathrm{g}{ }^{-1}$ & $2944 \pm 68$ & 2,3 & 0,82 & 0,17 & $2920 \pm 180$ \\
\hline $\mathrm{Mn} \mu \mathrm{g} \mathrm{g}^{-1}$ & $188,1 \pm 9,7$ & 5,2 & 1,5 & 0,22 & $191 \pm 12$ \\
\hline $\mathrm{Na} \mu \mathrm{g} \mathrm{g}^{-1}$ & $346,7 \pm 7,0$ & 2,0 & & & (350) \\
\hline $\mathrm{Zn} \mu \mathrm{g} \mathrm{g}^{-1}$ & $33,3 \pm 1,6$ & 4,8 & 0,60 & 0,06 & $33,5 \pm 2,1$ \\
\hline
\end{tabular}

$\mathrm{V}_{\text {non. certificado }}=$ valor nominal ou valor certificado

Tabela 11 - Concentrações dos elementos no Mixed Polish Herbs (INCT-MPH-2) em base seca analisados por INAA

${ }^{a}$ Média e desvio-padrão de dez determinações

${ }^{\mathrm{b}}$ DPR \%: Desvio-Padrão Relativo

${ }^{\mathrm{C}} \mathrm{ER} \%$ : Erro relativo

${ }^{d}$ Valores em parênteses indicam valores informativos

- : Indica valor não determinado ou não apresentado no certificado 
Tabela 12 - Concentrações dos elementos no Bovine Liver (NIST 1577b) em base seca analisados por INAA

\begin{tabular}{|c|c|c|c|c|c|}
\hline \multirow[b]{2}{*}{ Elemento } & \multicolumn{5}{|c|}{ Bovine Liver (NIST-1577b) } \\
\hline & 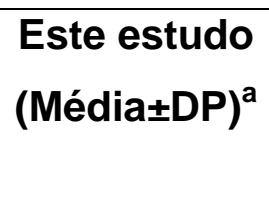 & $\begin{array}{c}\text { DPR }^{b} \\
(\%)\end{array}$ & $\begin{array}{l}E^{c} \\
(\%)\end{array}$ & |Z-score| & $\begin{array}{l}\text { Valores do } \\
\text { Certificado } \\
\text { (NIST-1577b) }\end{array}$ \\
\hline $\mathrm{Ca} \mu \mathrm{g} \cdot \mathrm{g}^{-1}$ & - & - & - & - & $116 \pm 4$ \\
\hline $\mathrm{Cl} \mu \mathrm{g} \cdot \mathrm{g}^{-1}$ & $2797 \pm 234$ & 8,4 & 0,61 & 0,13 & $2780 \pm 60$ \\
\hline Co $n g . g^{-1}$ & $249,1 \pm 7,0$ & 2,8 & - & - & $(250)^{d}$ \\
\hline $\mathrm{Fe} \mu \mathrm{g} \cdot \mathrm{g}^{-1}$ & $185,2 \pm 8,2$ & 4,4 & 0,65 & 0,07 & $184 \pm 15$ \\
\hline $\mathrm{K} \mu \mathrm{g} \cdot \mathrm{g}^{-1}$ & $9486 \pm 764$ & 8,1 & 4,6 & 1,19 & $9940 \pm 20$ \\
\hline $\mathrm{Mg} \mu \mathrm{g} \cdot \mathrm{g}^{-1}$ & $575 \pm 52$ & 9,0 & 4,3 & 0,74 & $601 \pm 28$ \\
\hline $\mathrm{Mn} \mu \mathrm{g} \cdot \mathrm{g}^{-1}$ & $10,28 \pm 0,89$ & 8,7 & 2,1 & 0,17 & $10,5 \pm 1,7$ \\
\hline $\mathrm{Na} \mu \mathrm{g} \cdot \mathrm{g}^{-1}$ & $2217 \pm 136$ & 6,1 & 8,4 & 1,82 & $2420 \pm 60$ \\
\hline Se $n g . g^{-1}$ & $728 \pm 25$ & 3,4 & 0,27 & 0,02 & $730 \pm 60$ \\
\hline $\mathrm{Zn} \mu \mathrm{g} \cdot \mathrm{g}^{-1}$ & $128,4 \pm 8,2$ & 6,4 & 1,1 & 0,10 & $127 \pm 16$ \\
\hline
\end{tabular}

A validação do método AAS, utilizado para a determinação dos elementos tóxicos $\mathrm{Cd}$ e $\mathrm{Hg}$, foi realizada por meio da análise de dois materiais de referência: NIST - SRM 1548a Typical Diet e NIST - SRM 1547 Peach Leaves, ambos produzidos no National Institute of Standards and Technology, localizado na cidade de Gaitersburgo, nos Estados Unidos.

Os valores obtidos para os elementos $\mathrm{Cd}$ e $\mathrm{Hg}$ estão apresentados nas Tabelas 13 e 14, para o NIST - SRM 1548a Typical Diet e NIST - SRM 1547 Peach Leaves, respectivamente. Devido à baixa concentração dos elementos analisados, houve uma discrepância entre os valores obtidos para o Hg em comparação aos valores do certificado do material de referência Peach Leaves. 
Tabela 13 - Concentrações dos elementos no Typical Diet (NIST-1548a) em base seca analisados por AAS

\begin{tabular}{|c|c|c|c|c|c|}
\hline \multirow[b]{2}{*}{ Elemento } & \multicolumn{5}{|c|}{ Typical Diet (NIST - 1548a) } \\
\hline & $\begin{array}{l}\text { Este estudo } \\
{\text { (Média } \pm D P)^{a}}^{\text {a }}\end{array}$ & $\begin{array}{c}\text { DPR }^{\text {b }} \\
(\%)\end{array}$ & $\begin{array}{l}E^{c} \\
(\%)\end{array}$ & |Z-score| & $\begin{array}{c}\text { Valores } \\
\text { Certificados } \\
\text { (NIST - 1548a) }\end{array}$ \\
\hline $\mathrm{Cd} \mu \mathrm{g} \cdot \mathrm{g}^{-1}$ & $0,02902 \pm 0,00081$ & 2,8 & 17 & 0,94 & $0,035 \pm 0,0015$ \\
\hline $\mathrm{Hg} \mu \mathrm{g} \cdot \mathrm{g}^{-1}$ & $0,00551 \pm 0,00008$ & 1,5 & - & - & $(0,005)^{d}$ \\
\hline
\end{tabular}

Tabela 14 - Concentrações dos elementos no Peach Leaves (NIST-1547) em base seca analisados por AAS

\begin{tabular}{|c|c|c|c|c|c|}
\hline \multirow[b]{2}{*}{ Elemento } & \multicolumn{5}{|c|}{ Peach Leaves (NIST-1547) } \\
\hline & $\begin{array}{l}\text { Este estudo } \\
{\text { (Média } \pm D P)^{a}}^{\text {a }}\end{array}$ & $\begin{array}{c}\text { DPR }^{b} \\
(\%)\end{array}$ & $\begin{array}{l}E^{c}{ }^{c} \\
(\%)\end{array}$ & |Z-score| & $\begin{array}{c}\text { Valores } \\
\text { Certificados(NIST- } \\
1547)\end{array}$ \\
\hline $\mathrm{Cd} \mu \mathrm{g} \cdot \mathrm{g}^{-1}$ & $0,026 \pm 0,001$ & 3,8 & 0 & 0 & $0,026 \pm 0,003$ \\
\hline $\mathrm{Hg} \mu \mathrm{g} \cdot \mathrm{g}^{-1}$ & $0,024 \pm 0,007$ & 29 & 23 & 1,33 & $0,031 \pm 0,007$ \\
\hline
\end{tabular}




\subsection{Concentração dos elementos nas amostras de alimentos comerciais infantis pelo método de INAA}

Na Tabela 15 estão apresentados os limites de detecção (LD) obtidos por INAA para a matriz de alimentos comerciais infantis, para as condições de análise utilizadas neste trabalho. Para este cálculo foram utilizados os alimentos com menor concentração do elemento de interesse.

Para a determinação do LD, utilizou-se o método proposto por Currie (Currie, 1999), de acordo com a Equação 7:

$$
\operatorname{LD}=3,29 \sigma_{\circ}
$$

(Equação 7)

Sendo:

$$
\sigma_{0}=\frac{\sqrt{R F}}{t v}
$$

Onde:

$\mathrm{RF}=$ número de contagens da radiação de fundo sob o pico do analito tv = tempo total de medição da amostra (tempo vivo)

As concentrações de As presentes em todas as amostras analisadas de alimentos comerciais infantis ficaram abaixo do limite de detecção, por isso este elemento não foi colocado nas tabelas que apresentam os resultados das amostras, bem como nos gráficos para análise das concentrações encontradas. Os efeitos tóxicos deste elemento dependem, principalmente, do estado de oxidação e das espécies químicas a ele ligadas. Arsênio inorgânico é considerado cancerígeno, afetando principalmente rim, pulmão, bexiga, além de poder causar doenças de pele. Pesquisas mostram que a exposição ao arsênio está relacionada à redução da função intelectual em crianças. Os principais alimentos que contêm este elemento são peixes e frutos do mar, porém, nenhuma das amostras analisadas tinha esses alimentos em sua composição. A ausência dos principais alimentos que contêm arsênio pode ser uma possível explicação para as concentrações abaixo do limite de detecção nos alimentos analisados (Morais et al., 2012; Nookabkaew et al., 2012). 
Tabela 15 - Limites de detecção dos elementos determinados por INAA

\begin{tabular}{c|c|c}
\hline Elemento & LD (base seca) & LD (In natura) \\
\hline As $(\mathrm{ng} / \mathrm{g})$ & 0,86 & 0,14 \\
\hline $\mathrm{Ca}(\mu \mathrm{g} / \mathrm{g})$ & 81 & 12 \\
\hline $\mathrm{Cl}(\mu \mathrm{g} / \mathrm{g})$ & 9,5 & 1,4 \\
\hline $\mathrm{Co}(\mathrm{ng} / \mathrm{g})$ & 3,8 & 0,75 \\
\hline $\mathrm{Cr}(\mathrm{ng} / \mathrm{g})$ & 60 & 11 \\
\hline $\mathrm{Fe}(\mu \mathrm{g} / \mathrm{g})$ & 1,57 & 0,24 \\
\hline $\mathrm{K}(\mu \mathrm{g} / \mathrm{g})$ & 58 & 1,8 \\
\hline $\mathrm{Mg}(\mu \mathrm{g} / \mathrm{g})$ & 18 & 2,8 \\
\hline $\mathrm{Mn}(\mu \mathrm{g} / \mathrm{g})$ & 0,03 & 0,005 \\
\hline $\mathrm{Na}(\mu \mathrm{g} / \mathrm{g})$ & 2,60 & 0,39 \\
\hline $\mathrm{Se}(\mathrm{ng} / \mathrm{g})$ & 25 & 0,20 \\
\hline $\mathrm{Zn}(\mu \mathrm{g} / \mathrm{g})$ & 0,16 & 0,024 \\
\hline
\end{tabular}

$\mathrm{Na}$ Tabela 16 estão apresentados os resultados das concentrações dos elementos essenciais obtidas pelas análises das 27 amostras, na base seca, de alimentos comerciais infantis, adquiridos em redes de supermercados durante os anos de 2010 e 2011. Para garantir a validade estatística, todas as análises foram feitas em triplicata. 
Tabela16 - Concentrações dos elementos essenciais nas amostras em base seca (média \pm desvio padrão)

\begin{tabular}{|c|c|c|c|c|c|c|c|c|c|c|c|}
\hline $\begin{array}{c}\text { Amostra } \\
\text { (Etapa) }\end{array}$ & $\begin{array}{c}\mathrm{Ca} \\
\mu \mathrm{g} / \mathrm{g}\end{array}$ & $\begin{array}{c}\mathrm{Cl} \\
\mu \mathrm{g} / \mathrm{g}\end{array}$ & $\begin{array}{c}\mathrm{Co} \\
\mathrm{ng} / \mathrm{g}\end{array}$ & $\begin{array}{c}\mathrm{Cr} \\
\mathrm{ng} / \mathrm{g}\end{array}$ & $\begin{array}{c}\mathrm{Fe} \\
\mu \mathrm{g} / \mathrm{g}\end{array}$ & $\begin{array}{c}\mathrm{K} \\
\mu \mathrm{g} / \mathrm{g}\end{array}$ & $\begin{array}{c}\mathrm{Mg} \\
\mu \mathrm{g} / \mathrm{g}\end{array}$ & $\begin{array}{c}M n \\
\mu g / g\end{array}$ & $\begin{array}{c}\mathrm{Na} \\
\mu \mathrm{g} / \mathrm{g}\end{array}$ & $\begin{array}{c}\mathrm{Se} \\
\mathrm{ng} / \mathrm{g}\end{array}$ & $\begin{array}{c}\mathrm{Zn} \\
\mu \mathrm{g} / \mathrm{g}\end{array}$ \\
\hline $1 a$ & $652 \pm 54$ & $212 \pm 20$ & $31,6 \pm 3,1$ & $253 \pm 21$ & $13,9 \pm 1,3$ & $7935 \pm 637$ & $310 \pm 31$ & $4,52 \pm 0,40$ & $265 \pm 22$ & $27,0 \pm 2,7$ & $4,45 \pm 0,42$ \\
\hline $2 a$ & $394 \pm 26$ & $479 \pm 44$ & $34,8 \pm 3,3$ & $420 \pm 37$ & $14,0 \pm 1,2$ & $6343 \pm 504$ & $502 \pm 46$ & $7,50 \pm 0,50$ & $266 \pm 20$ & $28,0 \pm 2,8$ & $8,40 \pm 0,71$ \\
\hline $3 a$ & $509 \pm 20$ & $145,9 \pm 5,7$ & $25,4 \pm 1,8$ & $255 \pm 18$ & $7,40 \pm 0,70$ & $5425 \pm 299$ & $183 \pm 12$ & $2,78 \pm 0,24$ & $215 \pm 18$ & $<25$ & $2,90 \pm 0,10$ \\
\hline $4 a$ & $417 \pm 39$ & $989 \pm 91$ & $31,5 \pm 2,6$ & $152 \pm 11$ & $9,64 \pm 0,48$ & $8598 \pm 602$ & $609 \pm 60$ & $11,80 \pm 0,79$ & $213 \pm 16$ & $<25$ & $12,06 \pm 0,21$ \\
\hline $5 a$ & $484 \pm 45$ & $176 \pm 14$ & $21,8 \pm 1,8$ & $809 \pm 45$ & $19,3 \pm 1,9$ & $7545 \pm 555$ & $291 \pm 22$ & $6,41 \pm 0,31$ & $225 \pm 13$ & $<25$ & $4,52 \pm 0,34$ \\
\hline $1 b$ & $5984 \pm 529$ & $3794 \pm 366$ & $27,7 \pm 2,5$ & $257,0 \pm 4,2$ & $24,2 \pm 2,3$ & $10548 \pm 669$ & $761 \pm 65$ & $11,96 \pm 0,89$ & $105 \pm 89$ & $26,3 \pm 2,3$ & $16,57 \pm 0,92$ \\
\hline $2 b$ & $6139 \pm 605$ & $2853 \pm 230$ & $35,8 \pm 3,3$ & $687 \pm 53$ & $23,6 \pm 2,3$ & $8550 \pm 518$ & $493 \pm 42$ & $5,82 \pm 0,51$ & $1191 \pm 104$ & $33,5 \pm 2,1$ & $16,4 \pm 1,6$ \\
\hline $3 b$ & $327 \pm 32$ & $380 \pm 34$ & $31,6 \pm 3,1$ & $398,3 \pm 9,9$ & $16,63 \pm 0,69$ & $5867 \pm 539$ & $266 \pm 25$ & $2,71 \pm 0,24$ & $205 \pm 18$ & $65,5 \pm 3,4$ & $3,18 \pm 0,21$ \\
\hline $4 b$ & $486 \pm 46$ & $1282 \pm 90$ & $31,1 \pm 2,2$ & $376 \pm 37$ & $11,5 \pm 1,0$ & $8991 \pm 710$ & $752 \pm 66$ & $35,3 \pm 3,1$ & $126 \pm 10$ & $69,9 \pm 3,2$ & $5,34 \pm 0,41$ \\
\hline $5 b$ & $499 \pm 22$ & $801 \pm 58$ & $23,9 \pm 2,0$ & $468 \pm 42$ & $12,3 \pm 1,1$ & $6562 \pm 206$ & $449 \pm 40$ & $5,76 \pm 0,48$ & $274 \pm 23$ & $63,0 \pm 4,2$ & $4,79 \pm 0,16$ \\
\hline $6 b$ & $603 \pm 58$ & $144 \pm 12$ & $33,0 \pm 2,9$ & $218 \pm 18$ & $9,36 \pm 0,88$ & $7566 \pm 700$ & $394 \pm 27$ & $6,51 \pm 0,59$ & $83,4 \pm 7,2$ & $<25$ & $4,59 \pm 0,30$ \\
\hline $7 b$ & $7910 \pm 774$ & $2380 \pm 103$ & $31,2 \pm 2,8$ & $130 \pm 11$ & $19,3 \pm 1,8$ & $7728 \pm 429$ & $383 \pm 37$ & $4,27 \pm 0,36$ & $1069 \pm 94$ & $<25$ & $16,7 \pm 1,5$ \\
\hline $1 c$ & $613 \pm 56$ & $5945 \pm 385$ & $55,5 \pm 3,6$ & $187 \pm 16$ & $31,2 \pm 2,3$ & $12895 \pm 749$ & $735 \pm 65$ & $4,09 \pm 0,32$ & $3135 \pm 288$ & $70,0 \pm 5,7$ & $62,7 \pm 3,0$ \\
\hline $2 c$ & $553 \pm 47$ & $7721 \pm 55$ & $105,9 \pm 8,8$ & $352 \pm 10$ & $30,9 \pm 3,0$ & $13809 \pm 879$ & $921 \pm 87$ & $6,26 \pm 0,61$ & $4005 \pm 328$ & $115 \pm 11$ & $59,3 \pm 5,6$ \\
\hline $3 c$ & $527,3 \pm 5,5$ & $6393 \pm 110$ & $64,7 \pm 6,1$ & $120,5 \pm 4,9$ & $22,6 \pm 1,8$ & $12439 \pm 1185$ & $625 \pm 61$ & $4,31 \pm 0,41$ & $3106 \pm 283$ & $90,50 \pm 0,71$ & $14,36 \pm 0,79$ \\
\hline $4 c$ & $421 \pm 23$ & $6469 \pm 246$ & $21,5 \pm 1,7$ & $209 \pm 18$ & $20,4 \pm 1,9$ & $11247 \pm 312$ & $562 \pm 35$ & $3,60 \pm 0,32$ & $2909 \pm 254$ & $88,0 \pm 8,5$ & $13,90 \pm 0,99$ \\
\hline $5 c$ & $1237 \pm 111$ & $6387 \pm 606$ & $52,6 \pm 4,9$ & $193,0 \pm 7,1$ & $21,7 \pm 1,9$ & $10883 \pm 912$ & $804 \pm 68$ & $12,5 \pm 1,0$ & $2994 \pm 275$ & $112,0 \pm 5,7$ & $34,6 \pm 1,8$ \\
\hline $6 c$ & $588 \pm 36$ & $5757 \pm 475$ & $39,3 \pm 2,5$ & $323,0 \pm 2,8$ & $20,9 \pm 2,0$ & $10178 \pm 340$ & $504 \pm 45$ & $3,10 \pm 0,30$ & $3034 \pm 279$ & $134,5 \pm 9,2$ & $40,8 \pm 3,8$ \\
\hline $7 c$ & $707 \pm 65$ & $5566 \pm 529$ & $56,1 \pm 3,2$ & $142,0 \pm 1,4$ & $11,48 \pm 0,97$ & $9681 \pm 529$ & $592 \pm 56$ & $3,89 \pm 0,37$ & $3232 \pm 293$ & $44,0 \pm 2,8$ & $15,83 \pm 0,75$ \\
\hline $1 d$ & $868 \pm 64$ & $8720 \pm 675$ & $78,4 \pm 6,4$ & $557 \pm 47$ & $34,0 \pm 3,2$ & $11013 \pm 1067$ & $808 \pm 49$ & $6,72 \pm 0,63$ & $4346 \pm 401$ & $93,5 \pm 4,9$ & $10,95 \pm 0,88$ \\
\hline $2 d$ & $435 \pm 22$ & $7324 \pm 426$ & $24,0 \pm 2,3$ & $747 \pm 32$ & $25,8 \pm 2,4$ & $13382 \pm 1200$ & $603 \pm 43$ & $5,27 \pm 0,45$ & $4608 \pm 253$ & $54,0 \pm 4,2$ & $36,8 \pm 2,0$ \\
\hline $3 d$ & $532 \pm 41$ & $8722 \pm 708$ & $21,4 \pm 2,0$ & $404 \pm 34$ & $15,7 \pm 1,4$ & $10487 \pm 977$ & $592 \pm 57$ & $2,98 \pm 0,24$ & $4566 \pm 229$ & $95,5 \pm 4,9$ & $13,9 \pm 1,0$ \\
\hline $4 d$ & $459 \pm 36$ & $8519 \pm 631$ & $34,4 \pm 3,3$ & $313 \pm 22$ & $28,3 \pm 2,3$ & $8844 \pm 783$ & $450 \pm 41$ & $3,86 \pm 0,34$ & $3965 \pm 235$ & $39,3 \pm 2,1$ & $42,3 \pm 2,1$ \\
\hline $1 \mathrm{e}$ & $518 \pm 47$ & $16642 \pm 1383$ & $50,9 \pm 4,6$ & $472 \pm 43$ & $150 \pm 11$ & $15464 \pm 1318$ & $415 \pm 13$ & $5,27 \pm 0,47$ & $5723 \pm 430$ & $26,3 \pm 2,3$ & $50,8 \pm 3,1$ \\
\hline $2 \mathrm{e}$ & $617 \pm 59$ & $22032 \pm 781$ & $64,5 \pm 5,6$ & $1191 \pm 61$ & $170 \pm 14$ & $22144 \pm 1190$ & $1136 \pm 65$ & $5,63 \pm 0,49$ & $8345 \pm 777$ & $61,0 \pm 5,6$ & $60,7 \pm 5,0$ \\
\hline $3 e$ & $2252 \pm 207$ & $21351 \pm 1909$ & $42,8 \pm 4,0$ & $545 \pm 47$ & $115 \pm 11$ & $13748 \pm 1267$ & $645 \pm 16$ & $4,41 \pm 0,33$ & $8447 \pm 677$ & $91,7 \pm 9,1$ & $17,5 \pm 1,5$ \\
\hline $4 \mathrm{e}$ & $3550 \pm 353$ & $19179 \pm 1706$ & $47,7 \pm 4,5$ & $616 \pm 24$ & $152 \pm 13$ & $19090 \pm 1018$ & $573 \pm 44$ & $4,44 \pm 0,33$ & $7187 \pm 574$ & $119,7 \pm 5,9$ & $46,3 \pm 4,0$ \\
\hline
\end{tabular}
(a): Etapa 1
(b) Etapa 2 sabor doce
(c) Etapa 2 sabor salgado
(d) Etapa 3
(e) Etapa Junior 
As porcentagens de água nas amostras variaram de 78,7\% (amostra $4 d-$ Etapa 3) a 87,7\% (amostra 2a - Etapa 1) em massa, ou seja, as taxas de umidade variaram entre 0,787 e 0,877 , sendo que as amostras de fórmulas doces apresentaram as maiores porcentagens de água. Para calcular o valor da concentração do elemento na amostra in natura foi necessário multiplicar o valor da concentração do elemento em peso seco de amostra pelo seu índice de massa seca, conforme apresentado pela Equação 8:

$$
\mathrm{C}_{\text {in natura }}=\mathrm{C}_{\text {peso seco }} \mathrm{XI}
$$

Sendo:

$\mathrm{C}_{\text {in natura }}=$ Concentração do elemento na amostra in natura

$\mathrm{C}_{\text {peso seco }}=$ Concentração do elemento na amostra seca

I = Índice de massa seca $=(1-$ taxa de umidade $)$

$\mathrm{Na}$ Tabela 17 estão apresentadas as concentrações dos elementos analisados por INAA por grama de amostra in natura.

Embora nenhum pote de alimento comercial infantil brasileiro apresente massa líquida de 100 gramas, a maioria dos trabalhos publicados que analisam alimentos complementares, ao invés de calcular a quantidade de nutriente total presente em cada pote, calcula a quantidade de nutriente presente em $100 \mathrm{~g}$ do alimento complementar. Na Tabela 18 estão apresentadas as quantidades de nutrientes encontradas por $100 \mathrm{~g}$ de amostra, bem como os valores de recomendados de ingestão.

As recomendações nutricionais (DRI - Ingestão diária Recomendada) para indivíduos saudáveis foram elaboradas pelo comitê do Food and Nutrition Board (FNB) do Institute of Medicine (IOM) dos Estados Unidos (Institute of Medicine, 1999). As DRl's englobam 4 níveis de referência: EAR (Necessidade Média Estimada); RDA (Ingestão Dietética Recomendada); AI (Ingestão Adequada) e UL (Limite Superior Tolerável de Ingestão) 
$\mathrm{Na}$ Tabela 19 estão apresentadas as massas dos elementos contidos na massa total de alimento presente em cada frasco comercial de amostra. Ao final desta tabela estão apresentados os valores de Ingestão Dietética Recomendada (RDA). Apenas os elementos Fe e $\mathrm{Zn}$ apresentam valores de RDA, enquanto os demais elementos apresentam valores de Ingestão Adequada (Al). As quantidades de massa de alimento presentes nos potes de alimentos comerciais infantis variam de acordo com as diferentes etapas da vida da criança. Essa variação na massa está apresentada na Tabela 19.

Os Gráficos 1-11 ilustram a quantidade de nutriente presente na massa de cada pote comercial de amostra, em $100 \mathrm{~g}$ de amostra e a comparação com os valores de RDA e Al, para crianças de 7 a 12 meses de idade. 
Tabela 17- Concentrações dos elementos essenciais na amostra in natura (média \pm desvio padrão).

\begin{tabular}{|c|c|c|c|c|c|c|c|c|c|c|c|}
\hline $\begin{array}{c}\text { Amostra } \\
\text { (Etapa) }\end{array}$ & $\begin{array}{c}\mathrm{Ca} \\
\mu \mathrm{g} / \mathrm{g}\end{array}$ & $\begin{array}{c}\mathrm{Cl} \\
\mu \mathrm{g} / \mathrm{g}\end{array}$ & $\begin{array}{c}\mathrm{Co} \\
\mathrm{ng} / \mathrm{g}\end{array}$ & $\begin{array}{c}\mathrm{Cr} \\
\mathrm{ng} / \mathrm{g}\end{array}$ & $\begin{array}{c}\mathrm{Fe} \\
\mu \mathrm{g} / \mathrm{g}\end{array}$ & $\begin{array}{c}\mathrm{K} \\
\mu \mathrm{g} / \mathrm{g}\end{array}$ & $\begin{array}{c}\mathrm{Mg} \\
\mu \mathrm{g} / \mathrm{g}\end{array}$ & $\begin{array}{c}\mathrm{Mn} \\
\mu \mathrm{g} / \mathrm{g}\end{array}$ & $\begin{array}{c}\mathrm{Na} \\
\mu \mathrm{g} / \mathrm{g}\end{array}$ & $\begin{array}{c}\mathrm{Se} \\
\mathrm{ng} / \mathrm{g}\end{array}$ & $\begin{array}{c}\mathrm{Zn} \\
\mu \mathrm{g} / \mathrm{g}\end{array}$ \\
\hline $1 a$ & $129 \pm 11$ & $41,7 \pm 4,0$ & $6,23 \pm 0,61$ & $49,8 \pm 4,2$ & $2,74 \pm 0,26$ & $1563 \pm 125$ & $61,0 \pm 6,0$ & $0,890 \pm 0,079$ & $52,1 \pm 4,4$ & $5,32 \pm 0,50$ & $0,877 \pm 0,083$ \\
\hline $2 a$ & $48,5 \pm 3,2$ & $58,9 \pm 5,4$ & $4,27 \pm 0,41$ & $51,6 \pm 4,5$ & $1,72 \pm 0,15$ & $780 \pm 62$ & $61,8 \pm 5,6$ & $0,923 \pm 0,062$ & $32,7 \pm 2,5$ & $3,44 \pm 0,34$ & $1,032 \pm 0,088$ \\
\hline $3 a$ & $77,4 \pm 3,1$ & $22,17 \pm 0,87$ & $3,86 \pm 0,28$ & $38,7 \pm 2,7$ & $1,12 \pm 0,11$ & $825 \pm 45$ & $27,8 \pm 1,9$ & $0,422 \pm 0,036$ & $32,6 \pm 2,7$ & $<0,20$ & $0,441 \pm 0,015$ \\
\hline $4 a$ & $60,5 \pm 5,6$ & $143 \pm 13$ & $4,57 \pm 0,38$ & $22,1 \pm 1,7$ & $1,40 \pm 0,07$ & $1247 \pm 87$ & $88,4 \pm 8,7$ & $1,71 \pm 0,11$ & $30,9 \pm 2,3$ & $<0,20$ & $1,748 \pm 0,031$ \\
\hline $5 a$ & $62,9 \pm 5,8$ & $22,9 \pm 1,8$ & $2,84 \pm 0,24$ & $105,2 \pm 5,8$ & $2,51 \pm 0,24$ & $981 \pm 72$ & $37,9 \pm 2,8$ & $0,834 \pm 0,040$ & $29,2 \pm 1,7$ & $<0,20$ & $0,587 \pm 0,044$ \\
\hline $1 b$ & $1209 \pm 107$ & $766 \pm 74$ & $5,59 \pm 0,51$ & $51,91 \pm 0,86$ & $4,88 \pm 0,46$ & $2131 \pm 135$ & $154 \pm 13$ & $2,42 \pm 0,18$ & $212 \pm 18$ & $5,32 \pm 0,47$ & $3,35 \pm 0,19$ \\
\hline $2 b$ & $1314 \pm 129$ & $611 \pm 49$ & $7,66 \pm 0,71$ & $147 \pm 11$ & $5,04 \pm 0,49$ & $1830 \pm 111$ & $105,4 \pm 9,0$ & $1,25 \pm 0,11$ & $255 \pm 22$ & $7,16 \pm 0,45$ & $3,51 \pm 0,34$ \\
\hline $3 b$ & $52,6 \pm 5,2$ & $61,1 \pm 5,5$ & $5,09 \pm 0,49$ & $64,1 \pm 1,6$ & $2,68 \pm 0,11$ & $945 \pm 87$ & $42,8 \pm 4,1$ & $0,436 \pm 0,039$ & $33,0 \pm 3,0$ & $12,2 \pm 1,0$ & $0,512 \pm 0,034$ \\
\hline $4 b$ & $73,4 \pm 7,0$ & $194 \pm 14$ & $4,69 \pm 0,34$ & $56,8 \pm 5,6$ & $1,74 \pm 0,15$ & $1358 \pm 107$ & $113,5 \pm 9,9$ & $5,34 \pm 0,47$ & $19,1 \pm 1,6$ & $12,1 \pm 1,1$ & $0,806 \pm 0,061$ \\
\hline $5 b$ & $82,3 \pm 3,6$ & $132,2 \pm 9,6$ & $3,94 \pm 0,32$ & $77,1 \pm 6,8$ & $2,02 \pm 0,19$ & $1083 \pm 34$ & $74,0 \pm 6,7$ & $0,951 \pm 0,080$ & $45,2 \pm 3,8$ & $10,40 \pm 0,70$ & $0,790 \pm 0,026$ \\
\hline $6 b$ & $97,1 \pm 9,4$ & $23,1 \pm 1,9$ & $5,31 \pm 0,48$ & $37,7 \pm 3,7$ & $1,51 \pm 0,14$ & $1218 \pm 113$ & $63,5 \pm 4,3$ & $1,049 \pm 0,094$ & $13,4 \pm 1,2$ & $<0,20$ & $0,739 \pm 0,048$ \\
\hline $7 b$ & $1582 \pm 155$ & $476 \pm 21$ & $6,25 \pm 0,56$ & $25,9 \pm 2,3$ & $3,87 \pm 0,35$ & $1546 \pm 86$ & $76,7 \pm 7,4$ & $0,854 \pm 0,071$ & $214 \pm 19$ & $<0,20$ & $3,34 \pm 0,30$ \\
\hline $1 \mathrm{c}$ & $103,6 \pm 9,5$ & $1005 \pm 65$ & $9,38 \pm 0,61$ & $31,7 \pm 2,7$ & $5,27 \pm 0,40$ & $2179 \pm 127$ & $124 \pm 11$ & $0,691 \pm 0,055$ & $530 \pm 49$ & $11,83 \pm 0,96$ & $10,59 \pm 0,51$ \\
\hline $2 c$ & $86,9 \pm 8,3$ & $1212,2 \pm 8,7$ & $16,6 \pm 1,4$ & $55,2 \pm 1,6$ & $4,85 \pm 0,47$ & $2168 \pm 138$ & $145 \pm 14$ & $0,98 \pm 0,10$ & $629 \pm 51$ & $18,0 \pm 1,8$ & $9,31 \pm 0,88$ \\
\hline $3 c$ & $99,1 \pm 1,0$ & $1202 \pm 21$ & $12,2 \pm 1,1$ & $22,65 \pm 0,93$ & $4,25 \pm 0,34$ & $2338 \pm 223$ & $117 \pm 11$ & $0,810 \pm 0,077$ & $584 \pm 53$ & $17,01 \pm 0,13$ & $2,70 \pm 0,15$ \\
\hline $4 c$ & $83,4 \pm 4,5$ & $1281 \pm 49$ & $4,26 \pm 0,34$ & $41,3 \pm 3,6$ & $4,03 \pm 0,37$ & $2227 \pm 62$ & $111,2 \pm 6,9$ & $0,712 \pm 0,064$ & $576 \pm 50$ & $17,4 \pm 1,7$ & $2,75 \pm 0,20$ \\
\hline $5 c$ & $229 \pm 21$ & $1182 \pm 112$ & $9,73 \pm 0,91$ & $35,7 \pm 1,3$ & $4,01 \pm 0,35$ & $2013 \pm 169$ & $149 \pm 13$ & $2,32 \pm 0,19$ & $554 \pm 51$ & $20,7 \pm 1,0$ & $6,41 \pm 0,35$ \\
\hline $6 c$ & $111,6 \pm 6,9$ & $1094 \pm 90$ & $7,46 \pm 0,47$ & $61,37 \pm 0,54$ & $3,97 \pm 0,38$ & $1934 \pm 65$ & $95,7 \pm 8,6$ & $0,590 \pm 0,056$ & $576 \pm 53$ & $25,6 \pm 1,7$ & $7,76 \pm 0,72$ \\
\hline $7 c$ & $129 \pm 12$ & $1013 \pm 96$ & $10,21 \pm 0,59$ & $25,84 \pm 0,26$ & $2,09 \pm 0,18$ & $1762 \pm 96$ & $108 \pm 10$ & $0,708 \pm 0,068$ & $588 \pm 53$ & $8,00 \pm 0,51$ & $2,88 \pm 0,14$ \\
\hline $1 d$ & $172 \pm 13$ & $1727 \pm 134$ & $15,5 \pm 1,3$ & $110,2 \pm 9,2$ & $6,74 \pm 0,63$ & $2181 \pm 211$ & $159,9 \pm 9,8$ & $1,33 \pm 0,13$ & $861 \pm 79$ & $18,51 \pm 0,98$ & $2,17 \pm 0,17$ \\
\hline $2 d$ & $90,5 \pm 4,6$ & $1523 \pm 89$ & $4,99 \pm 0,48$ & $155,3 \pm 6,7$ & $5,37 \pm 0,49$ & $2784 \pm 250$ & $125,4 \pm 9,0$ & $1,096 \pm 0,093$ & $959 \pm 53$ & $11,23 \pm 0,88$ & $7,65 \pm 0,43$ \\
\hline $3 d$ & $110,1 \pm 8,6$ & $1806 \pm 147$ & $4,42 \pm 0,41$ & $83,5 \pm 7,1$ & $3,25 \pm 0,29$ & $2171 \pm 202$ & $123 \pm 12$ & $0,62 \pm 0,50$ & $945 \pm 47$ & $19,8 \pm 1,0$ & $2,87 \pm 0,21$ \\
\hline $4 d$ & $97,7 \pm 7,6$ & $1814 \pm 134$ & $7,33 \pm 0,71$ & $66,7 \pm 4,7$ & $6,03 \pm 0,50$ & $1884 \pm 167$ & $95,9 \pm 8,8$ & $0,823 \pm 0,072$ & $845 \pm 50$ & $8,36 \pm 0,44$ & $9,01 \pm 0,47$ \\
\hline $1 \mathrm{e}$ & $92,2 \pm 8,4$ & $2962 \pm 246$ & $9,07 \pm 0,82$ & $84,1 \pm 7,7$ & $26,7 \pm 1,9$ & $2753 \pm 235$ & $73,8 \pm 2,3$ & $0,939 \pm 0,083$ & $1019 \pm 77$ & $4,68 \pm 0,40$ & $9,04 \pm 0,54$ \\
\hline $2 \mathrm{e}$ & $98,7 \pm 9,5$ & $3525 \pm 125$ & $10,33 \pm 0,91$ & $190,5 \pm 9,8$ & $27,2 \pm 2,3$ & $3543 \pm 190$ & $182 \pm 10$ & $0,901 \pm 0,078$ & $1335 \pm 124$ & $9,76 \pm 0,89$ & $9,71 \pm 0,80$ \\
\hline $3 e$ & $435 \pm 40$ & $4121 \pm 368$ & $8,26 \pm 0,77$ & $105,1 \pm 9,0$ & $22,2 \pm 2,2$ & $2653 \pm 245$ & $124,5 \pm 3,0$ & $0,850 \pm 0,063$ & $1630 \pm 131$ & $17,7 \pm 1,7$ & $3,38 \pm 0,29$ \\
\hline $4 \mathrm{e}$ & $678 \pm 67$ & $3663 \pm 326$ & $9,12 \pm 0,86$ & $117,7 \pm 4,6$ & $29,0 \pm 2,4$ & $3646 \pm 194$ & $109,4 \pm 8,3$ & $0,847 \pm 0,063$ & $1373 \pm 110$ & $22,9 \pm 1,1$ & $8,83 \pm 0,77$ \\
\hline
\end{tabular}

$\begin{array}{lllll}\text { (a): Etapa } 1 & \text { (b) Etapa } 2 \text { sabor doce } & \text { (c) Etapa } 2 \text { sabor salgado } & \text { (d) Etapa } 3 & \text { (e) Etapa Junior }\end{array}$ 
Tabela 18 - Massas dos elementos essenciais presentes em $100 \mathrm{~g}$ de amostra (média \pm desvio padrão) e valores de Al ou RDA

\begin{tabular}{|c|c|c|c|c|c|c|c|c|c|c|c|}
\hline $\begin{array}{c}\text { Amostra } \\
\text { (Etapa) }\end{array}$ & $\begin{array}{l}\mathrm{Ca} \\
\mathrm{mg}\end{array}$ & $\begin{array}{c}\mathrm{Cl} \\
\mathrm{mg}\end{array}$ & $\begin{array}{l}\text { Co } \\
\mu g\end{array}$ & $\begin{array}{l}\mathrm{Cr} \\
\mu \mathrm{g}\end{array}$ & $\begin{array}{l}\mathrm{Fe} \\
\mu \mathrm{g}\end{array}$ & $\begin{array}{c}\mathrm{K} \\
\mathrm{mg}\end{array}$ & $\begin{array}{l}\mathrm{Mg} \\
\mathrm{mg}\end{array}$ & $\begin{array}{l}\mathrm{Mn} \\
\mu \mathrm{g}\end{array}$ & $\begin{array}{l}\mathrm{Na} \\
\mathrm{mg}\end{array}$ & $\begin{array}{l}\text { Se } \\
\mu g\end{array}$ & $\begin{array}{l}\mathrm{Zn} \\
\mu \mathrm{g}\end{array}$ \\
\hline $1 a$ & $12,9 \pm 1,1$ & $4,17 \pm 0,40$ & $0,623 \pm 0,060$ & $4,91 \pm 0,42$ & $274 \pm 26$ & $156 \pm 13$ & $6,10 \pm 0,60$ & $89,0 \pm 7,9$ & $5,21 \pm 0,44$ & $0,532 \pm 0,053$ & $87,7 \pm 8,3$ \\
\hline $2 a$ & $4,85 \pm 0,32$ & $5,89 \pm 0,54$ & $0,427 \pm 0,041$ & $5,16 \pm 0,45$ & $172 \pm 15$ & $78,0 \pm 6,2$ & $6,18 \pm 0,56$ & $92,3 \pm 6,2$ & $3,27 \pm 0,25$ & $0,344 \pm 0,034$ & $103,2 \pm 8,8$ \\
\hline $3 a$ & $7,74 \pm 0,31$ & $2,22 \pm 0,09$ & $0,386 \pm 0,028$ & $3,87 \pm 0,27$ & $112 \pm 11$ & $82,4 \pm 4,5$ & $2,78 \pm 0,20$ & $42,2 \pm 3,6$ & $3,26 \pm 0,27$ & - & $44,1 \pm 1,5$ \\
\hline $4 a$ & $6,05 \pm 0,56$ & $14,3 \pm 1,3$ & $0,457 \pm 0,038$ & $2,21 \pm 0,17$ & $140,0 \pm 7,0$ & $124,7 \pm 8,7$ & $8,84 \pm 0,87$ & $171 \pm 11$ & $3,09 \pm 0,23$ & - & $174,8 \pm 3,1$ \\
\hline $5 a$ & $6,29 \pm 0,58$ & $2,29 \pm 0,18$ & $0,284 \pm 0,024$ & $10,52 \pm 0,58$ & $251 \pm 24$ & $98,1 \pm 7,2$ & $3,79 \pm 0,28$ & $83,4 \pm 4,0$ & $2,92 \pm 0,17$ & - & $58,7 \pm 4,4$ \\
\hline $1 b$ & $121 \pm 11$ & $76,6 \pm 7,4$ & $0,559 \pm 0,050$ & $5,19 \pm 0,086$ & $488 \pm 46$ & $213 \pm 14$ & $15,4 \pm 1,3$ & $242 \pm 18$ & $21,2 \pm 1,8$ & $0,532 \pm 0,047$ & $335 \pm 19$ \\
\hline $2 b$ & $131 \pm 13$ & $61,1 \pm 4,9$ & $0,766 \pm 0,071$ & $14,7 \pm 1,1$ & $504 \pm 49$ & $183 \pm 11$ & $10,5 \pm 9,0$ & $125 \pm 11$ & $25,5 \pm 2,2$ & $0,72 \pm 0,045$ & $351 \pm 34$ \\
\hline $3 b$ & $5,26 \pm 0,51$ & $6,11 \pm 0,55$ & $0,510 \pm 0,050$ & $6,41 \pm 0,16$ & $268 \pm 11$ & $94,5 \pm 8,7$ & $4,28 \pm 0,41$ & $43,6 \pm 3,9$ & $3,31 \pm 0,30$ & $1,22 \pm 0,10$ & $51,2 \pm 3,4$ \\
\hline $4 b$ & $7,34 \pm 0,70$ & $19,4 \pm 1,4$ & $0,470 \pm 0,034$ & $5,68 \pm 0,56$ & $174 \pm 15$ & $136 \pm 11$ & $11,4 \pm 1,0$ & $534 \pm 47$ & $1,91 \pm 0,16$ & $1,21 \pm 0,11$ & $80,6 \pm 6,1$ \\
\hline $5 b$ & $8,23 \pm 0,36$ & $13,22 \pm 0,96$ & $0,395 \pm 0,033$ & $7,71 \pm 0,69$ & $202 \pm 19$ & $108,3 \pm 3,4$ & $7,40 \pm 0,67$ & $95,1 \pm 8,0$ & $4,52 \pm 0,38$ & $1,04 \pm 0,070$ & $79,0 \pm 2,6$ \\
\hline $6 b$ & $9,71 \pm 0,94$ & $2,31 \pm 0,19$ & $0,531 \pm 0,048$ & $3,78 \pm 0,37$ & $151 \pm 14$ & $122 \pm 11$ & $6,35 \pm 0,43$ & $104,9 \pm 9,4$ & $1,34 \pm 0,12$ & - & $73,9 \pm 4,8$ \\
\hline $7 b$ & $158 \pm 15$ & $47,6 \pm 2,1$ & $0,625 \pm 0,056$ & $2,59 \pm 0,23$ & $387 \pm 35$ & $154,6 \pm 8,6$ & $7,67 \pm 0,74$ & $85,4 \pm 7,1$ & $21,4 \pm 1,9$ & - & $334 \pm 30$ \\
\hline $1 c$ & $10,36 \pm 0,95$ & $100,5 \pm 6,5$ & $0,948 \pm 0,061$ & $3,17 \pm 0,27$ & $527 \pm 40$ & $218 \pm 13$ & $12,4 \pm 1,1$ & $69,1 \pm 5,5$ & $53,0 \pm 4,9$ & $1,18 \pm 0,10$ & $1059 \pm 51$ \\
\hline 2c & $8,69 \pm 0,73$ & $121,2 \pm 0,87$ & $1,66 \pm 0,14$ & $5,52 \pm 0,16$ & $485 \pm 47$ & $217 \pm 14$ & $14,5 \pm 1,4$ & $98,3 \pm 9,5$ & $62,9 \pm 5,1$ & $1,80 \pm 0,18$ & $931 \pm 88$ \\
\hline $3 c$ & $9,91 \pm 0,10$ & $120,2 \pm 2,1$ & $1,22 \pm 0,11$ & $2,265 \pm 0,093$ & $425 \pm 34$ & $234 \pm 22$ & $11,7 \pm 1,1$ & $81,0 \pm 7,7$ & $58,4 \pm 5,3$ & $1,701 \pm 0,013$ & $270 \pm 15$ \\
\hline $4 c$ & $8,34 \pm 0,45$ & $128,1 \pm 4,9$ & $0,426 \pm 0,034$ & $4,13 \pm 0,36$ & $403 \pm 37$ & $222,7 \pm 6,2$ & $11,12 \pm 0,69$ & $71,2 \pm 6,4$ & $57,6 \pm 5,0$ & $1,74 \pm 0,16$ & $275 \pm 20$ \\
\hline $5 c$ & $22,9 \pm 2,1$ & $118 \pm 11$ & $0,973 \pm 0,091$ & $3,57 \pm 0,13$ & $401 \pm 35$ & $201 \pm 17$ & $14,9 \pm 1,3$ & $232 \pm 19$ & $55,4 \pm 5,1$ & $2,07 \pm 0,10$ & $641 \pm 35$ \\
\hline $6 c$ & $11,16 \pm 0,69$ & $109,4 \pm 9,0$ & $0,746 \pm 0,047$ & $6,137 \pm 0,054$ & $397 \pm 38$ & $193,4 \pm 6,5$ & $9,57 \pm 0,86$ & $59,0 \pm 5,6$ & $57,6 \pm 5,3$ & $2,56 \pm 0,17$ & $776 \pm 72$ \\
\hline $7 c$ & $12,9 \pm 1,2$ & $101,3 \pm 9,6$ & $1,021 \pm 0,059$ & $2,584 \pm 0,026$ & $209 \pm 18$ & $176,2 \pm 9,6$ & $10,8 \pm 1,0$ & $70,8 \pm 6,8$ & $58,8 \pm 5,3$ & $0,801 \pm 0,051$ & $288 \pm 14$ \\
\hline $1 d$ & $17,2 \pm 1,3$ & $173 \pm 13$ & $1,55 \pm 0,13$ & $11,02 \pm 0,92$ & $674 \pm 63$ & $218 \pm 21$ & $15,99 \pm 0,98$ & $133 \pm 12$ & $86,1 \pm 7,9$ & $1,851 \pm 0,098$ & $217 \pm 17$ \\
\hline $2 d$ & $9,05 \pm 0,46$ & $152,3 \pm 8,9$ & $0,499 \pm 0,048$ & $15,53 \pm 0,67$ & $537 \pm 49$ & $278 \pm 25$ & $12,54 \pm 0,90$ & $109,3 \pm 9,6$ & $95,9 \pm 5,3$ & $1,123 \pm 0,088$ & $765 \pm 43$ \\
\hline $3 d$ & $11,01 \pm 0,86$ & $181 \pm 15$ & $0,442 \pm 0,041$ & $8,35 \pm 0,71$ & $325 \pm 29$ & $217 \pm 20$ & $12,2 \pm 1,2$ & $61,6 \pm 5,0$ & $94,5 \pm 4,7$ & $1,98 \pm 0,10$ & $287 \pm 21$ \\
\hline $4 d$ & $9,77 \pm 0,76$ & $181 \pm 13$ & $0,733 \pm 0,072$ & $6,67 \pm 0,47$ & $603 \pm 50$ & $188 \pm 17$ & $9,59 \pm 0,88$ & $82,3 \pm 7,2$ & $84,5 \pm 5,0$ & $0,836 \pm 0,044$ & $901 \pm 47$ \\
\hline $1 e$ & $9,22 \pm 0,84$ & $296 \pm 25$ & $0,907 \pm 0,082$ & $8,41 \pm 0,77$ & $2671 \pm 189$ & $275 \pm 23$ & $7,38 \pm 0,23$ & $93,9 \pm 8,3$ & $101,9 \pm 7,7$ & $0,468 \pm 0,047$ & $904 \pm 54$ \\
\hline $2 \mathrm{e}$ & $9,87 \pm 0,95$ & $352 \pm 13$ & $1,033 \pm 0,090$ & $19,05 \pm 0,98$ & $2719 \pm 231$ & $354 \pm 19$ & $18,2 \pm 1,0$ & $90,1 \pm 7,8$ & $134 \pm 12$ & $0,976 \pm 0,089$ & $971 \pm 80$ \\
\hline $3 e$ & $43,5 \pm 4,0$ & $412 \pm 37$ & $0,826 \pm 0,077$ & $10,51 \pm 0,90$ & $2223 \pm 221$ & $265 \pm 24$ & $12,45 \pm 0,30$ & $85,0 \pm 6,3$ & $163 \pm 13$ & $1,77 \pm 0,17$ & $338 \pm 29$ \\
\hline $4 \mathrm{e}$ & $67,8 \pm 6,7$ & $366 \pm 33$ & $0,912 \pm 0,086$ & $11,77 \pm 0,46$ & $2899 \pm 240$ & $365 \pm 19$ & $10,94 \pm 0,83$ & $84,7 \pm 6,3$ & $137 \pm 11$ & $2,29 \pm 0,11$ & $883 \pm 77$ \\
\hline RDA/Al & $\begin{array}{c}270 \\
\mathrm{mg} / \mathrm{dia}^{\mathrm{a}}\end{array}$ & $\begin{array}{c}570 \\
\mathrm{mg} / \mathrm{dia}^{\mathrm{a}}\end{array}$ & & $\begin{array}{c}5,5 \\
\mu g / \text { dia }^{a}\end{array}$ & $\begin{array}{c}11 \\
\mathrm{mg} / \mathrm{dia}^{\mathrm{b}}\end{array}$ & $\begin{array}{c}700 \\
\mathrm{mg} / \mathrm{dia}^{\mathrm{a}}\end{array}$ & $\begin{array}{c}75 \\
\mathrm{mg} / \mathrm{dia}^{\mathrm{a}}\end{array}$ & $\begin{array}{c}600 \\
\mu \mathrm{g} / \mathrm{dia}^{\mathrm{a}}\end{array}$ & $\begin{array}{c}370 \\
\mu \mathrm{g} / \mathrm{dia}^{\mathrm{a}}\end{array}$ & $\begin{array}{c}20 \\
\mu \mathrm{g} / \mathrm{dia}^{\mathrm{a}}\end{array}$ & $\begin{array}{c}3 \\
\mathrm{mg} / \mathrm{dia}^{\mathrm{b}}\end{array}$ \\
\hline
\end{tabular}

$\begin{array}{lllll}\text { (a): Etapa } 1 & \text { (b) Etapa } 2 \text { sabor doce } & \text { (c) Etapa } 2 \text { sabor salgado } & \text { (d) Etapa } 3 & \text { (e) Etapa Junior a Al segundo IOM }{ }^{b} \text { RDA segundo IOM }\end{array}$

- Indica valor não determinado 
Tabela 19 - Massas dos elementos essenciais por frasco comercial de amostra (média \pm desvio padrão) e valores de Al ou RDA

\begin{tabular}{|c|c|c|c|c|c|c|c|c|c|c|c|c|}
\hline $\begin{array}{c}\text { Amostra } \\
\text { (Etapa) }\end{array}$ & $\begin{array}{c}\text { Massa do } \\
\text { alimento em } \\
\text { cada pote }\end{array}$ & $\begin{array}{l}\mathrm{Ca} \\
\mathrm{mg}\end{array}$ & $\begin{array}{c}\mathrm{Cl} \\
\mathrm{mg}\end{array}$ & $\begin{array}{l}\text { Co } \\
\mu \mathrm{g}\end{array}$ & $\begin{array}{l}\mathrm{Cr} \\
\mu \mathrm{g}\end{array}$ & $\begin{array}{l}\mathrm{Fe} \\
\mu \mathrm{g}\end{array}$ & $\begin{array}{c}\mathrm{K} \\
\mathrm{mg}\end{array}$ & $\begin{array}{l}\mathrm{Mg} \\
\mathrm{mg}\end{array}$ & $\begin{array}{c}\mathrm{Mn} \\
\mu \mathrm{g}\end{array}$ & $\begin{array}{l}\mathrm{Na} \\
\mathrm{mg}\end{array}$ & $\begin{array}{l}\mathrm{Se} \\
\mu \mathrm{g}\end{array}$ & $\begin{array}{l}\mathrm{Zn} \\
\mu \mathrm{g}\end{array}$ \\
\hline $1 a$ & $120 \mathrm{~g}$ & $15,4 \pm 1,2$ & $5,00 \pm 0,48$ & $0,747 \pm 0,072$ & $6,00 \pm 0,50$ & $329 \pm 31$ & $188 \pm 15$ & $7,32 \pm 0,72$ & $106,8 \pm 9,5$ & $6,26 \pm 0,52$ & $0,638 \pm 0,063$ & $105 \pm 10$ \\
\hline $2 a$ & $120 \mathrm{~g}$ & $5,82 \pm 0,38$ & $7,07 \pm 0,65$ & $0,513 \pm 0,048$ & $6,20 \pm 0,54$ & $206 \pm 18$ & $93,6 \pm 7,4$ & $7,41 \pm 0,67$ & $110,7 \pm 7,4$ & $3,91 \pm 0,30$ & $0,413 \pm 0,041$ & $124 \pm 11$ \\
\hline $3 a$ & $120 \mathrm{~g}$ & $9,28 \pm 0,37$ & $2,66 \pm 0,10$ & $0,463 \pm 0,034$ & $4,64 \pm 0,32$ & $134 \pm 13$ & $99,0 \pm 5,5$ & $3,34 \pm 0,23$ & $50,7 \pm 4,3$ & $3,91 \pm 0,32$ & - & $53,0 \pm 1,8$ \\
\hline $4 a$ & $120 \mathrm{~g}$ & $7,26 \pm 0,67$ & $17,2 \pm 1,6$ & $0,548 \pm 0,046$ & $2,65 \pm 0,20$ & $167,7 \pm 8,4$ & $150 \pm 10$ & $10,6 \pm 1,0$ & $205 \pm 14$ & $3,71 \pm 0,28$ & - & $209,8 \pm 3,7$ \\
\hline $5 a$ & $120 \mathrm{~g}$ & $7,55 \pm 0,70$ & $2,74 \pm 0,22$ & $0,341 \pm 0,029$ & $12,62 \pm 0,69$ & $301 \pm 29$ & $117,7 \pm 8,7$ & $4,55 \pm 0,34$ & $100,0 \pm 4,8$ & $3,51 \pm 0,20$ & - & $70,5 \pm 5,2$ \\
\hline $1 b$ & $120 \mathrm{~g}$ & $145 \pm 13$ & $92,0 \pm 8,9$ & $0,671 \pm 0,061$ & $6,23 \pm 0,10$ & $586 \pm 55$ & $256 \pm 16$ & $18,4 \pm 1,6$ & $290 \pm 22$ & $25,4 \pm 2,2$ & $0,638 \pm 0,056$ & $402 \pm 22$ \\
\hline $2 b$ & $120 \mathrm{~g}$ & $158 \pm 15$ & $73,3 \pm 5,9$ & $0,919 \pm 0,085$ & $17,6 \pm 1,3$ & $605 \pm 59$ & $220 \pm 13$ & $12,7 \pm 1,1$ & $149 \pm 13$ & $30,6 \pm 2,7$ & $0,86 \pm 0,054$ & $421 \pm 40$ \\
\hline $3 b$ & $120 \mathrm{~g}$ & $6,31 \pm 0,62$ & $7,33 \pm 0,65$ & $0,611 \pm 0,059$ & $7,70 \pm 0,19$ & $321 \pm 13$ & $113 \pm 10$ & $5,14 \pm 0,49$ & $52,3 \pm 4,7$ & $3,97 \pm 0,36$ & $1,46 \pm 0,12$ & $61,4 \pm 4,1$ \\
\hline $4 b$ & $120 \mathrm{~g}$ & $8,81 \pm 0,83$ & $23,2 \pm 1,6$ & $0,564 \pm 0,041$ & $6,81 \pm 0,67$ & $208 \pm 18$ & $163 \pm 13$ & $13,6 \pm 1,2$ & $640 \pm 57$ & $2,29 \pm 0,19$ & $1,45 \pm 0,13$ & $96,8 \pm 7,3$ \\
\hline $5 b$ & $120 \mathrm{~g}$ & $9,44 \pm 0,94$ & $15,9 \pm 1,2$ & $0,473 \pm 0,039$ & $9,30 \pm 0,83$ & $243 \pm 22$ & $129,9 \pm 4,0$ & $8,88 \pm 0,80$ & $114,1 \pm 9,6$ & $5,42 \pm 0,46$ & $1,25 \pm 0,084$ & $94,8 \pm 3,1$ \\
\hline $6 b$ & $120 \mathrm{~g}$ & $11,7 \pm 1,1$ & $2,78 \pm 0,23$ & $0,638 \pm 0,057$ & $4,53 \pm 0,44$ & $180 \pm 17$ & $146 \pm 14$ & $7,61 \pm 0,51$ & $126 \pm 11$ & $1,61 \pm 0,14$ & - & $88,7 \pm 5,8$ \\
\hline $7 b$ & $120 \mathrm{~g}$ & $190 \pm 19$ & $57,1 \pm 2,5$ & $0,749 \pm 0,067$ & $3,11 \pm 0,27$ & $464 \pm 42$ & $186 \pm 10$ & $9,20 \pm 0,89$ & $102,4 \pm 8,6$ & $25,7 \pm 2,3$ & - & $401 \pm 37$ \\
\hline $1 c$ & $115 \mathrm{~g}$ & $11,9 \pm 1,1$ & $115,5 \pm 7,5$ & $1,079 \pm 0,071$ & $3,64 \pm 0,31$ & $607 \pm 45$ & $251 \pm 15$ & $14,3 \pm 1,3$ & $79,5 \pm 6,3$ & $60,9 \pm 5,6$ & $1,36 \pm 0,11$ & $1217 \pm 59$ \\
\hline 2c & $115 \mathrm{~g}$ & $9,99 \pm 0,84$ & $139,4 \pm 1,0$ & $1,91 \pm 0,16$ & $6,35 \pm 0,18$ & $557 \pm 54$ & $249 \pm 16$ & $16,6 \pm 1,6$ & $113 \pm 11$ & $72,3 \pm 5,9$ & $2,07 \pm 0,20$ & $1070 \pm 102$ \\
\hline $3 c$ & $115 \mathrm{~g}$ & $11,40 \pm 0,12$ & $138,2 \pm 2,4$ & $1,39 \pm 0,12$ & $2,60 \pm 0,11$ & $489 \pm 39$ & $269 \pm 26$ & $13,5 \pm 1,3$ & $93,1 \pm 8,8$ & $67,1 \pm 6,1$ & $1,957 \pm 0,015$ & $310 \pm 17$ \\
\hline $4 c$ & $115 \mathrm{~g}$ & $9,59 \pm 0,52$ & $147,3 \pm 5,6$ & $0,489 \pm 0,039$ & $4,75 \pm 0,42$ & $464 \pm 43$ & $256,1 \pm 7,1$ & $12,79 \pm 0,79$ & $81,9 \pm 7,4$ & $66,2 \pm 5,8$ & $2,00 \pm 0,19$ & $316 \pm 22$ \\
\hline $5 c$ & $115 \mathrm{~g}$ & $26,3 \pm 2,4$ & $136 \pm 13$ & $1,12 \pm 0,11$ & $4,11 \pm 0,15$ & $461 \pm 40$ & $231 \pm 19$ & $17,1 \pm 1,4$ & $266 \pm 21$ & $63,7 \pm 5,9$ & $2,38 \pm 0,12$ & $737 \pm 40$ \\
\hline $6 c$ & $115 \mathrm{~g}$ & $12,83 \pm 0,79$ & $126 \pm 10$ & $0,858 \pm 0,054$ & $7,057 \pm 0,062$ & $456 \pm 44$ & $222,4 \pm 7,4$ & $11,00 \pm 0,99$ & $67,8 \pm 6,4$ & $66,3 \pm 6,1$ & $2,93 \pm 0,20$ & $892 \pm 83$ \\
\hline $7 c$ & $115 \mathrm{~g}$ & $14,8 \pm 1,4$ & $116 \pm 11$ & $1,175 \pm 0,068$ & $2,972 \pm 0,029$ & $240 \pm 20$ & $203 \pm 11$ & $12,4 \pm 1,2$ & $81,4 \pm 7,8$ & $67,6 \pm 6,1$ & $0,921 \pm 0,059$ & $331 \pm 16$ \\
\hline $1 d$ & $170 \mathrm{~g}$ & $29,2 \pm 2,2$ & $294 \pm 23$ & $2,64 \pm 0,22$ & $18,7 \pm 1,5$ & $1145 \pm 108$ & $371 \pm 36$ & $27,2 \pm 1,7$ & $226 \pm 21$ & $146 \pm 13$ & $3,15 \pm 0,17$ & $369 \pm 30$ \\
\hline $2 d$ & $170 \mathrm{~g}$ & $15,39 \pm 0,78$ & $259 \pm 15$ & $0,849 \pm 0,082$ & $26,4 \pm 1,1$ & $914 \pm 83$ & $473 \pm 42$ & $21,3 \pm 1,5$ & $186 \pm 16$ & $162,9 \pm 8,9$ & $1,91 \pm 0,15$ & $1300 \pm 72$ \\
\hline $3 d$ & $170 \mathrm{~g}$ & $18,7 \pm 1,5$ & $307 \pm 25$ & $0,752 \pm 0,071$ & $14,2 \pm 1,2$ & $553 \pm 49$ & $369 \pm 34$ & $20,8 \pm 2,0$ & $104,7 \pm 8,5$ & $160,7 \pm 8,0$ & $3,36 \pm 0,17$ & $488 \pm 36$ \\
\hline $4 d$ & $170 \mathrm{~g}$ & $16,6 \pm 1,3$ & $308 \pm 23$ & $1,25 \pm 0,12$ & $11,33 \pm 0,79$ & $1024 \pm 85$ & $320 \pm 28$ & $16,3 \pm 1,5$ & $140 \pm 12$ & $143,6 \pm 8,5$ & $1,421 \pm 0,075$ & $1532 \pm 80$ \\
\hline $1 \mathrm{e}$ & $250 \mathrm{~g}$ & $23,0 \pm 2,1$ & $741 \pm 62$ & $2,27 \pm 0,21$ & $21,0 \pm 1,9$ & $6677 \pm 473$ & $688 \pm 59$ & $18,45 \pm 0,57$ & $235 \pm 21$ & $255 \pm 19$ & $1,17 \pm 0,12$ & $2259 \pm 136$ \\
\hline $2 \mathrm{e}$ & $250 \mathrm{~g}$ & $24,7 \pm 2,4$ & $881 \pm 31$ & $2,58 \pm 0,22$ & $47,6 \pm 2,5$ & $6797 \pm 577$ & $886 \pm 48$ & $45,4 \pm 2,6$ & $225 \pm 20$ & $333 \pm 31$ & $2,44 \pm 0,22$ & $2429 \pm 199$ \\
\hline $3 e$ & $250 \mathrm{~g}$ & $109 \pm 10$ & $1030 \pm 92$ & $2,07 \pm 0,19$ & $26,3 \pm 2,3$ & $5556 \pm 552$ & $663 \pm 61$ & $31,12 \pm 0,75$ & $213 \pm 16$ & $408 \pm 33$ & $4,42 \pm 0,44$ & $844 \pm 72$ \\
\hline $4 \mathrm{e}$ & $250 \mathrm{~g}$ & $170 \pm 17$ & $916 \pm 81$ & $2,28 \pm 0,21$ & $29,4 \pm 1,1$ & $7247 \pm 599$ & $912 \pm 49$ & $27,3 \pm 2,1$ & $212 \pm 16$ & $343 \pm 27$ & $5,71 \pm 0,28$ & $2208 \pm 193$ \\
\hline RDA/AI & - & $270 \mathrm{mg} / \mathrm{dia}^{\mathrm{a}}$ & $570 \mathrm{mg} / \mathrm{dia}^{\mathrm{a}}$ & & $5,5 \mu \mathrm{g} / \mathrm{dia}^{\mathrm{a}}$ & $11 \mathrm{mg} / \mathrm{dia}^{\mathrm{b}}$ & $700 \mathrm{mg} / \mathrm{dia}^{\mathrm{a}}$ & $75 \mathrm{mg} / \mathrm{dia}^{\mathrm{a}}$ & $\begin{array}{c}600 \\
\mu g / \text { dia }^{a}\end{array}$ & $\begin{array}{c}370 \\
\mu g / \text { dia }^{a}\end{array}$ & $20 \mu \mathrm{g} / \mathrm{dia}^{\mathrm{a}}$ & $3 \mathrm{mg} / \mathrm{dia}^{\mathrm{b}}$ \\
\hline
\end{tabular}

a): Etapa 1 (b) Etapa 2 sabor doce (c) Etapa 2 sabor salgado $\quad$ (d) Etapa 3 (e) Etapa Junior ${ }^{a}$ Al segundo IOM ${ }^{b}$ RDA segundo IOM 


\section{$\mathrm{Ca}$}

Cálcio é um elemento de extrema importância para os seres vivos. Dentre suas funções no organismo é possível destacar a mineralização óssea, principalmente a saúde óssea, desempenhando funções que compreendem a formação, manutenção da estrutura e rigidez do esqueleto (Bueno e Czepielewski, 2008).

Cálcio é responsável por regular diversos processos orgânicos, como a contração muscular, mitose, transmissão do impulso nervoso e coagulação sanguínea. Acredita-se que este elemento esteja relacionado à prevenção de diversas doenças como obesidade, diabetes, hipertensão arterial e câncer de cólon (Pereira et al., 2009).

A deficiência deste elemento pode levar a enfraquecimento dos ossos, dado que o organismo retira o cálcio dos ossos, enfraquecendo-os, podendo levar a fraturas (Bueno e Czepielewski, 2007).

As recomendações nutricionais de ingestão de cálcio variam durante a vida do indivíduo, mas a infância é uma das fases com maior necessidade deste mineral. $O$ excesso deste elemento pode resultar na formação de cálculos renais. As principais fontes de cálcio são o leite e seus derivados. Estes alimentos não devem ser consumidos em refeições ricas em ferro, pois há uma competição entre os dois elementos (Bueno e Czepielewski, 2008; Guerra et al., 2012).

Fontes de Ca: prioritariamente leite e soja (Guerra et al., 2012). 


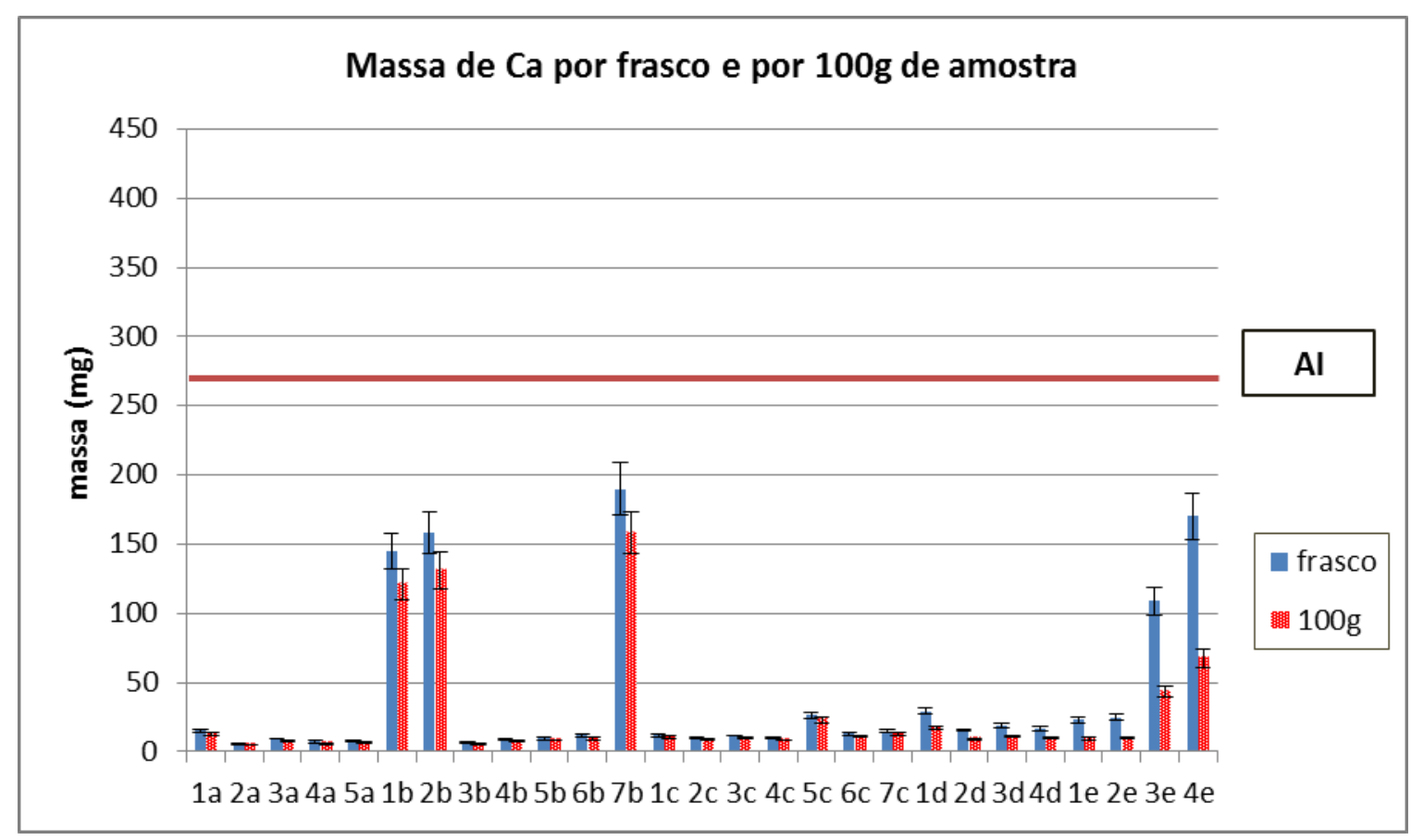

Gráfico 1 - Massa de Ca presente no conteúdo do frasco comercial e em $100 \mathrm{~g}$ de amostra

As amostras 1b, 2b, 7b (todas pertencentes à etapa 2), e 3e e 4e (da Etapa Jr) se destacaram pela grande quantidade de cálcio presente em suas composições, em comparação com as outras amostras, conforme observado no Gráfico 1. Uma importante fonte de cálcio que é comum a essas 5 amostras com alto teor deste elemento é o leite (Guerra, et al., 2012). Embora nas amostras 3e e 4e o leite não apareça como ingrediente principal, sua presença está indicada no rótulo na categoria dos ingredientes de ambas as amostras.

Embora 5 das amostras analisadas contenham uma concentração maior de $\mathrm{Ca}$, a maioria está bastante abaixo do valor de Al. Para atingir o valor de Al é necessário o oferecimento de leite, de preferência materno, à criança. Este gráfico ilustra a importância de manter a amamentação, mesmo após a introdução dos alimentos complementares, pois se a criança for alimentada exclusivamente com esses alimentos complementares, não será possível atingir o valor de Al ao se optar por amostras das Etapas 1 e 3. 
Cl

Tanto cloro quanto sódio são elementos fundamentais no equilíbrio hídrico, além de serem responsáveis por processos fisiológicos relacionados com os músculos e com o metabolismo do organismo. A utilização de sal de cozinha $(\mathrm{NaCl})$ no preparo dos alimentos para crianças no primeiro ano de vida não é recomendada, pois a imaturidade renal da criança nem sempre permite a eliminação de excessos, podendo levar a uma hipertensão arterial precoce (Guerra et al., 2012; Silva e Aguiar, 2011).

Fontes de $\mathrm{Na}$ e $\mathrm{Cl}$ : sal de cozinha, frutos do mar, leite, carne, temperos e boa parte de alimentos processados (Guerra et al., 2012; Silva e Aguiar, 2011).

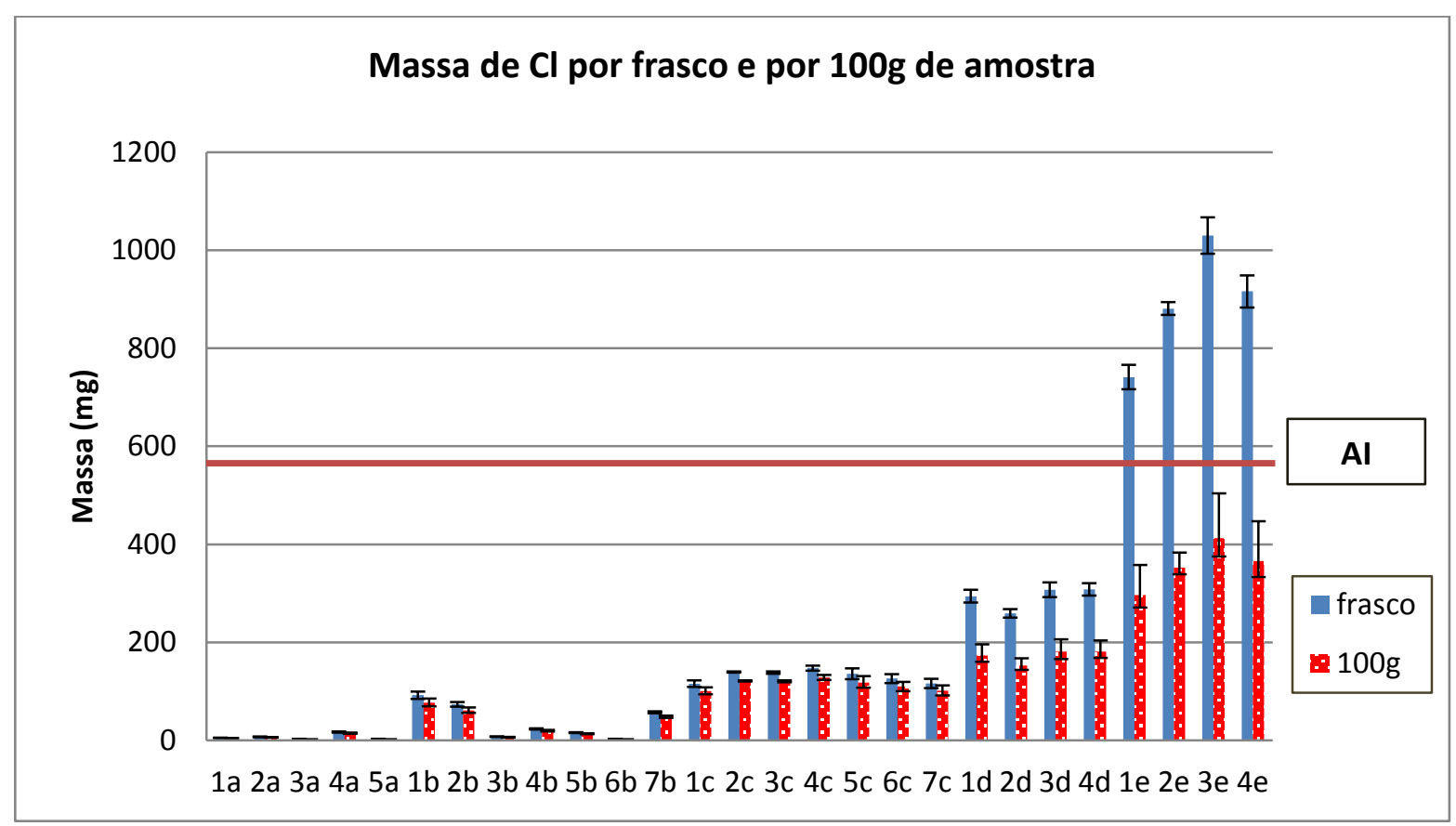

Gráfico 2 - Massa de $\mathrm{Cl}$ presente no conteúdo do frasco comercial e em 100 g de amostra

As amostras salgadas contêm quantidade de cloro mais expressiva em comparação com as amostras doces, indicando o sal, provavelmente cloreto de sódio, como possível fonte deste elemento. Dentre as amostras doces, se destacaram as amostras $1 \mathrm{~b}$ e $2 \mathrm{~b}$, todas pertencentes à etapa 2. Essas amostras contêm como ingrediente comum o leite, que pode ter sido a fonte de cloro. A 
quantidade de cloro também aumenta com o avanço da etapa, isto pode estar relacionado ao aumento do peso líquido da quantidade de amostra com relação à etapa. As etapas indicadas às crianças mais velhas apresentam um peso líquido maior do que as etapas direcionadas às crianças mais novas. Em comum, as amostras salgadas contêm carne em sua composição, que é uma fonte de cloro (Guerra et al., 2012; Silva e Aguiar, 2011).

Todas as amostras da etapa Jr ultrapassaram o valor de Al, porém o valor encontrado nessas amostras está bastante abaixo do Limite Máximo de Ingestão Tolerável (UL), que é de 2,3 g/dia para crianças nessa faixa etária $(\mathrm{NIH}, 2001$; Vieira et al., 2008).

Com relação às etapas indicadas às crianças mais novas, a mãe conseguirá atingir os valores de $\mathrm{Al}$, desde que não opte por oferecer os alimentos comerciais infantis pertencentes à Etapa 1, pois a concentração de cloro nesses alimentos é muito pequena.

\section{Co}

A deficiência de Co provoca carência da vitamina B12 e hipotireoidismo e pode também causar anemia perniciosa. Já o excesso pode levar à intoxicação com sintomas como náusea, vômito e arritmia (Guerra et al., 2012). Este mineral se encontra integrado à vitamina B12, portanto, sua ingestão está ligada à ingestão desta vitamina (Donati, 2006).

Fontes de vitamina B12: peixes, ovos, fígado, leite, frutas, verduras e legumes (Donati, 2006). 


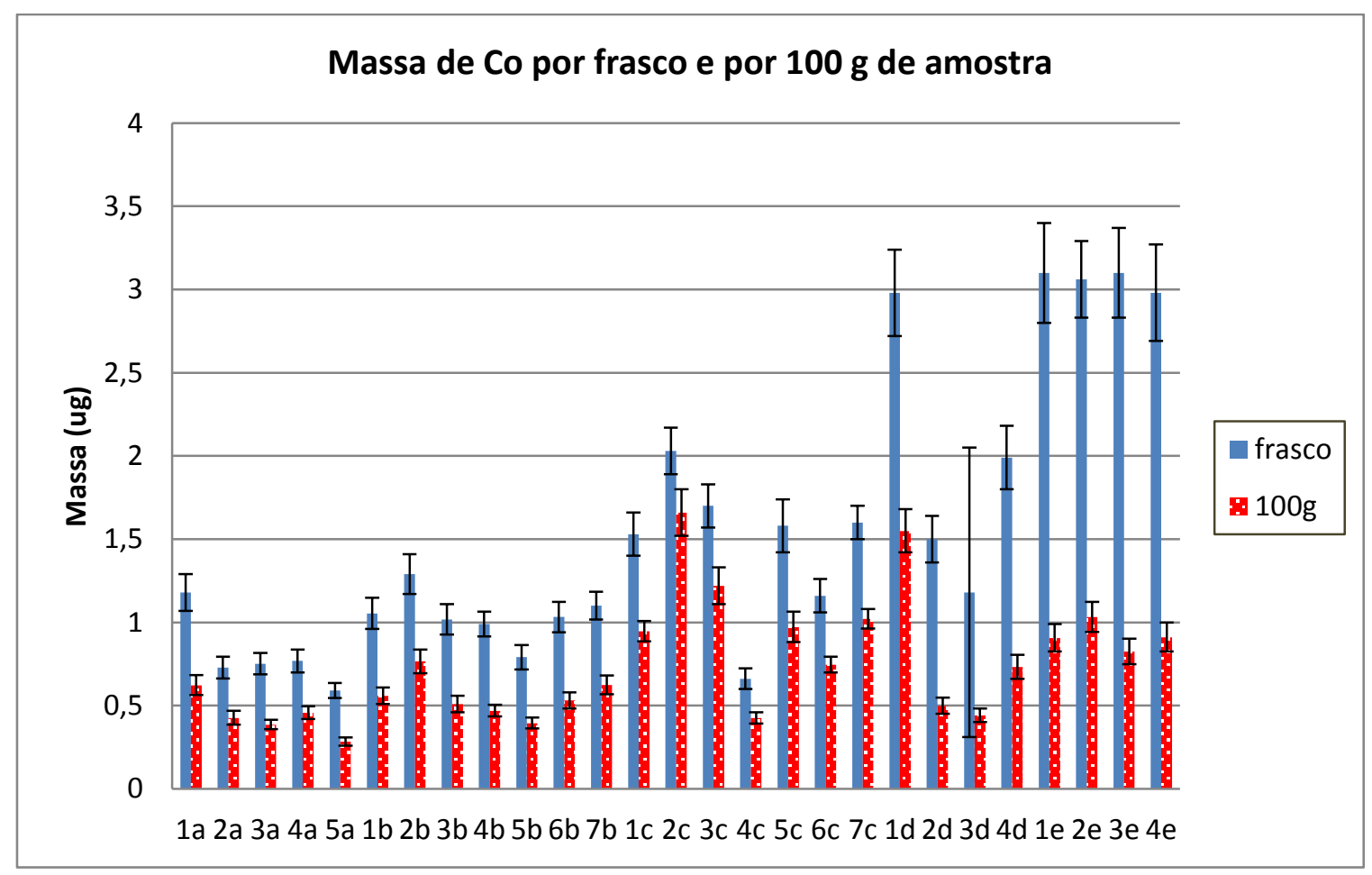

\section{Gráfico 3 - Massa de Co presente no conteúdo do frasco comercial e em $100 \mathrm{~g}$ de amostra}

A quantidade de cobalto entre as amostras é bastante irregular, sem apresentar uma amostra com valor muito discrepante em relação às outras. Estes resultados podem estar relacionados às diversas fontes deste mineral, como ovos, leite, frutas, verduras e legumes (Donati, 2006). Todas as amostras analisadas contêm pelo menos uma das possíveis fontes deste mineral, o que torna a quantidade de cobalto bastante distribuída entre elas.

Não foi encontrado nenhum valor de AI/RDA para este elemento, por isso não foi possível fazer uma comparação entre valor recomendado e quantidade encontrada nas amostras de alimentos comerciais infantis.

$\mathrm{Cr}$

Cromo é um elemento essencial que não é produzido pelo organismo e que deve ser obtido através da dieta. A principal função do cromo no corpo humano é potencializar a interação da insulina com o seu receptor na superfície da célula. É 
um dos constituintes do fator de tolerância à glicose e juntamente com a insulina, promove o metabolismo de gordura, carboidratos e lipídeos (Dutta e Mukta, 2012).

Estudos clínicos mostraram que este elemento diminui a intolerância do corpo humano à glicose, além de possuir efeitos benéficos sobre doenças cardiovasculares. Cromo desempenha um papel vital na vida de pessoas diabéticas. A suplementação de cromo não acarreta em nenhum benefício para pessoas com diabetes do tipo 1 , uma vez que o problema é a insuficiência de insulina. Porém, há casos em que o diabetes tipo 1 está relacionado com a diabetes tipo 2, nesta situação a suplementação de cromo ajuda o paciente (Deeba et al., 2010)

A deficiência de cromo costuma ser observada em pacientes em nutrição parenteral total. Dentre os problemas observados em pessoas com deficiência de cromo é possível citar: hiperglicemia, tolerância prejudicada à glicose, neuropatia, encefalopatia, elevada concentração de ácidos graxos livres no plasma e anormalidades no metabolismo do nitrogênio (Dutta e Mukta, 2012).

Fontes de Cr: levedo de cerveja, carne, ovos, trigo, brócolis, frango, suco de uva, batata, maçã, banana, espinafre, óleos vegetais, açúcar não refinado (Dutta e Mukta, 2012; Pereira e Muniz, 2012). 


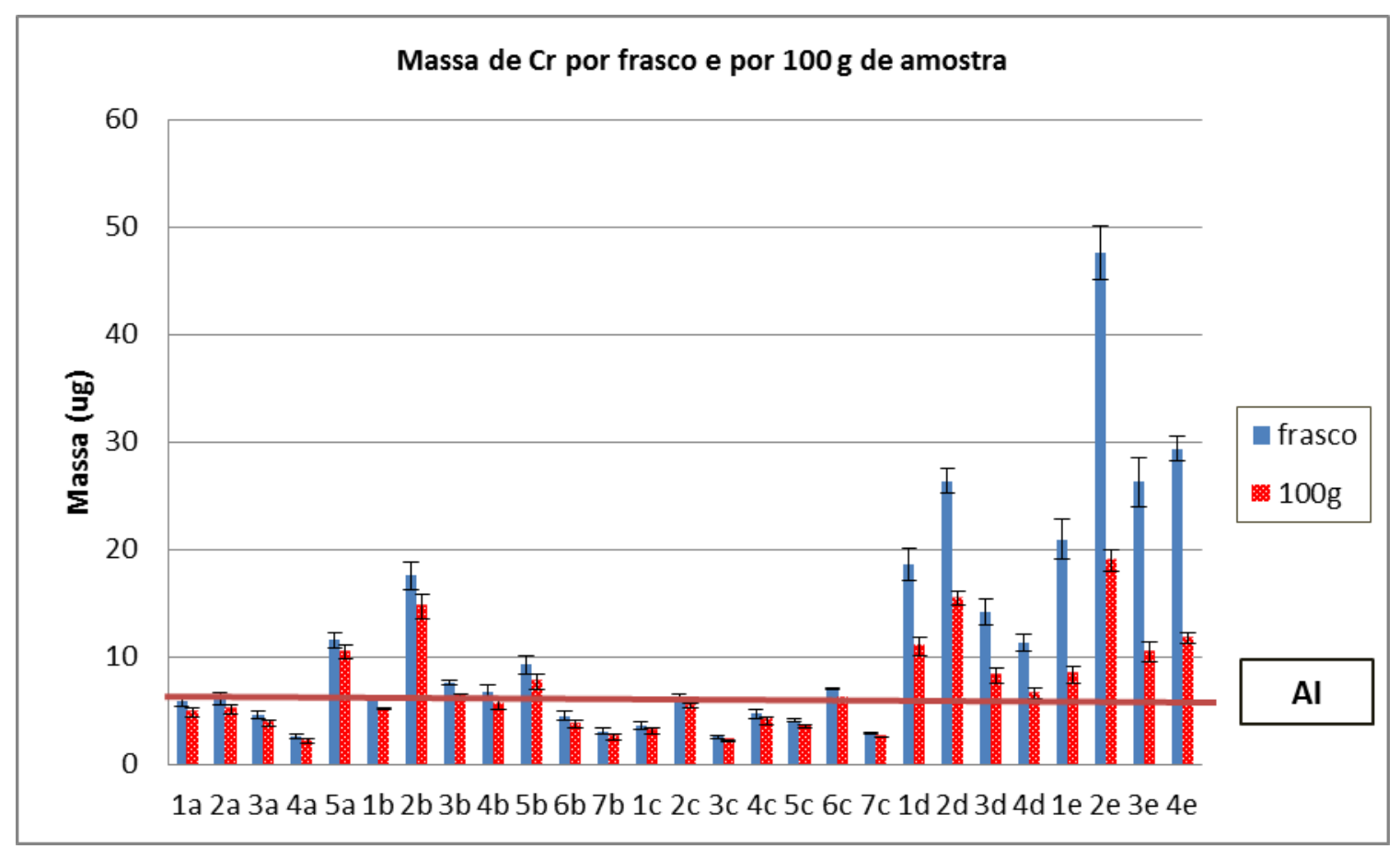

Gráfico 4 - Massa de Cr presente no conteúdo do frasco comercial e em $100 \mathrm{~g}$ de amostra

A concentração de cromo nas amostras analisadas é bastante irregular. Dentre as amostras doces é possível identificar quantidades expressivas deste mineral nas amostras $5 a, 2 b, 5 b$. As possíveis fontes deste mineral são uva na primeira amostra, leite na segunda amostra e maçã na terceira amostra. Nas amostras salgadas das etapas 3 e Jr, há uma quantidade maior deste elemento em quase todas as amostras. A amostra com uma concentração mais discrepante de cromo é a $2 e$, que contém carne, leite e batata em sua composição, que são importantes fontes deste elemento (Pereira e Muniz, 2012). Os valores encontrados de cromo na maioria das amostras ultrapassam o valor de $\mathrm{Al}$, porém não foram encontradas informações sobre o UL.

A absorção deste elemento oferecido por via oral é pobre, por isso o risco de toxicidade é baixo. Não há descrições dos efeitos colaterais no caso de ingestão excessiva deste elemento (Casey e Walravens, 1988). 


\section{$\mathrm{Fe}$}

Ferro desempenha papel fundamental no crescimento e desenvolvimento da criança. A deficiência deste elemento pode levar ao desenvolvimento da anemia ferropriva. A anemia ferropriva é a carência nutricional de maior prevalência no mundo. Estima-se que entre 30\% e 50\% dos lactentes brasileiros sofram deste tipo de anemia (Wayhs et al., 2012).

A prevalência da anemia entre crianças com menos de 4 anos de idade se situa entre $46 \%$ e $66 \%$ nos países em desenvolvimento. O período crítico se concentra entre 6 meses e 2 anos. Crianças pobres e/ou imigrantes em países subdesenvolvidos são as mais afetadas com a deficiência de ferro (Lozoff, 2007).

Muitos processos que se desenvolvem no sistema nervoso central são altamente dependentes de enzimas e proteínas que contêm ferro. Assim, a deficiência de ferro pode acarretar em diversas consequências, particularmente durante o crescimento cerebral (Lozoff, 2007).

Segundo Black et al. (2011), a deficiência de ferro (DF) tem sido associada a atrasos no desenvolvimento sócio-emocional, cognitivo, motor e no funcionamento neurofisiológico. A DF ocorre frequentemente no contexto de outras deficiências nutricionais, tornando difícil isolar os efeitos dessa deficiência. A deficiência crônica de ferro pode alterar o metabolismo da dopamina, a mielinização, além de implicar em mudanças genômicas em longo prazo.

A deficiência de ferro pode causar anemia, podendo trazer consequências negativas no desenvolvimento psicomotor e cognitivo, diminuição na capacidade de aprendizagem e comprometimento da imunidade celular com menor resistência às infecções (Bortolini e Vitolo, 2010).

Fontes de Fe: carne vermelha, peixe e frango (Giugliani e Victora, 2000; Wayhs, 2012). 


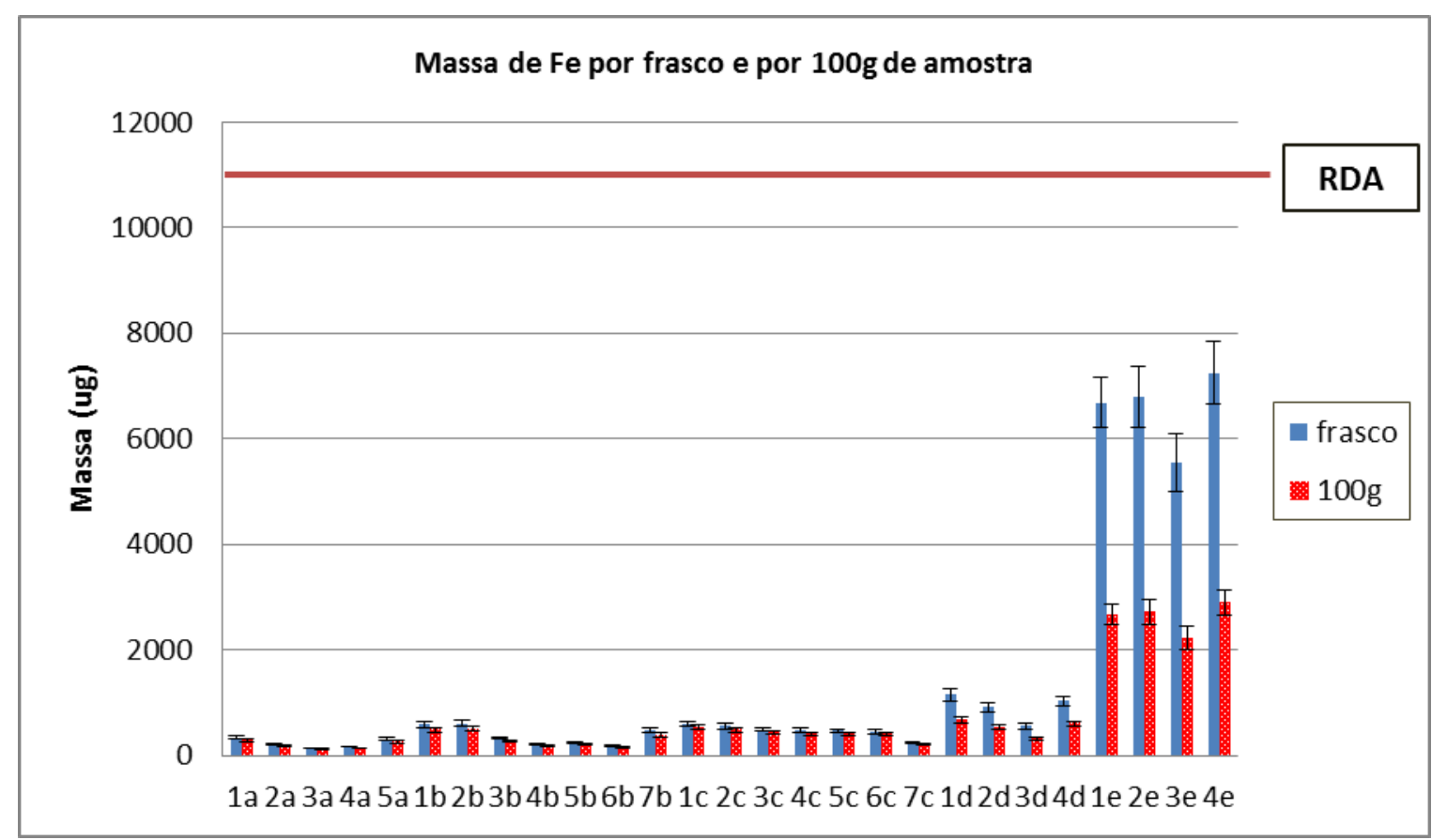

Gráfico 5 - Massa de Fe presente no conteúdo do frasco comercial e em $100 \mathrm{~g}$ de amostra

A quantidade de ferro presente nas amostras da etapa Jr é muito superior a quantidade deste elemento presente nas amostras pertencentes às outras etapas. Esta discrepância pode ser explicada pela diferença do peso líquido dos alimentos da Etapa Jr em relação aos alimentos das outras etapas. Esta grande diferença, também pode ser atribuída à quantidade de carne presente nas amostras da Etapa Jr. Sabe-se que a carne vermelha é uma fonte de ferro melhor do que o frango (Giugliani e Victora, 2000) e isso pode ser observado neste gráfico, pois a única amostra da Etapa Jr que contém frango em sua composição, 3e, foi a que apresentou a menor quantidade de ferro.

Seguindo as orientações do Ministério da Saúde, não é possível atingir o valor de RDA em nenhuma das amostras até a Etapa 3, cuja concentração de ferro está muito aquém do valor de ingestão diária recomendado.

K

Potássio é ativador de algumas reações enzimáticas. Dentre essas reações, é possível citar a síntese de ATP (trifosfato de adenosina). Outra função 
importante desempenhada por este elemento está na bomba de sódio e potássio, onde o potássio é o principal cátion intracelular e o sódio, o cátion extracelular. 0 potássio, devido ao seu papel facilitador da excreção renal do sódio, é um elemento importante na regulação da pressão arterial (Santos e Abreu-Lima, 2009).

O rim humano possui capacidade altamente eficiente para excretar potássio. Assim, a função renal normal impede a sobrecarga de potássio no corpo (Morris et al., 2006). Um problema comum é a baixa ingestão de potássio que implica em uma deficiência deste mineral. Uma das consequências da deficiência de potássio é a mudança na função da membrana, particularmente significativa em sistemas de condução neuromuscular e cardíaco. Outros efeitos incluem arritmias cardíacas, fraqueza muscular e intolerância à glicose (Nielsen, 2012).

Fontes de K: banana, abacate, batata, leite, frutas cítricas e secas, vegetais verdes, leguminosas e produtos de grão integral (Jardim et al., 2004; Guerra et al., 2012).

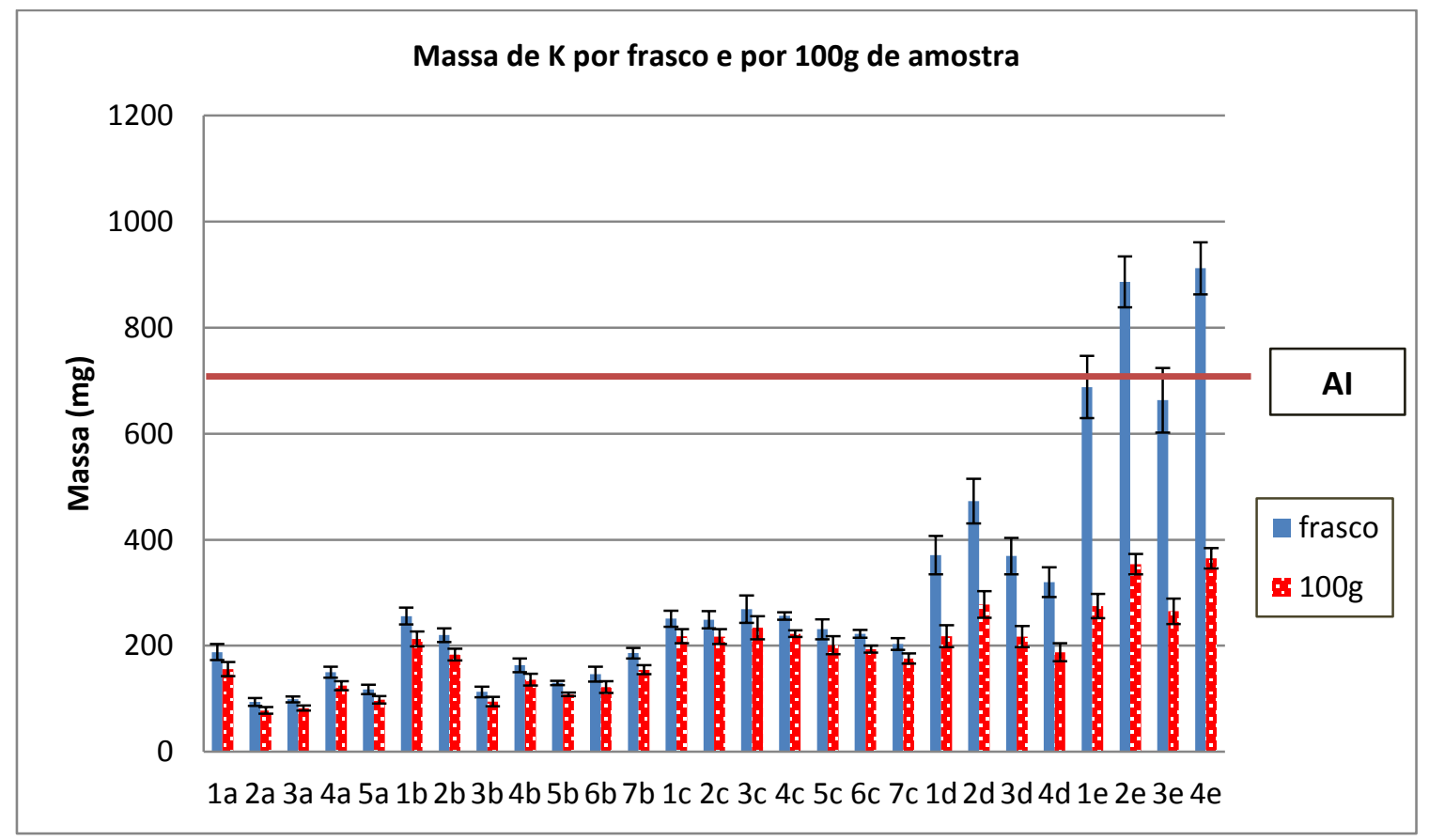

Gráfico 6 - Massa de K presente no conteúdo do frasco comercial e por $100 \mathrm{~g}$ de amostra 
As amostras da etapa Jr apresentam valores mais altos em comparação às outras chegando a ultrapassar o valor de Al. Este fato pode estar relacionado às diferentes fontes de potássio conhecidas. Em cada amostra há, pelo menos, uma fonte deste elemento, como batata, leite, vegetais verdes, leguminosas e produtos de grão integral (Jardim et al., 2004; Guerra et al., 2012). Outra possibilidade para a alta concentração de potássio é a utilização do sal light. No sal light, parte do cloreto de sódio é substituída por cloreto de potássio. O sal light possui uma concentração de cloreto de sódio menor em relação ao sal de cozinha comum.

Ao oferecer, como alimentação complementar, apenas alimentos comerciais infantis, seguindo as recomendações do Ministério da Saúde, é possível alcançar o valor de Al, e, em alguns casos, ultrapassar este valor. Quando ocorre ingestão em excesso de potássio, os rins são capazes de excretar este excesso na urina. Portanto, não há necessidade de preocupação caso ocorra ingestão de potássio superior ao valor de Al (Riella e Pachaly, 1996). Não foram encontrados valores de UL para este elemento.

\section{Mg}

Magnésio é responsável pela ativação de mais de 300 enzimas no corpo. Ele auxilia na manutenção muscular e funções nervosas do corpo humano. Estudos mostram que o magnésio é um componente importante na construção de um osso forte e saudável, além de auxiliar no sistema nervoso e na manutenção do ritmo cardíaco. O magnésio ajuda a regular os níveis de açúcar no sangue e ajuda a manutenção da pressão arterial normal. Este elemento previne e controla a hipertensão, doenças cardiovasculares, diabetes e dores articulares (Faryadi, 2012).

A deficiência de magnésio está associada a várias condições patológicas. Pesquisas mostram que pessoas com baixo nível de magnésio precisam de mais oxigênio e energia, e se cansam mais rapidamente (Faryadi, 2012).

Fonte de magnésio: feijão, verduras, carnes, peixes e ovos (Guerra et al., 2012). 


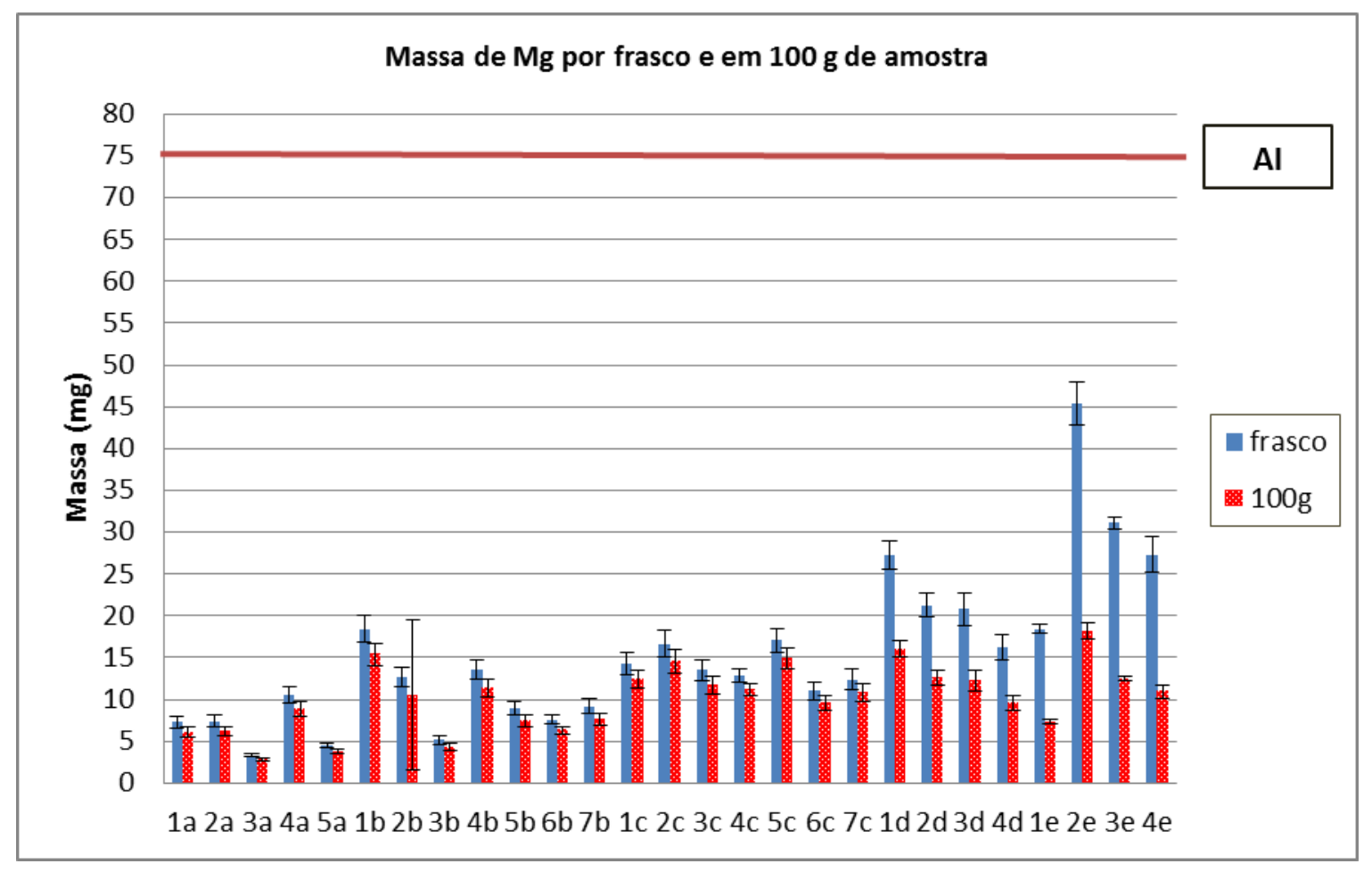

Gráfico 7 - Massa de Mg presente no conteúdo do frasco comercial e em $100 \mathrm{~g}$ de amostra

A grande variabilidade de magnésio encontrada em quase todas as amostras pode ser atribuída à utilização de fertilizantes nas fazendas produtoras dos vegetais utilizados e nas indústrias agrícolas. A amostra $2 \mathrm{e}$ da etapa Jr se destacou por apresentar quantidade maior deste nutriente em comparação com as outras, como pode ser observado no Gráfico 7 , considerando a quantidade por frasco. Porém, em termos de massa em $100 \mathrm{~g}$, apresenta quantidade de $\mathrm{Mg}$ próxima às amostras $1 \mathrm{~b}$ (etapa 2 ) e $1 \mathrm{~d}$ (etapa 3 ). Dentre as principais fontes de Mg, esta amostra possui em sua composição: carne, couve, repolho e farinha de arroz (Guerra et al., 2012).

Embora nenhuma das amostras tenha alcançado o valor de $\mathrm{Al}$, ao seguir as recomendações do Ministério da Saúde, Tabela 3, é possível alcançar este valor para todas as Etapas. Ao oferecer algumas amostras, este valor de Al pode ser ultrapassado, mas não há informações sobre o valor de UL para magnésio proveniente de alimentos, há apenas este valor para o magnésio proveniente de fármacos (NIH, 2001; Vieira et al., 2008). 


\section{Mn}

Manganês é considerado elemento essencial para seres humanos porque ativa diversas enzimas e é um constituinte de diversas metaloenzimas. O manganês está localizado, principalmente, nas mitocôndrias. Ele é absorvido no intestino delgado, em seguida, ligado à albumina em circulação, é transportado para o fígado e excretado na bile (Nielsen, 2012; Dutta e Mukta, 2012).

A deficiência de manganês causa diminuição de tolerância à glicose, dermatite, mudanças na cor do cabelo, anormalidades esqueléticas, infertilidade, surdez e síntese prejudicada da vitamina K (Dutta e Mukta, 2012).

Fontes de Mn: grãos não refinados, nozes, abacaxi e vegetais de folhas verdes (Cozzolino, 2005; Nielsen, 2012).

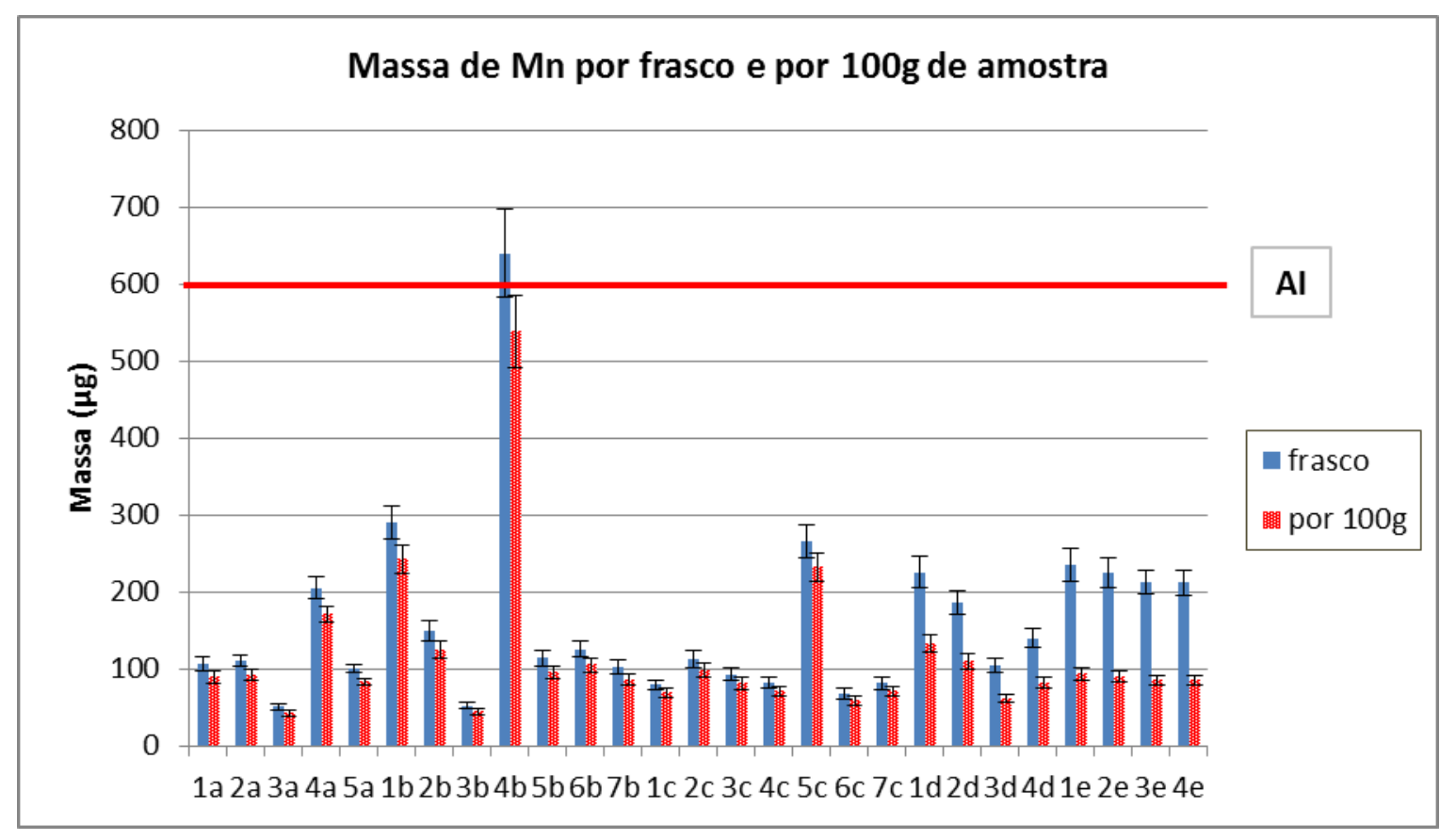

Gráfico 8 - Massa de Mn presente no conteúdo do frasco comercial e em $100 \mathrm{~g}$ de amostra

Quase nenhuma das amostras atingiu o valor da recomendação diária para o manganês, porém, a amostra $4 \mathrm{~b}$ apresentou alta quantidade deste nutriente. Esta discrepância encontrada pode ser atribuída ao abacaxi presente como um 
dos ingredientes desta amostra. Há muitas fontes de manganês, por isso há uma grande variação da quantidade deste elemento nas diferentes amostras analisadas. As amostras que apresentam quantidade maior deste elemento contêm pelo menos uma das diversas fontes de manganês conhecidas (Cozzolino, 2005; Nielsen, 2012).

Crianças até 8 meses que recebam apenas alimentos comerciais como forma de alimentação complementar, possivelmente receberão a quantidade de manganês recomendada, principalmente se em uma das refeições for oferecida a amostra 4b. As amostras da Etapa 3, que corresponde à crianças a partir de 8 meses, apresentam quantidade menor deste elemento, o que dificulta atingir o valor de $\mathrm{Al}$, sendo necessário a complementação com outro tipo de alimento.

\section{$\mathrm{Na}$}

Semelhante ao cloro, sódio é fundamental no equilíbrio hídrico, além de ser responsável por processos fisiológicos relacionados com os músculos e com o metabolismo do organismo (Guerra et al., 2012; Silva e Aguiar, 2011).

Fontes de $\mathrm{Na}$ e $\mathrm{Cl}$ : sal de cozinha, frutos do mar, leite, carne, temperos e boa parte de alimentos processados (Guerra et al., 2012; Silva e Aguiar, 2011). 


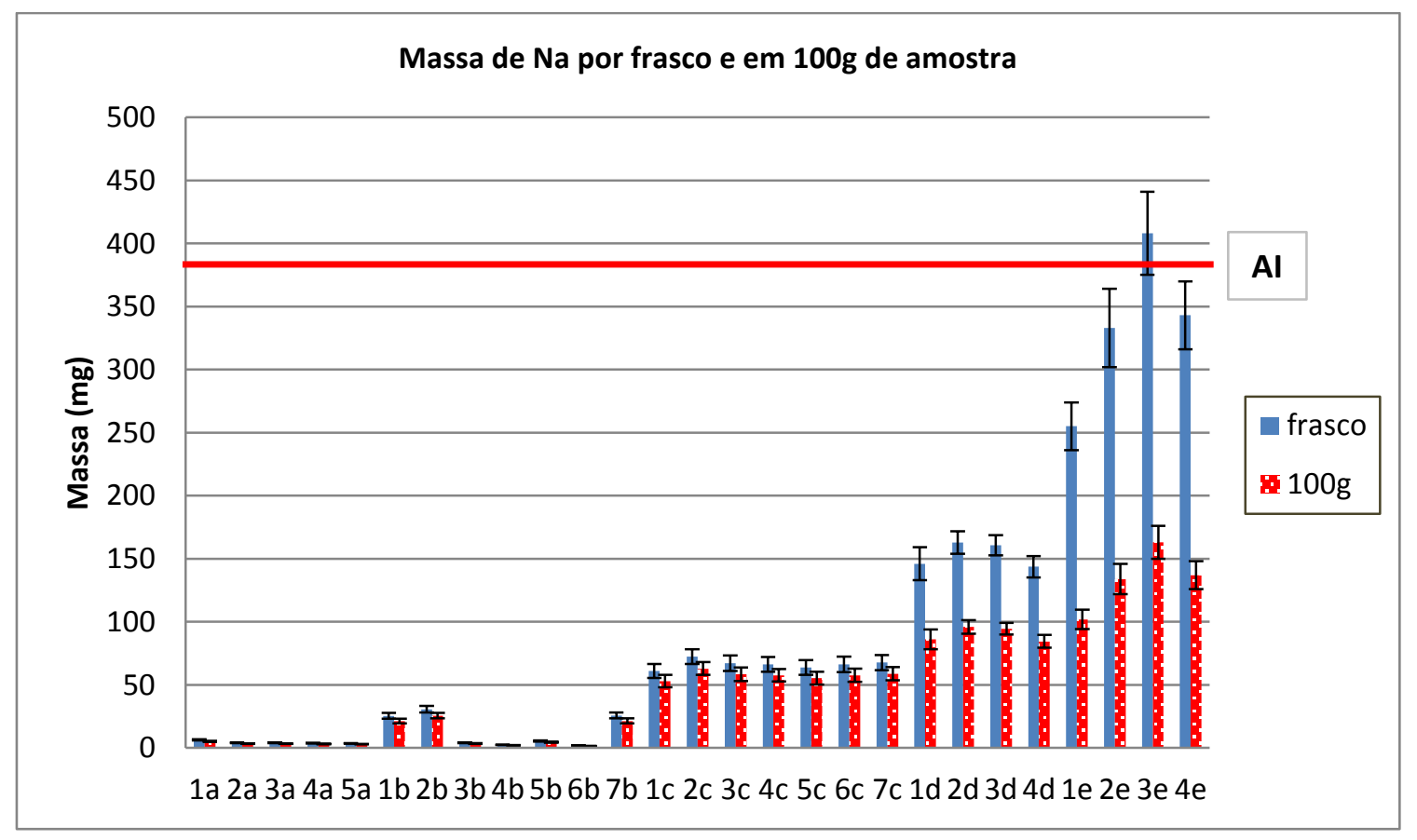

Gráfico 9 - Massa de Na presente no conteúdo do frasco comercial e em $100 \mathrm{~g}$ de amostra

Semelhante ao que ocorreu com o cloro, as amostras salgadas têm quantidade de sódio mais expressiva em comparação com as amostras doces, indicando o sal, provavelmente cloreto de sódio, como possível fonte deste elemento. Dentre as amostras doces, se destacaram as amostras $1 \mathrm{~b}, 2 \mathrm{~b}$ e $7 \mathrm{~b}$, todas pertencentes à etapa 2. Essas amostras têm como ingrediente comum o leite, que pode ter sido a fonte de sódio. A quantidade deste elemento, assim como observado com o cloro, também aumenta com o avanço da etapa. As etapas direcionadas às crianças mais velhas apresentam um peso líquido maior do que as etapas direcionadas às crianças mais novas. Em comum, as amostras salgadas contêm carne em sua composição, que é uma importante fonte de sódio (Guerra et al., 2012; Silva e Aguiar, 2011).

A quantidade de sódio encontrada nas amostras doces das Etapas 1 e 2 é muito pequena. Uma criança de até 8 meses, que seja alimentada exclusivamente com alimentos comerciais, não receberá a quantidade recomendada deste elemento, por isso é recomendado utilizar esses alimentos em adição a outros tipos de alimentação. A amostra 3e, pertencente à Etapa Jr ultrapassa o valor de 
Al com apenas a massa de um pote, porém ainda está distante do valor de UL, que é de $1,5 \mathrm{~g} / \mathrm{dia}(\mathrm{NIH}, 2001$; Vieira et al., 2008).

\section{Se}

De todos os elementos, selênio tem um dos mais estreitos intervalos entre a deficiência na dieta e o nível tóxico, o que torna necessário um controle cuidadoso de sua ingestão (Fordyce, 2005). A necessidade de ingestão deste elemento é muito próxima do limite superior tolerável, por isso, dependendo da quantidade de selênio ingerida, podem ser observados sintomas de deficiência bem como de toxicidade (Cominetti et al., 2011).

A identificação de patologias relacionadas com a deficiência de selênio, demostraram que ele é um nutriente essencial. Evidências demonstraram a importância do selênio na prevenção de câncer, doenças cardiovasculares e infecções virais, bem como possui papel fundamental em funções da tireoide, sistema imunológico, fertilidade e envelhecimento (Rederstorff et al., 2006).

Duas doenças estão associadas à deficiência grave de selênio: doença de Keshan, uma cardiomiopatia e doença de Kashin-Beck, uma osteoartrite endêmica (Cominetti et al., 2011).

O excesso de selênio pode levar à intoxicação, que pode ser observada por levar a graves distúrbios gastrointestinais, distúrbios neurológicos, infarto do miocárdio e falência renal (Cozzolino, 2005).

Fontes de Se: castanha, rim bovino, salmão, bacalhau, lentilha, ovos (Guerra et al., 2012). 


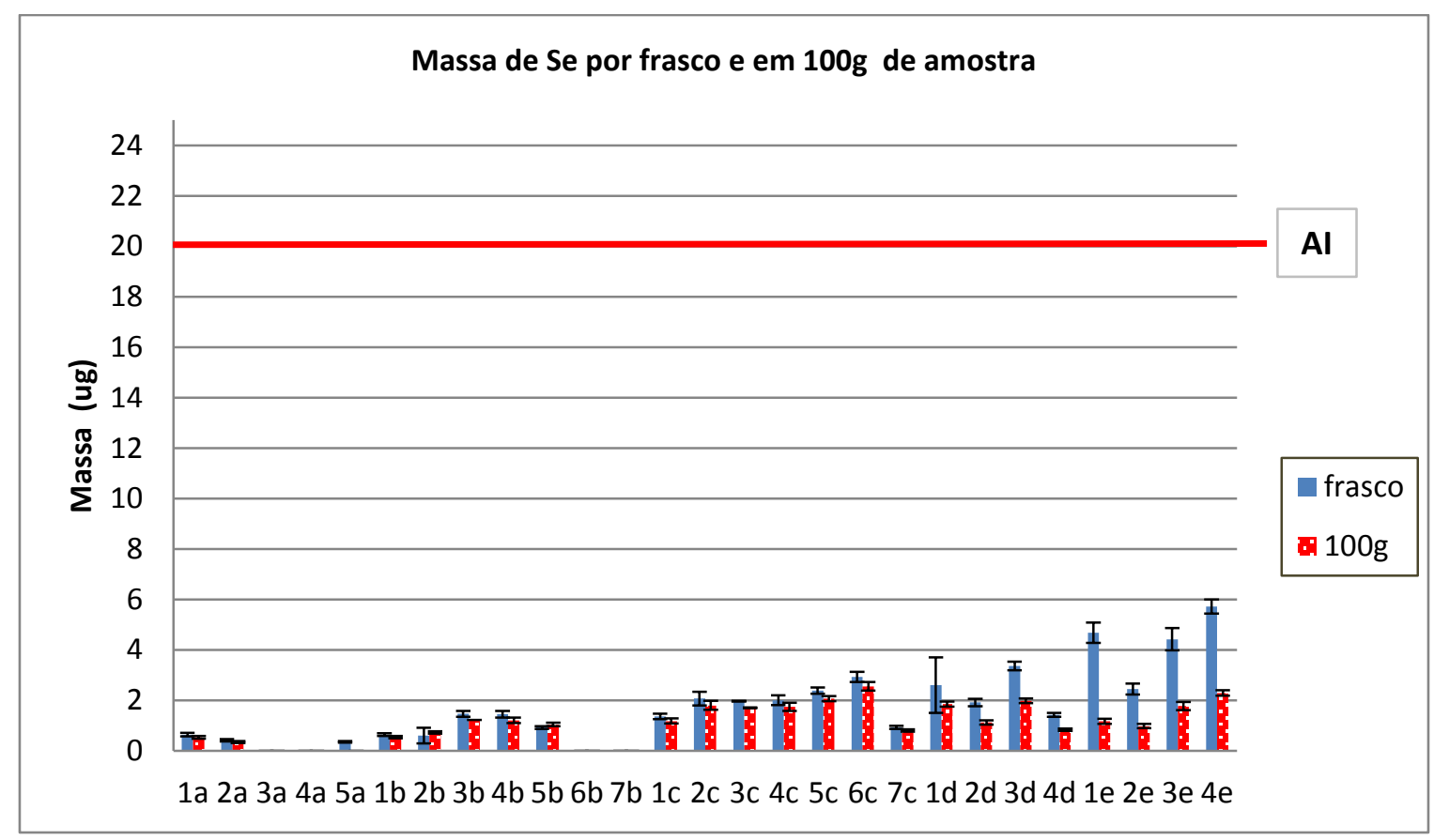

Gráfico 10 - Massa de Se presente no conteúdo do frasco comercial e em $100 \mathrm{~g}$ de amostra

A distribuição da quantidade de selênio presente é bastante variável entre as amostras analisadas. Em algumas amostras, as concentrações de Se estavam abaixo do limite de detecção. É possível verificar que as amostras salgadas contem quantidade maior deste elemento do que as amostras doces, isto pode estar relacionado à carne presente nessas amostras, que pode ser considerada uma fonte deste elemento. Embora as amostras salgadas tenham maior concentração de selênio, ainda estão distantes do valor de ingestão diária recomendada (Cozzolino, 2005).

A maior parte das amostras pertencentes à Etapa Jr, atingiria o valor de $\mathrm{Al}$, se as recomendações para alimentação de crianças nessa faixa etária fosse seguida (Tabela 3). Em relação às outras etapas, há grande variabilidade, por isso a escolha do sabor que será oferecido à criança é bastante importante para evitar os sabores com baixa concentração deste elemento. $O$ valor de UL para este elemento, $90 \mu \mathrm{g} / \mathrm{dia}$, está bastante distante de todas as amostras analisadas, portanto não há necessidade de preocupação com relação à toxicidade deste 
elemento em relação aos alimentos comerciais infantis $(\mathrm{NIH}, 2001$; Vieira et al., 2008).

\section{$\mathrm{Zn}$}

Zinco é o segundo elemento-traço mais abundante no corpo humano. É componente de mais de 100 enzimas. Desempenha também papel fundamental em todas as fases do metabolismo da insulina. Uma pequena deficiência deste elemento pode causar o atraso do crescimento da criança. Uma deficiência grave pode levar ao nanismo e cardiomiopatia em crianças, além de hipogonadismo, dificuldade de cicatrização, deformidade óssea, diarreia, estrias na pele e alteração das unhas (Dutta e Mukta, 2012).

É essencial para o desenvolvimento neurológico e funções do sistema nervoso central. Crianças de países em desenvolvimento podem ter uma deficiência de zinco, devido à ingestão inadequada deste elemento e às altas taxas de necessidade diária de zinco (Black et al., 2011).

Zinco compete com cobre pela absorção intestinal. Altas concentrações de zinco levam à redução da absorção do cobre, gastrite, sudorese febre, náuseas e vômitos (Dutta e Mukta, 2012).

Fontes de Zn: carne, frutos do mar, ovos, soja, leite, queijo e amendoim (Dutta e Mukta, 2012). 


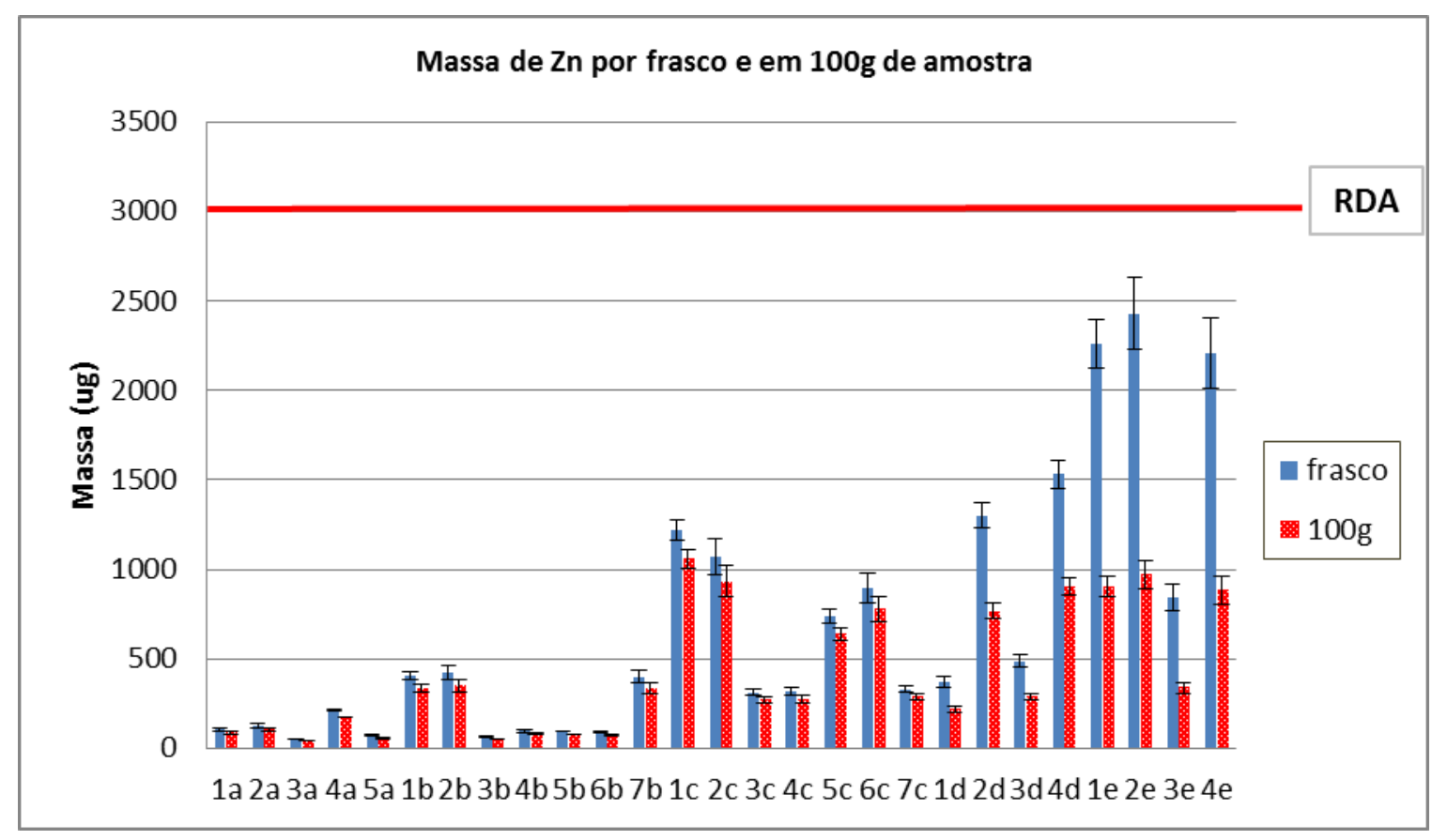

Gráfico 11 - Massa de Zn presente no conteúdo do frasco comercial e em $100 \mathrm{~g}$ de amostra

Há grande variação na quantidade de zinco presente nas amostras analisadas. É possível verificar uma quantidade maior deste nutriente nas amostras salgadas, principalmente nas amostras da Etapa Jr. A amostra 3e apresenta a menor quantidade deste elemento com relação às amostras da mesma etapa, isto pode ser explicado porque esta amostra contém frango em sua composição, enquanto as outras desta etapa contêm carne bovina. As amostras doces apresentam uma quantidade pequena de zinco, mas é possível observar que dentre elas, as amostras $1 b, 2 b$ e $7 b$ têm uma quantidade maior deste elemento em relação às outras, isto ocorre porque as três amostras citadas contêm leite em sua composição, que é considerado uma importante fonte de zinco (Dutta e Mukta, 2012).

Nenhuma amostra analisada ultrapassou o valor de RDA. Ao seguir as recomendações do Ministério da Saúde, o valor de RDA poderá ser atingido apenas na Etapa Jr, independentemente da escolha do sabor do alimento. 
A Tabela 19 e os Gráficos de 1 a 11 forneceram a quantidade de cada nutriente presente em cada pote comercial de alimento comercial infantil. Com esses dados é possível ter uma ideia da quantidade desses nutrientes que a criança está ingerindo ao comer um pote inteiro deste alimento. Se a criança for alimentada exclusivamente com esses alimentos comerciais infantis, seguindo as recomendações do Ministério da Saúde, não é possível atingir os valores de recomendação diária recomendada para a maioria os elementos analisados nos primeiros 8 meses de vida. Para alcançar estes valores, seria necessário ultrapassar a quantidade de alimentos oferecidos à criança por dia, o que poderia causar danos à saúde, já que este aumento de micronutrientes implicaria em aumento de calorias e gorduras na dieta diária.

A massa indicada pelo fabricante nos rótulos dos alimentos comerciais infantis estava bastante próxima da massa real contida nos potes. Devido a esta proximidade, para padronizar os valores de massa de alimento comercial infantil contida em cada pote, optou-se por utilizar o valor informado pelo fabricante no rótulo de cada pote comercial.

Os rótulos desses alimentos trazem pouca informação sobre seu conteúdo nutricional. De acordo com as normas da ANVISA, é obrigatório que o rótulo do alimento informe a quantidade do valor energético e dos nutrientes: carboidratos, proteínas, gorduras totais, gorduras saturadas, gorduras trans, fibra alimentar e sódio (Brasil, 2003). Na Tabela 20 são apresentados os valores dos nutrientes obtidos neste estudo e a informação presente nó rótulo.

Semelhante ao trabalho publicado por Zand et al. (2011), as baixas concentrações encontradas para os diversos nutrientes analisados neste estudo podem indicar uma explicação para a inexistência do valor informativo desses nutrientes no rótulo.

Os valores obtidos neste estudo estavam próximos dos valores informados no rótulo, porém todas as amostras da Etapa 1 e algumas amostras da Etapa 2 traziam no rótulo a informação de quantidade de sódio igual a zero, podendo levar o consumidor a acreditar que aquele alimento estava isento de sódio, quando na realidade há a presença de sódio em sua composição. Esta situação é semelhante 
ao que acontece com relação às gorduras trans, onde os fabricantes colocam no rótulo que a quantidade desta gordura é zero, podendo levar o consumidor a acreditar que o alimento está isento de gordura trans, quando na realidade ele não é isento, mas possui uma quantidade abaixo de um determinado limite estabelecido pelos órgãos de saúde.

Na Tabela 21 são apresentados os valores mínimos e máximos por $100 \mathrm{~g}$ de amostra obtidos neste estudo e os valores obtidos para a concentração desses elementos por $100 \mathrm{~g}$ de amostra, publicados por outros autores.

Tabela 20 - Comparação entre as massas dos elementos essenciais por frasco comercial de amostra obtida neste estudo com as informações presentes no rótulo (média \pm desvio-padrão)

\begin{tabular}{c|c|c|c|c|c|c|c}
\hline $\begin{array}{c}\text { Amostra } \\
\text { (Etapa) }\end{array}$ & $\begin{array}{c}\text { Massa do } \\
\text { alimento } \\
\text { contido em } \\
\text { cada pote }\end{array}$ & $\begin{array}{c}\text { Ca (Neste } \\
\text { trabalho) } \\
\mathrm{mg}\end{array}$ & $\begin{array}{c}\text { Ca } \\
\text { (rótulo) } \\
\mathrm{mg}\end{array}$ & $\begin{array}{c}\text { Fe (Neste } \\
\text { trabalho) } \\
\mathrm{mg}\end{array}$ & $\begin{array}{c}\text { Fe } \\
\text { (rótulo) } \\
\mathrm{mg}\end{array}$ & $\begin{array}{c}\text { Na (Neste } \\
\text { trabalho) } \\
\mathrm{mg}\end{array}$ & $\begin{array}{c}\text { Na } \\
\text { (rótulo) } \\
\mathrm{mg}\end{array}$ \\
\hline $1 \mathrm{a}$ & $120 \mathrm{~g}$ & $15,4 \pm 1,2$ & - & $0,329 \pm 0,031$ & - & $6,26 \pm 0,52$ & 0 \\
\hline $2 \mathrm{a}$ & $120 \mathrm{~g}$ & $5,82 \pm 0,38$ & - & $0,206 \pm 0,018$ & - & $3,91 \pm 0,30$ & 0 \\
\hline $3 \mathrm{a}$ & $120 \mathrm{~g}$ & $9,28 \pm 0,37$ & - & $0,135 \pm 0,013$ & - & $3,91 \pm 0,32$ & 0 \\
\hline $4 \mathrm{a}$ & $120 \mathrm{~g}$ & $7,26 \pm 0,67$ & - & $0,1677 \pm 0,0084$ & - & $3,71 \pm 0,28$ & 0 \\
\hline $5 \mathrm{a}$ & $120 \mathrm{~g}$ & $7,55 \pm 0,70$ & - & $0,301 \pm 0,029$ & - & $3,51 \pm 0,20$ & 0 \\
\hline $1 \mathrm{~b}$ & $120 \mathrm{~g}$ & $145 \pm 13$ & 180 & $0,586 \pm 0,055$ & - & $25,4 \pm 2,2$ & 32 \\
\hline $2 \mathrm{~b}$ & $120 \mathrm{~g}$ & $158 \pm 15$ & 180 & $0,605 \pm 0,059$ & - & $30,6 \pm 2,7$ & 32 \\
\hline $3 \mathrm{~b}$ & $120 \mathrm{~g}$ & $6,31 \pm 0,62$ & - & $0,321 \pm 0,013$ & - & $3,97 \pm 0,36$ & 0 \\
\hline $4 \mathrm{~b}$ & $120 \mathrm{~g}$ & $8,81 \pm 0,83$ & - & $0,208 \pm 0,018$ & - & $2,29 \pm 0,19$ & 0 \\
\hline $5 \mathrm{~b}$ & $120 \mathrm{~g}$ & $9,44 \pm 0,94$ & - & $0,243 \pm 0,022$ & - & $5,42 \pm 0,46$ & 0 \\
\hline $6 \mathrm{~b}$ & $120 \mathrm{~g}$ & $11,7 \pm 1,1$ & - & $0,181 \pm 0,017$ & - & $1,61 \pm 0,14$ & 0 \\
\hline $7 \mathrm{~b}$ & $120 \mathrm{~g}$ & $190 \pm 19$ & 180 & $0,464 \pm 0,042$ & - & $25,7 \pm 2,3$ & 32 \\
\hline $1 \mathrm{c}$ & $115 \mathrm{~g}$ & $11,9 \pm 1,1$ & - & $0,607 \pm 0,046$ & - & $60,9 \pm 5,6$ & 76 \\
\hline $2 \mathrm{c}$ & $115 \mathrm{~g}$ & $9,99 \pm 0,84$ & - & $0,557 \pm 0,054$ & - & $72,3 \pm 5,9$ & 75 \\
\hline $3 \mathrm{c}$ & $115 \mathrm{~g}$ & $11,40 \pm 0,12$ & - & $0,489 \pm 0,039$ & - & $67,1 \pm 6,1$ & 75 \\
\hline $4 \mathrm{c}$ & $115 \mathrm{~g}$ & $9,59 \pm 0,52$ & - & $0,464 \pm 0,043$ & - & $66,2 \pm 5,8$ & 80 \\
\hline $5 \mathrm{c}$ & $115 \mathrm{~g}$ & $26,3 \pm 2,4$ & - & $0,461 \pm 0,040$ & - & $63,7 \pm 5,9$ & 71 \\
\hline $6 \mathrm{c}$ & $115 \mathrm{~g}$ & $12,83 \pm 0,79$ & - & $0,456 \pm 0,039$ & - & $66,3 \pm 6,1$ & 79 \\
\hline $7 \mathrm{c}$ & $115 \mathrm{~g}$ & $14,8 \pm 1,4$ & - & $0,240 \pm 0,020$ & - & $67,6 \pm 6,1$ & 81 \\
\hline $1 \mathrm{~d}$ & $170 \mathrm{~g}$ & $29,2 \pm 2,2$ & - & $1,155 \pm 0,11$ & - & $146 \pm 13$ & 157 \\
\hline $2 \mathrm{~d}$ & $170 \mathrm{~g}$ & $15,39 \pm 0,78$ & - & $0,914 \pm 0,083$ & - & $162,9 \pm 8,9$ & 160 \\
\hline $3 \mathrm{~d}$ & $170 \mathrm{~g}$ & $18,7 \pm 1,5$ & - & $0,552 \pm 0,049$ & - & $160,7 \pm 8,0$ & 178 \\
\hline $4 \mathrm{~d}$ & $170 \mathrm{~g}$ & $16,6 \pm 1,3$ & - & $1,024 \pm 0,085$ & - & $143,6 \pm 8,5$ & 156 \\
\hline $1 \mathrm{e}$ & $250 \mathrm{~g}$ & $23,0 \pm 2,1$ & - & $6,68 \pm 0,48$ & 5,6 & $255 \pm 19$ & 299 \\
\hline $2 \mathrm{e}$ & $250 \mathrm{~g}$ & $24,7 \pm 2,4$ & - & $6,80 \pm 0,58$ & 5,6 & $333 \pm 31$ & 325 \\
\hline $3 \mathrm{e}$ & $250 \mathrm{~g}$ & $109 \pm 10$ & - & $5,56 \pm 0,55$ & 5,6 & $408 \pm 33$ & 480 \\
\hline $4 \mathrm{e}$ & $250 \mathrm{~g}$ & $170 \pm 17$ & - & $7,25 \pm 0,60$ & 5,6 & $343 \pm 27$ & 354 \\
\hline
\end{tabular}


Tabela 21 - Comparação entre os valores dos elementos essenciais obtidos neste trabalho com os valores publicados por outros autores por $100 \mathrm{~g}$ de amostra (média \pm desvio-padrão)

\begin{tabular}{|c|c|c|c|c|c|c|c|}
\hline Elemento & $\begin{array}{c}\text { Este trabalho } \\
\text { (Valor } \\
\text { mínimo) }\end{array}$ & $\begin{array}{c}\text { Este trabalho } \\
\text { (Valor } \\
\text { máximo) }\end{array}$ & $\begin{array}{l}\text { Saracoglu, } \\
\text { et al., } 2007\end{array}$ & $\begin{array}{c}\text { Melo et al., } \\
2008\end{array}$ & $\begin{array}{c}\text { Khalifa e } \\
\text { Ahmad, } 2010\end{array}$ & $\begin{array}{c}\text { Zand, et al., } \\
2011\end{array}$ & $\begin{array}{c}\text { Zand, et al., } \\
2012\end{array}$ \\
\hline $\mathrm{Ca}(\mathrm{mg})$ & $4,85 \pm 0,32$ & $158 \pm 15$ & - & $584 \pm 158$ & $19,77 \pm 14,41$ & 140,4 & $15 \pm 3$ \\
\hline $\mathrm{Cl}(\mathrm{mg})$ & $2,22 \pm 0,09$ & $412 \pm 37$ & - & - & - & - & - \\
\hline Co $(\mu g)$ & $0,284 \pm 0,024$ & $1,66 \pm 0,14$ & $2,25 \pm 0,21$ & $0,32 \pm 0,65$ & - & - & - \\
\hline $\mathrm{Cr}(\mu \mathrm{g})$ & $2,21 \pm 0,17$ & $19,05 \pm 0,98$ & $1,74 \pm 0,14$ & ND & $6 \pm 5$ & - & 51 \\
\hline $\mathrm{Fe}(\mu \mathrm{g})$ & $112 \pm 11$ & $2899 \pm 240$ & $3320 \pm 270$ & $9480 \pm 1040$ & $10,935 \pm 3,35$ & 1200 & $2000 \pm 1000$ \\
\hline $\mathrm{K}(\mathrm{mg})$ & $78,0 \pm 6,2$ & $365 \pm 19$ & - & $827 \pm 152$ & $116,02 \pm 51,93$ & 315 & $93 \pm 85$ \\
\hline $\mathrm{Mg}(\mathrm{mg})$ & $2,78 \pm 0,20$ & $15,99 \pm 0,98$ & - & $88,4 \pm 19,8$ & $42,0 \pm 33,83$ & 31,6 & $17 \pm 2$ \\
\hline$M n(\mu g)$ & $42,2 \pm 3,6$ & $242 \pm 18$ & $136 \pm 12$ & - & $648 \pm 750$ & - & 127 \\
\hline $\mathrm{Na}(\mathrm{mg})$ & $1,34 \pm 0,12$ & $163 \pm 13$ & - & $126 \pm 46,3$ & $179,61 \pm 131,5$ & 118 & $34 \pm 40$ \\
\hline $\mathrm{Se}(\mu \mathrm{g})$ & $0,293 \pm 0,028$ & $2,29 \pm 0,11$ & $16 \pm 1$ & - & - & ND & - \\
\hline $\mathrm{Zn}(\mu \mathrm{g})$ & $51,2 \pm 3,4$ & $971 \pm 80$ & $1150 \pm 110$ & $2110 \pm 360$ & $1540 \pm 1590$ & 850 & $200 \pm 30$ \\
\hline
\end{tabular}

ND: Valor não detectado, abaixo do limite de detecção

- : Valor não publicado 
As diferenças encontradas podem estar relacionadas à diferença dos ingredientes e quantidades utilizados na composição das amostras analisadas, dado que todos os trabalhos publicados sobre alimentos comerciais infantis analisaram amostras não fabricadas no Brasil, ao contrário do que foi realizado no presente estudo. Outro problema encontrado nesta comparação é com a divisão escolhida pelos autores ao apresentar seus resultados, pois alguns optam por generalizar as amostras como purês de vegetais, outros fazem uma separação entre frutas e cereais e outros fazem divisão entre alimentos compostos por carnes ou por vegetais. Esta separação feita por outros autores dificulta a comparação, dado que no Brasil todos os alimentos comerciais infantis salgados são compostos por carnes e vegetais, não havendo separação por grupos de alimentos.

Um problema da utilização exclusiva de alimentos comerciais infantis como única fonte de alimentação complementar é a pequena ou quase nula variedade dentro da refeição. Os alimentos comerciais infantis possuem sabor homogêneo em toda a sua porção, bem como uma pequena variação ou até mesmo nenhuma variação em sua textura e cor. Isto dificulta a aceitação de outros alimentos pela criança. Segundo Mennella e Trabulsi (2012), estudos comprovam que crianças expostas a alimentos com diferentes características sensoriais, desenvolveram preferência por maior variedade de sabores do que aquelas crianças expostas a um único alimento por refeição.

Confirmando a afirmação de Mennella e Trabulsi (2012), o Ministério da Saúde recomenda no guia Dez Passos para uma Alimentação Saudável para Crianças Brasileiras Menores de Dois Anos (Brasil, 2010) que os alimentos complementares oferecidos ao bebê não devem ser batidos em liquidificador, permitindo assim que a criança experimente novas consistências, sabores e cores, além de estimular a mastigação. Isto explicita a vantagem de uma alimentação complementar preparada em casa em comparação a alimentos complementares industrializados oferecidos na forma de papa, onde não é possível a distinção entre os diferentes alimentos presentes na mistura. 


\subsection{Concentração dos elementos nas amostras de alimentos comerciais infantis pelo método AAS}

A exposição a qualquer elemento-traço não essencial é indesejável. Elementos-traço não essenciais podem ser tóxicos e causarem efeitos adversos à saúde em crianças, mesmo em níveis baixos. Estudos indicam que crianças são mais susceptíveis à exposição a elementos potencialmente tóxicos, pois a sua absorção intestinal é proporcionalmente maior em comparação com a dos adultos (Carbonell-Barrachina et al., 2012).

Existem diversas fontes de elementos tóxicos, como o solo, a erosão da crosta, descarga industrial, esgotos, pragas ou agentes controladores de doenças em plantas, poluição atmosférica, dentre outros. Entretanto, para a maioria das pessoas, a forma de exposição mais usual a estes elementos tóxicos é através da dieta (Morais et al., 2012).

Metais como mercúrio e cádmio são encontrados em todo o ambiente e estão presentes em praticamente todos os alimentos em níveis extremamente baixos (Saracoglu et al., 2007). A absorção de cádmio em seres humanos a partir da exposição alimentar é relativamente baixa, entre $3-5 \%$, mas o cádmio absorvido se mantém nos rins e no fígado por um período que varia entre 10 e 30 anos (Pandelova et al., 2012). Assim como ocorre com o Cd, o mercúrio inorgânico se mantém nos rins. Já o metil mercúrio tem grande afinidade pelo cérebro (Cozzolino, 2005).

As concentrações de $\mathrm{Cd}$ e $\mathrm{Hg}$ em algumas amostras estavam abaixo do limite de deteç̧ão (LD). Para a determinação do LD, utilizou-se a Equação 9 (Welz e Sperling, 1999). Na Tabela 22 são apresentados os valores de limite de detecção para $\mathrm{Cd}$ e $\mathrm{Hg}$.

$$
L D=\frac{3 \sigma_{0}}{\alpha}
$$

(Equação 9)

Onde:

$\sigma_{0}=$ desvio padrão de 10 determinações do branco analítico;

$\alpha=$ é o coeficiente angular da curva de calibração. 
Tabela 22 - Limites de detecção dos elementos determinados por AAS

\begin{tabular}{c|c|c}
\hline Elemento (concentração) & LD (base seca) & LD (In natura) \\
\hline $\mathrm{Cd}(\mathrm{ng} / \mathrm{g})$ & 0,25 & 0,04 \\
\hline $\mathrm{Hg}(\mathrm{ng} / \mathrm{g})$ & 0,29 & 0,04 \\
\hline
\end{tabular}

As Tabelas 23 a 26 apresentam os valores de concentração de $\mathrm{Cd}$ e $\mathrm{Hg}$ determinados nas amostras em base seca, in natura, em $100 \mathrm{~g}$ da amostra e por cada frasco, respectivamente. Os Gráficos 12 e 13 ilustram a quantidade de $\mathrm{Cd}$ e $\mathrm{Hg}$ por grama de amostra, respectivamente, em comparação com o valor do limite superior tolerável de ingestão (UL).

\section{Cd}

A exposição e o acúmulo de cádmio podem acontecer em crianças pequenas. Sua acumulação nos rins é responsável pela nefrotoxicidade e osteoporose. Embora estas doenças só apareçam na idade adulta, o início do acúmulo se dá ainda na infância (Nookabkaew et al., 2012).

Cádmio é absorvido através das raízes das plantas, possibilitando seu acúmulo em folhas comestíveis, frutos e sementes. Também se acumula no leite animal e tecidos gordurosos. Este elemento se acumula no organismo, afetando negativamente diversos órgãos como: rins, fígado, pulmão, ossos, placenta e sistema nervoso central (Morais et al., 2012).

Principais alimentos que podem ter contaminação por Cd: arroz (Kazi et al., 2010; Morais et al., 2012).

\section{$\mathrm{Hg}$}

Mercúrio é um dos elementos mais tóxico do ambiente. A exposição a níveis elevados de mercúrio metálico, orgânico ou inorgânico pode trazer danos permanentes ao cérebro e rins, além de atrapalhar o desenvolvimento do feto. Sua toxicidade depende de sua forma química (iônico < metálico < orgânico). O metilmercúrio tem uma tendência de aumento de acúmulo conforme aumenta a idade do peixe e o nível trófico (Morais et al., 2012). 
Principais alimentos que podem ter contaminação por $\mathrm{Hg}$ : peixes, repolho, mandioca, batata doce, manga e caju (Cunha, 2012).

Tabela 23 - Concentrações dos elementos tóxicos nas amostras em base seca (média \pm desvio-padrão).

\begin{tabular}{|c|c|c|}
\hline Amostra (Etapa) & $\mathrm{Cd}(\mathrm{ng} / \mathrm{g})$ & $\mathrm{Hg}(\mathrm{ng} / \mathrm{g})$ \\
\hline $1 \mathrm{a}$ & $3,54 \pm 0,025$ & $2,76 \pm 0,16$ \\
\hline $2 a$ & $<\mathrm{LD}$ & $<\mathrm{LD}$ \\
\hline $3 a$ & $<\mathrm{LD}$ & $<\mathrm{LD}$ \\
\hline $4 a$ & $<\mathrm{LD}$ & $<\mathrm{LD}$ \\
\hline $5 a$ & $2,58 \pm 0,05$ & $1,43 \pm 0,11$ \\
\hline $1 \mathrm{~b}$ & $<\mathrm{LD}$ & $<\mathrm{LD}$ \\
\hline $2 b$ & $<\mathrm{LD}$ & $<\mathrm{LD}$ \\
\hline $3 b$ & $<\mathrm{LD}$ & $1,639 \pm 0,027$ \\
\hline $4 \mathrm{~b}$ & $<\mathrm{LD}$ & $4,46 \pm 0,11$ \\
\hline $5 b$ & $2,76 \pm 0,03$ & $<\mathrm{LD}$ \\
\hline $6 b$ & $4,35 \pm 0,05$ & $<\mathrm{LD}$ \\
\hline $7 b$ & $<\mathrm{LD}$ & $<\mathrm{LD}$ \\
\hline $1 \mathrm{c}$ & $11,62 \pm 0,10$ & $1,806 \pm 0,037$ \\
\hline $2 c$ & $24,04 \pm 0,25$ & $1,050 \pm 0,043$ \\
\hline $3 c$ & $11,13 \pm 0,25$ & $1,404 \pm 0,017$ \\
\hline $4 c$ & $7,84 \pm 0,25$ & $0,429 \pm 0,018$ \\
\hline $5 c$ & $11,38 \pm 0,25$ & $0,804 \pm 0,036$ \\
\hline $6 c$ & $3,57 \pm 0,05$ & $0,304 \pm 0,012$ \\
\hline $7 \mathrm{c}$ & $11,00 \pm 0,05$ & $1,004 \pm 0,050$ \\
\hline $1 d$ & $18,72 \pm 0,76$ & $2,81 \pm 0,14$ \\
\hline $2 \mathrm{~d}$ & $12,14 \pm 0,51$ & $0,590 \pm 0,029$ \\
\hline $3 d$ & $7,59 \pm 0,25$ & $1,194 \pm 0,045$ \\
\hline $4 d$ & $10,145 \pm 0,050$ & $0,529 \pm 0,022$ \\
\hline $1 \mathrm{e}$ & $9,41 \pm 0,10$ & $1,110 \pm 0,043$ \\
\hline $2 \mathrm{e}$ & $21,505 \pm 0,025$ & $0,338 \pm 0,014$ \\
\hline $3 e$ & $5,85 \pm 0,15$ & $1,040 \pm 0,039$ \\
\hline $4 \mathrm{e}$ & $8,14 \pm 0,17$ & $0,548 \pm 0,022$ \\
\hline
\end{tabular}

$<$ LD: menor que o limite de detecção 
Tabela 24 - Concentrações dos elementos tóxicos nas amostras in natura (média \pm desvio-padrão).

\begin{tabular}{|c|c|c|}
\hline $\begin{array}{c}\text { Amostra } \\
\text { (Etapa) }\end{array}$ & $\mathrm{Cd}(\mathrm{ng} / \mathrm{g})$ & $\mathrm{Hg}(\mathrm{ng} / \mathrm{g})$ \\
\hline $1 a$ & $0,698 \pm 0,005$ & $0,543 \pm 0,031$ \\
\hline $2 a$ & $<L D$ & $<L D$ \\
\hline $3 a$ & $<\mathrm{LD}$ & $<\mathrm{LD}$ \\
\hline $4 a$ & $<\mathrm{LD}$ & $<\mathrm{LD}$ \\
\hline $5 a$ & $0,635 \pm 0,006$ & $0,187 \pm 0,014$ \\
\hline $1 b$ & $<\mathrm{LD}$ & $<\mathrm{LD}$ \\
\hline $2 b$ & $<\mathrm{LD}$ & $<\mathrm{LD}$ \\
\hline $3 b$ & $<\mathrm{LD}$ & $0,264 \pm 0,037$ \\
\hline $4 \mathrm{~b}$ & $<\mathrm{LD}$ & $0,673 \pm 0,017$ \\
\hline $5 b$ & $0,655 \pm 0,004$ & $<$ LD \\
\hline $6 b$ & $0,700 \pm 0,008$ & $<\mathrm{LD}$ \\
\hline $7 b$ & $<$ LD & $<\mathrm{LD}$ \\
\hline $1 \mathrm{c}$ & $1,964 \pm 0,016$ & $0,305 \pm 0,06$ \\
\hline $2 c$ & $3,773 \pm 0,040$ & $0,165 \pm 0,007$ \\
\hline $3 c$ & $2,092 \pm 0,047$ & $0,264 \pm 0,003$ \\
\hline $4 c$ & $1,553 \pm 0,050$ & $0,085 \pm 0,004$ \\
\hline $5 c$ & $2,106 \pm 0,047$ & $0,149 \pm 0,007$ \\
\hline $6 c$ & $11,39 \pm 0,16$ & $1,884 \pm 0,071$ \\
\hline $7 c$ & $2,00 \pm 0,01$ & $0,183 \pm 0,009$ \\
\hline $1 d$ & $3,71 \pm 0,15$ & $0,556 \pm 0,028$ \\
\hline $2 d$ & $2,53 \pm 0,11$ & $0,123 \pm 0,006$ \\
\hline $3 d$ & $1,571 \pm 0,052$ & $0,247 \pm 0,009$ \\
\hline $4 d$ & $2,161 \pm 0,011$ & $0,113 \pm 0,005$ \\
\hline $1 e$ & $1,675 \pm 0,018$ & $0,198 \pm 0,008$ \\
\hline $2 e$ & $6,796 \pm 0,079$ & $2,08 \pm 0,87$ \\
\hline $3 e$ & $1,129 \pm 0,029$ & $0,201 \pm 0,008$ \\
\hline $4 e$ & $1,554 \pm 0,032$ & $0,105 \pm 0,004$ \\
\hline UL $(\mathbf{n g} / \mathrm{g})^{\mathrm{a}}$ & 1000 & 500 \\
\hline
\end{tabular}


Tabela 25 - Massas dos elementos tóxicos presentes em $100 \mathrm{~g}$ de amostra (média \pm desvio-padrão).

\begin{tabular}{|c|c|c|}
\hline $\begin{array}{c}\text { Amostra } \\
\text { (Etapa) }\end{array}$ & $\mathrm{Cd}(\mathrm{ng})$ & $\mathrm{Hg}(\mathrm{ng})$ \\
\hline $1 \mathrm{a}$ & $69,78 \pm 0,50$ & $54,3 \pm 3,1$ \\
\hline $2 a$ & - & - \\
\hline $3 a$ & - & - \\
\hline $4 a$ & - & - \\
\hline $5 a$ & $33,54 \pm 0,65$ & $18,7 \pm 1,4$ \\
\hline $1 b$ & - & - \\
\hline $2 b$ & - & - \\
\hline $3 b$ & - & $26,4 \pm 3,7$ \\
\hline $4 b$ & - & $67,3 \pm 1,7$ \\
\hline $5 b$ & $45,54 \pm 0,41$ & - \\
\hline $6 b$ & $70,04 \pm 0,81$ & - \\
\hline $7 b$ & - & - \\
\hline $1 \mathrm{c}$ & $196,4 \pm 1,6$ & $30,52 \pm 0,63$ \\
\hline $2 c$ & $377,3 \pm 4,0$ & $16,49 \pm 0,68$ \\
\hline $3 c$ & $209,2 \pm 4,7$ & $26,40 \pm 0,32$ \\
\hline $4 \mathrm{c}$ & $155,3 \pm 5,0$ & $8,49 \pm 0,36$ \\
\hline $5 c$ & $210,6 \pm 4,7$ & $14,87 \pm 0,67$ \\
\hline $6 c$ & $1139 \pm 16$ & $188,4 \pm 7,1$ \\
\hline 7c & $200,20 \pm 0,91$ & $18,27 \pm 0,91$ \\
\hline 1d & $371 \pm 15$ & $55,6 \pm 2,8$ \\
\hline $2 d$ & $253 \pm 11$ & $12,27 \pm 0,60$ \\
\hline $3 d$ & $157,1 \pm 5,2$ & $24,72 \pm 0,93$ \\
\hline $4 d$ & $216,1 \pm 1,1$ & $11,27 \pm 0,47$ \\
\hline $1 \mathrm{e}$ & $167,5 \pm 1,8$ & $19,76 \pm 0,77$ \\
\hline $2 e$ & $679,6 \pm 7,9$ & $208,4 \pm 8,7$ \\
\hline $3 e$ & $112,9 \pm 2,9$ & $20,07 \pm 0,75$ \\
\hline $4 e$ & $155,4 \pm 3,2$ & $10,46 \pm 0,41$ \\
\hline
\end{tabular}

-: valor não determinado 
Tabela 26 - Massas dos elementos tóxicos por frasco comercial de amostra (média \pm desvio-padrão).

\begin{tabular}{|c|c|c|c|}
\hline $\begin{array}{c}\text { Amostra } \\
\text { (Etapa) }\end{array}$ & $\begin{array}{l}\text { Massa do alimento } \\
\text { contido em cada pote } \\
(\mathrm{g})\end{array}$ & $\mathrm{Cd}(\mathrm{ng})$ & $\mathrm{Hg}(\mathrm{ng})$ \\
\hline $1 \mathrm{a}$ & 120 & $83,73 \pm 0,60$ & $65,3 \pm 3,7$ \\
\hline $2 a$ & 120 & - & - \\
\hline $3 a$ & 120 & - & - \\
\hline $4 a$ & 120 & - & - \\
\hline $5 a$ & 120 & $40,25 \pm 0,78$ & $22,4 \pm 1,7$ \\
\hline $1 b$ & 120 & - & - \\
\hline $2 b$ & 120 & - & - \\
\hline $3 b$ & 120 & - & $31,7 \pm 4,4$ \\
\hline $4 b$ & 120 & - & $80,8 \pm 2,0$ \\
\hline $5 b$ & 120 & $54,65 \pm 0,50$ & - \\
\hline $6 b$ & 120 & $84,04 \pm 0,97$ & - \\
\hline $7 b$ & 120 & - & - \\
\hline $1 \mathrm{c}$ & 115 & $225,8 \pm 1,8$ & $35,10 \pm 0,72$ \\
\hline 2c & 115 & $434,0 \pm 4,6$ & $18,96 \pm 0,78$ \\
\hline $3 c$ & 115 & $240,6 \pm 5,4$ & $30,35 \pm 0,37$ \\
\hline $4 \mathrm{c}$ & 115 & $178,6 \pm 5,8$ & $9,77 \pm 0,41$ \\
\hline $5 c$ & 115 & $242,2 \pm 5,4$ & $17,11 \pm 0,77$ \\
\hline $6 c$ & 115 & $1310 \pm 18$ & $216,7 \pm 8,2$ \\
\hline $7 c$ & 115 & $230,2 \pm 1,0$ & $21,0 \pm 1,0$ \\
\hline $1 d$ & 170 & $630 \pm 26$ & $94,5 \pm 4,7$ \\
\hline $2 d$ & 170 & $429 \pm 18$ & $20,9 \pm 1,0$ \\
\hline $3 d$ & 170 & $267,1 \pm 8,9$ & $42,0 \pm 1,6$ \\
\hline $4 d$ & 170 & $367,4 \pm 1,8$ & $19,16 \pm 0,80$ \\
\hline $1 \mathrm{e}$ & 250 & $418,8 \pm 4,5$ & $49,4 \pm 1,9$ \\
\hline $2 e$ & 250 & $1699 \pm 20$ & $521 \pm 22$ \\
\hline $3 e$ & 250 & $282,2 \pm 7,1$ & $50,2 \pm 1,9$ \\
\hline $4 e$ & 250 & $388,6 \pm 8,0$ & $26,2 \pm 1,0$ \\
\hline
\end{tabular}

-: valor não determinado 


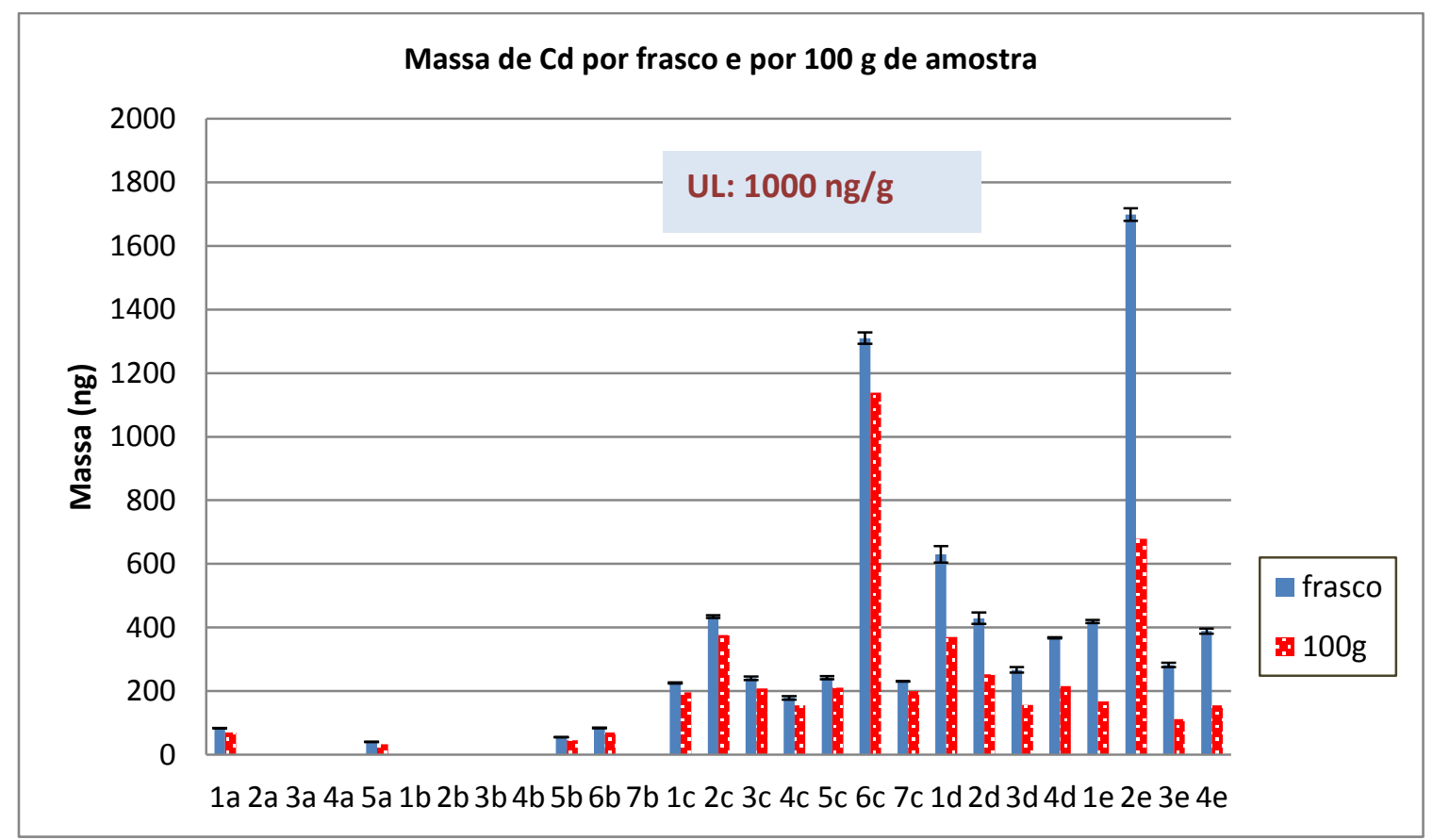

Gráfico 12 - Massa de Cd por frasco e em $100 \mathrm{~g}$ de amostra

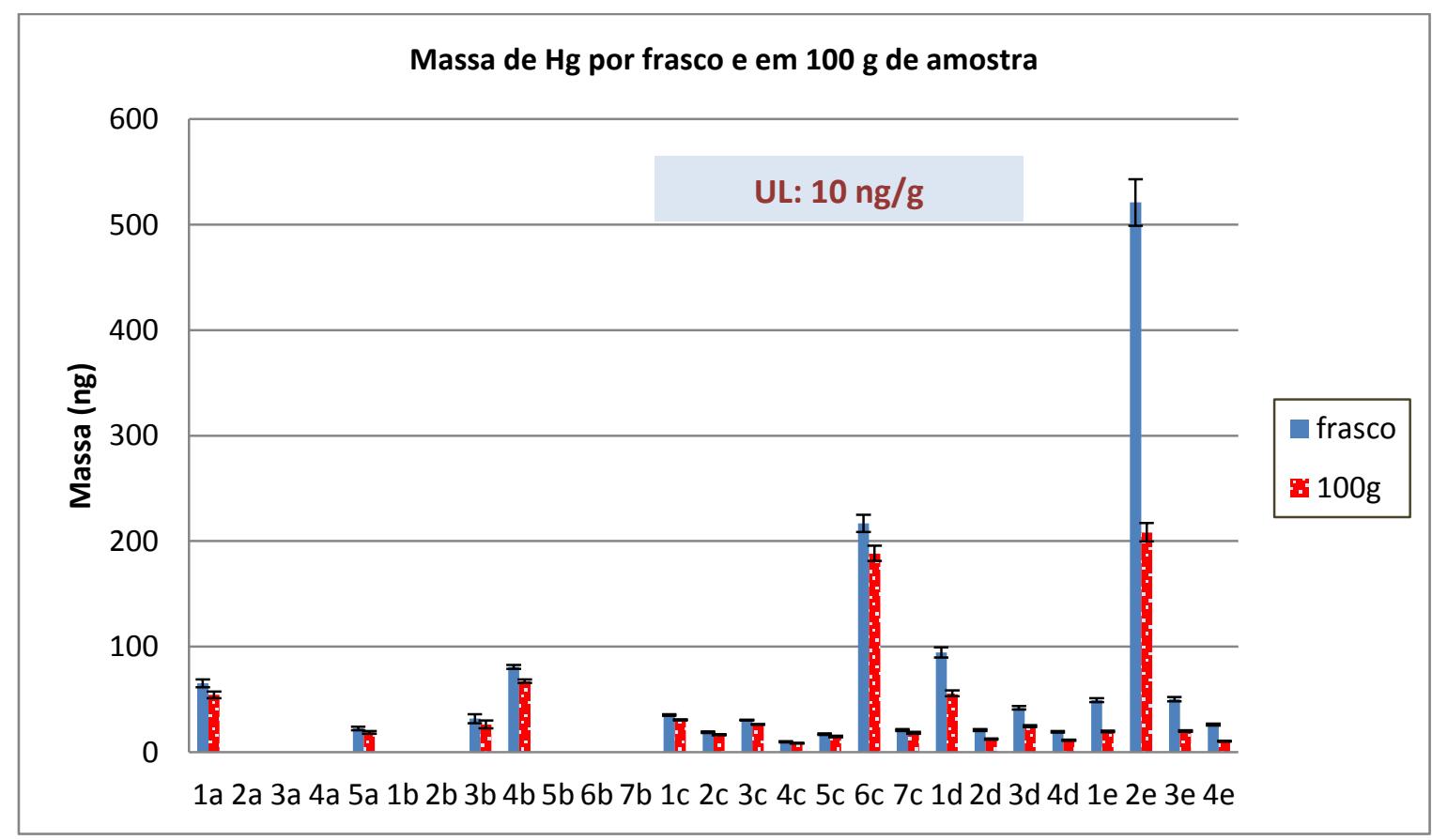

Gráfico 13 - Massa de $\mathrm{Hg}$ por frasco e em $100 \mathrm{~g}$ de amostra 
Algumas das amostras analisadas apresentaram concentração de $\mathrm{Cd}$ e $\mathrm{Hg}$ abaixo dos limites de detecção. O Cd e o Hg são bastante tóxicos e cumulativos, por isso a exposição a esses elementos deve ser analisada com bastante atenção (Morais et al., 2012). No caso dos alimentos comerciais infantis, a concentração encontrada para ambos os elementos foi muito inferior ao valor de UL, conforme ilustram os gráficos 12 e 13 para $\mathrm{Cd}$ e $\mathrm{Hg}$, respectivamente. Com base nesses dados, é possível afirmar que não há necessidade de nenhuma ação preventiva ou até mesmo de reparação para esses alimentos.

As amostras 6c (Etapa 3) e 2e (Etapa Jr) se destacaram por possuírem quantidade maior de ambos elementos analisados por AAS. Essas amostras têm em comum grande quantidade de legumes em sua composição, o que pode ter contribuído para o aumento das concentrações desses elementos.

Os resultados encontrados neste estudo confirmam os dados publicados por Zand et al. (2012), onde os níveis de cádmio nas amostras comerciais infantis estavam bastante abaixo do valor de UL. Pandelova et al. (2012) encontraram valores altos de $\mathrm{Hg}$ nas amostras analisadas, diferente dos resultados obtidos no presente trabalho. Isto pode estar relacionado ao peixe utilizado como um dos componentes desses alimentos analisados por Pandelova et al., sendo que no Brasil não há alimentos comerciais infantis que possuam peixe em sua composição. 


\section{TRATAMENTO ESTATÍSTICO}

As concentrações dos elementos determinados apresentaram considerável variação entre as amostras. Os diferentes alimentos utilizados em suas composições podem ser uma possível explicação para essa variação, conforme observaram Zand et al. (2012). Outra explicação considerável é a diferença nas recomendações nutricionais que varia com a idade (Brasil, 2010), como dito anteriormente. Para avaliar as diferenças encontradas, foram feitos 3 tratamentos estatísticos: análise de agrupamento, coeficientes de correlação e análise de variância.

\subsection{Análise de agrupamento}

A análise hierárquica de agrupamento, ou análise Clusters, foi realizada para a determinação de possíveis semelhanças entre as diferentes amostras.

Para esta análise foi aplicado o método Ward de ligação, ou método da mínima variância, e a distância Euclidiana foi utilizada como medida da distância entre os grupos formados. A Figura 8 apresenta o dendrograma obtido pela análise de agrupamento.

Pelo dendrograma da Figura 8 é possível distinguir três grupos principais: I, II e III. Era esperado que houvesse uma separação entre as amostras da Etapa Jr, devido à alta concentração da maioria dos elementos, como cloro, ferro e sódio em relação às amostras das outras etapas. A formação de um grupo composto por amostras doces (amostras "a" e "b") era esperada, devido às baixas concentrações de alguns elementos como sódio e cloro.

No grupo I encontram-se agrupadas as amostras da Etapa Jr, que são direcionadas às crianças que já completaram 12 meses de idade. Nesta fase as 
necessidades de diversos nutrientes aumentam, por isso há uma separação por idade nos valores de ingestão diária recomendada dos nutrientes, feitos pela OMS

No grupo II encontram-se as amostras da Etapa 3 (amostras "d"), as amostras salgadas da Etapa 2 (amostras "c") e três amostras doces da Etapa 2 (1b, $2 b$ e $4 b)$. Estas amostras doces encontram-se separadas em um subgrupo diferente dos grupos onde estão as amostras salgadas deste grupo. Cloro é um elemento com concentração próxima entre essas três amostras, o que pode ter levado a esta separação.

O grupo III é formado apenas por amostras doces pertencentes às Etapas 1 (amostras "a") e 2 (amostras "b"). A separação em um grupo formado apenas por amostras doces era esperada, devido às baixas concentrações de diversos elementos como: cloro, ferro, sódio e zinco, em relação às amostras salgadas.

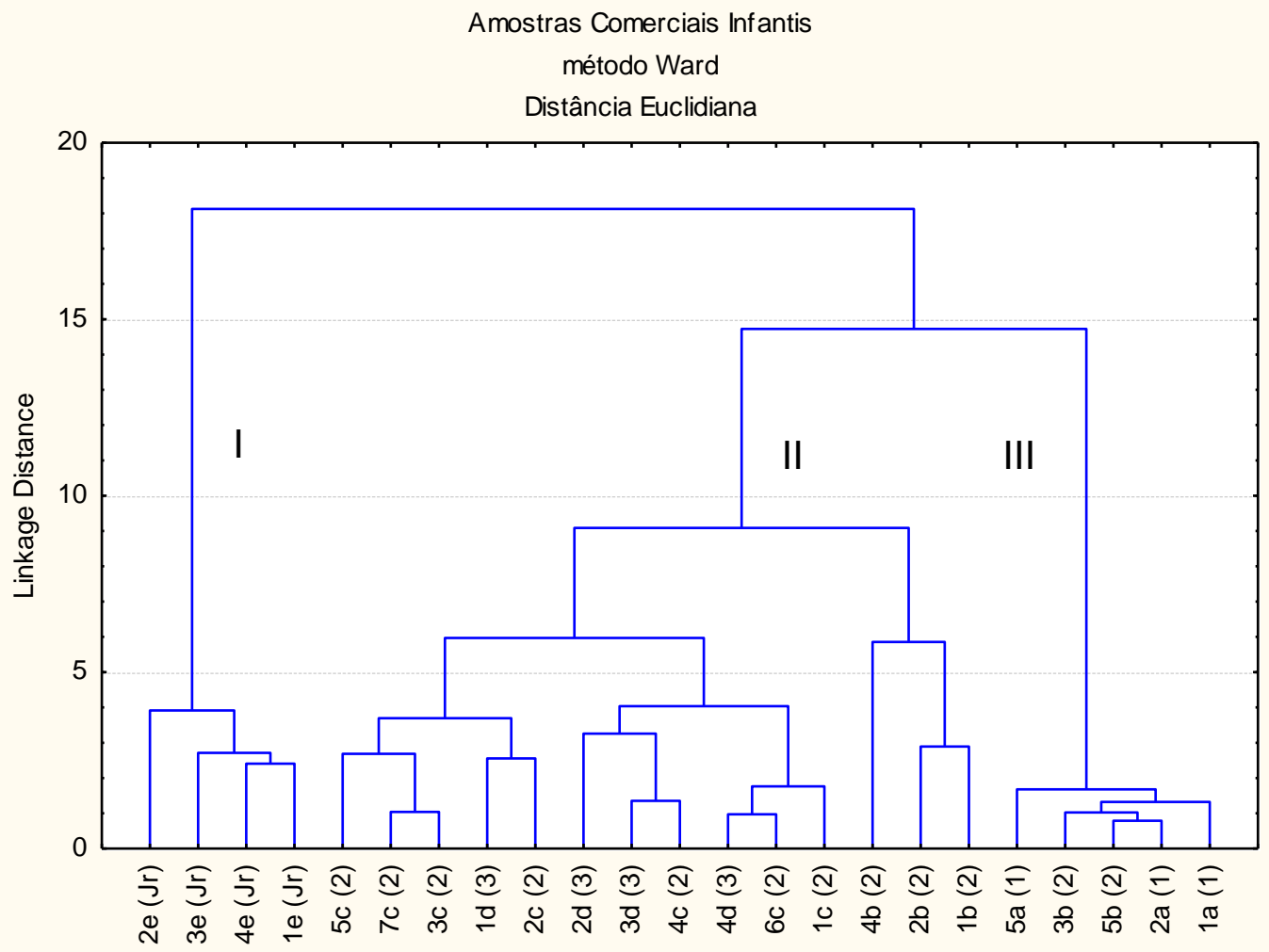

Figura 8 - Dendrograma da análise de agrupamento para os elementos analisados nas amostras de alimentos comerciais infantis 


\subsection{Coeficiente de correlação}

Os coeficientes de correlação foram determinados para verificar as correlações entre as concentrações dos elementos. Para este estudo foi utilizado um nível de significância de $p<0,05$. Na Tabela 27 são apresentados os resultados das correlações.

A partir da Tabela 27 é possível observar que há correlação positiva significativa entre o cloro e todos os elementos analisados, exceto cobalto e manganês. Isto pode ser explicado pelo cloro ser um ânion e ter atração pela maioria dos cátions que os elementos analisados podem formar. O sódio possui correlação positiva significativa com todos os elementos com exceção ao cálcio e ao manganês, isto pode ser explicado pela vasta utilização deste elemento como conservante e na manutenção do sabor dos alimentos fabricados. O cálcio e o manganês são os únicos elementos que não apresentam correlação significativa com nenhum dos outros elementos, ilustrando que o aumento ou a diminuição desses elementos, não afeta a concentração dos outros elementos analisados neste estudo. 
Tabela 27 - Coeficientes de correlação para os elementos analisados por INAA

\begin{tabular}{|c|c|c|c|c|c|c|c|c|c|c|c|}
\hline & $\mathrm{Ca}$ & $\mathrm{Cl}$ & Co & $\mathrm{Cr}$ & $\mathrm{Fe}$ & $\mathrm{K}$ & $\mathrm{Mg}$ & $\mathrm{Mn}$ & $\mathrm{Na}$ & $\mathrm{Se}$ & $\mathrm{Zn}$ \\
\hline $\mathrm{Ca}$ & 1,000000 & & & & & & & & & & \\
\hline $\mathrm{Cl}$ & 0,096954 & 1,000000 & & & & & & & & & \\
\hline Co & $-0,010663$ & 0,373012 & 1,000000 & & & & & & & & \\
\hline $\mathrm{Cr}$ & 0,245160 & 0,470431 & 0,017403 & 1,000000 & & & & & & & \\
\hline $\mathrm{Fe}$ & 0,155830 & 0,892560 & 0,266549 & 0,537006 & 1,000000 & & & & & & \\
\hline $\mathrm{K}$ & 0,199126 & 0,870313 & 0,442483 & 0,465943 & 0,787060 & 1,000000 & & & & & \\
\hline $\mathrm{Mg}$ & 0,236796 & 0,476432 & 0,572985 & 0,227411 & 0,257346 & 0,644282 & 1,000000 & & & & \\
\hline $\mathrm{Mn}$ & 0,156015 & $-0,215546$ & $-0,111533$ & $-0,105583$ & $-0,160446$ & $-0,142689$ & 0,245397 & 1,000000 & & & \\
\hline $\mathrm{Na}$ & 0,014335 & 0,969241 & 0,417513 & 0,456810 & 0,776857 & 0,869753 & 0,528887 & $-0,284199$ & 1,000000 & & \\
\hline $\mathrm{Se}$ & $-0,152891$ & 0,525181 & 0,328616 & $-0,020155$ & 0,514817 & 0,465835 & 0,099209 & $-0,084243$ & 0,491252 & 1,000000 & \\
\hline $\mathrm{Zn}$ & $-0,009055$ & 0,569377 & 0,451316 & 0,226839 & 0,522325 & 0,689122 & 0,442179 & $-0,202370$ & 0,598864 & 0,427960 & 1,000000 \\
\hline
\end{tabular}




\subsection{Análise de variância}

A análise de variância, ou ANOVA (ANalysis Of VAriance), foi realizada para comparar as médias das concentrações dos elementos entre as etapas dos alimentos comerciais infantis.

Se $\circ F_{\text {calculado }}$ for maior que $\circ F$ de Snedecor $(2,73)$, as médias dos elementos entre as diferentes etapas de alimentos comerciais infantis são diferentes. Para confirmar essa diferença entre as médias é necessário que o Pvalor referente a esse fator (o qual está relacionado às médias das concentrações dos elementos) seja menor que o nível de significância (a) pré-determinado, de $5 \%$.

Para este tratamento estatístico foram calculadas as médias para cada elemento dentro de cada um dos cinco grupos analisados, sendo o primeiro grupo correspondente à Etapa 1 (amostras "a"), o segundo, à Etapa 2 com sabor doce (amostras "b"), à Etapa 2 com sabor salgado (amostras "c"), à Etapa 3 (amostras "d") e à Etapa Jr (amostras "e").

$\mathrm{Na}$ Tabela 28 são apresentados os resultados para a análise de variância para os elementos analisados, cujas concentrações estavam acima do Limite de Detecção do equipamento. 
Tabela 28 - Análise de variância para as médias dos elementos entre as diferentes etapas de alimentos comerciais infantis

\begin{tabular}{c|c|c}
\hline Elemento & $\mathbf{F}_{\text {calculado }}$ & P-valor \\
\hline $\mathrm{Ca}$ & 2,33 & 0,0875 \\
\hline $\mathrm{Cl}$ & 146 & 0 \\
\hline $\mathrm{Co}$ & 3,99 & 0,014 \\
\hline $\mathrm{Cr}$ & 5,32 & 0,0038 \\
\hline $\mathrm{Fe}$ & 187 & 0 \\
\hline $\mathrm{K}$ & 22 & 0 \\
\hline $\mathrm{Mg}$ & 4,85 & 0,0059 \\
\hline $\mathrm{Mn}$ & 0,91 & 0,4766 \\
\hline $\mathrm{Na}$ & 113 & 0 \\
\hline $\mathrm{Se}$ & 6,47 & 0,0013 \\
\hline $\mathrm{Zn}$ & 6,71 & 0,0011 \\
\hline
\end{tabular}

Analisando a Tabela 28, os únicos elementos cujas médias podem ser consideradas estatisticamente iguais entre as diferentes etapas de alimentos comerciais infantis são o cálcio e o manganês. Todos os outros elementos apresentaram médias estatisticamente diferentes em relação às diferentes etapas.

Essa diferença encontrada entre as concentrações da maioria dos elementos analisada pode ser explicada pelo aumento da necessidade nutricional da criança com o aumento da idade, que exige maior concentração dos nutrientes. Conforme a criança cresce, a sua necessidade nutricional aumenta (Brasil, 1998). As Etapas das amostras de alimentos comerciais infantis são divididas de acordo com a idade da criança, portanto, se a necessidade nutricional aumenta com a idade, era de se esperar, que o fabricante aumentasse a quantidade de nutrientes com o aumento da Etapa, que corresponde ao aumento da idade da criança. 


\section{CONSIDERAÇÕES FINAIS}

A escolha dos alimentos complementares afeta não apenas o estado nutricional da criança naquele momento, como também pode trazer consequências a longo prazo. Outra preocupação na escolha dos alimentos utilizados nesta fase é que possivelmente irão afetar as preferências alimentares na vida adulta.

A informação nutricional apresentada no rótulo pode dificultar o consumidor no momento da escolha, pois poucos nutrientes têm suas quantidades informadas. Outro problema é a informação do sódio, pois alguns rótulos informam quantidade de sódio igual a zero, levando o consumidor a acreditar erroneamente que aquele alimento está isento de sódio.

Embora a utilização de alimentos comerciais infantis seja bastante prática, é necessário um cuidado na escolha do alimento complementar, pois não é possível atingir os valores de RDA/AI para todos os elementos analisados utilizando esse alimento de forma exclusiva. A alimentação complementar deve ser oferecida sempre em adição ao leite materno, pois, assim, a probabilidade de alcançar os valores de DRI (Ingestão Diária Recomendada) é maior. Se a criança não está em aleitamento materno, o uso exclusivo de alimentos complementares comerciais não é recomendado pela deficiência em alguns nutrientes conforme ilustrado no presente trabalho. 


\section{CONCLUSÕES}

Os métodos de Análise por Ativação com Nêutrons Instrumental e Espectrometria de Absorção Atômica se mostraram eficientes para a determinação dos elementos essenciais e tóxicos em amostras de alimentos comerciais infantis. Isso pode ser comprovado pela boa precisão e boa exatidão obtidas na determinação desses elementos nos materiais de referência certificados, onde o desvio-padrão relativo e o erro relativo foram menores do que $10 \%$ para a maioria dos elementos.

A maioria dos elementos essenciais encontrados nas amostras de alimentos comerciais infantis estava bastante abaixo do valor de ingestão dietética recomendada (RDA) ou de ingestão adequada ( $\mathrm{Al})$. Considerando que a criança receba exclusivamente este alimento, ao seguir a recomendação do Ministério da Saúde, para alguns elementos como ferro, cálcio e manganês, não é possível atingir os valores de RDA/AI para crianças até 8 meses. A partir dos 12 meses, as concentrações de alguns nutrientes superam os valores de ingestão dietética recomendada / ingestão adequada, porém estão abaixo do valor de UL, não trazendo risco devido à toxicidade do elemento.

A quantidade de elementos tóxicos como cádmio e mercúrio foi bastante baixa, sendo que em algumas amostras, sua concentração estava abaixo do limite de detecção. A concentração para ambos os elementos em todas as amostras é muito inferior ao valor do limite superior tolerável. 


\section{REFERÊNCIAS BIBLIOGRÁFICAS}

AGOSTONI, C., BRAEGGER, C., DECSI, T., KOLACEK, S., KOLETZKO, B., MICHAELSEN, K. F., MIHATSCH, W., MORENO, L. A., PUNTIS, J., SHAMIR, R., SZAJEWSKA, H., TURCK, D., van GOUDOEVER, J. Breast-feeding: a commentary by the ESPGHAN committee on nutrition. Journal of Pediatric Gastroenterology and Nutrition, v. 49, Issue 1, p. 112-125. 2009.

AGOSTONI, C., DECSI, T., FEWTRELL, M., GOULET, O., KOLACEK, S., KOLETZKO, B., MICHAELSEN, K. F., MORENO, L., PUNTIS, J., RIGO, J., SHAMIR, R., SZAJEWSKA, H., TURCK, D., van GOUDOEVER, J. Complementary feeding: a commentary by the ESPGHAN committee on nutrition. Journal of Pediatric Gastroenterology and Nutrition, v. 46, n. 1, p. 99-110. 2008.

AI KHALIFA, A. S., AHMAD, D. Determination of key elements by ICP-OES in commercially available infant formulae and baby foods in Saudi Arabia. African Journal of Food Science, v. 4, n. 7, p. 464-468. 2010.

AMORIM, F. A. C., LOBO, I. P., SANTOS, V. L. C. S., FERREIRA, S. L. C. Espectrometria de absorção atômica: 0 caminho para determinações multielementares. Química Nova, v. 31, n. 7, p. 1784 -1790. 2008.

ANATOLITOU, F. Human milk benefits and breastfeeding. Journal of Pediatric and Neonatal Individualized Medicine, v. 1, n. 1, review, p. 11-18. 2012.

AQUINO, R.C; PHILIPPI, S. T., Consumo infantil de alimentos industrializados e renda familiar na cidade de São Paulo. Revista de Saúde Pública, v. 36, n. 6, p. 655-660. 2002.

ARABI, M., FRONGILLO, E. A., AVULA, R., MANGASARYAN, N. Infant and young child feeding in developing countries. Child Development, v. 83, n. 1, p. 32-45. 2012.

BARBOSA, R. M. S., CROCCIA, C., CARVALHO, C. G. N., FRANCO, V. C., SALLES-COSTA, R., SOARES, E. A. Consumo alimentar de crianças com base na pirâmide alimentar brasileira infantil. Revista de Nutrição, v. 18, n. 5, p. 633641. 2005.

BERNARDI, J. L. D., JORDÃO, R. E., BARROS FILHO, A. A. Alimentação complementar de lactentes em uma cidade desenvolvida no contexto de um país em desenvolvimento. Revista Panamericana de Salud Pública, v. 26, n. 5, p. 405 - 411. 2009.

BLACK, M. M., QUIGG, A. M., HURLEY, K. M., PEPPER, M. R. Iron deficiency and iron-deficiency anemia in the first two years of life: strategies to prevent loss of development potential. Nutrition Reviews, v. 69, suppl. 1, p. 64 - 70. 2011. 
BORGES, D. L. G., CURTIUS, A. J., WELZ, B., HEITMANN, U. Fundamentos da espectrometria de Absorção Atômica de Alta Resolução com Fonte Contínua. Revista Analytica, n. 18, p. 58 - 67. 2005.

BORTOLINI, G. A., VITOLO, M. R Importância das práticas alimentares no primeiro ano de vida na prevenção da deficiência de ferro. Revista de Nutrição, v. 23, n. 6, p. 1051 - 1062. 2010.

BORTOLINI, G. A., VITOLO, M. R. Impacto de orientação dietética sistemática no primeiro ano de vida nas prevalências de anemia e deficiência de ferro aos 12-16 meses. Jornal de Pediatria, v. 88, n. 1, p. 33 - 39. 2012.

BORGES, D. L. G., CURTIUS, A. J., WELZ, B., HEITMANN, U. Fundamentos da espectrometria de absorção atômica de alta resolução com fonte contínua. Revista Analytica, n. 18, p. 58 - 67. 2005.

BRASIL. ANVISA, Portaria n. 685, de 26 de agosto de 1998. Princípios gerais para o estabelecimento de níveis máximos de contaminantes químicos em alimentos . Diário Oficial da União. Seção 1, parte 1, p. 1415- 1437. 1998.

BRASIL. Ministério da Saúde, Organização Pan-americana da Saúde. Guia alimentar para crianças menores de dois anos. Brasília. Ministério da Saúde (Série A Normas e manuais técnicos $\left.n^{\circ} 107\right) .2005$.

BRASIL. Departamento Científico de Nutrologia da Sociedade Brasileira de Pediatria. Manual de orientação para alimentação do lactente, do pré-escolar, do escolar, do adolescente e na escola. Sociedade Brasileira de Pediatria. 2006.

BRASIL. Ministério da Saúde, Dez passos para uma alimentação saudável. Guia alimentar para crianças brasileiras menores de dois anos. Brasília. Ministério da Saúde. 2010.

BRASIL. Ministério da Saúde, Dez passos para uma alimentação saudável para crianças brasileiras menores de dois anos. Brasília. Ministério da Saúde. 2010.

BRASIL. Resolução-RDC no 39, de 21 de março de 2001. Tabela de valores de referência para porções de alimentos e bebidas embalados para fins de Rotulagem Nutricional. Diário Oficial da União 2001. Março 22: seção 1, pt 1. 2001.

BRASIL. Resolução-RDC no 40, de 21 de março de 2001. Regulamento técnico para Rotulagem Nutricional Obrigatória de alimentos e bebidas embalados. Diário Oficial da União 2001. Março 22: seção 1, pt 1. 2001. 
BRASIL. Resolução-RDC no 360, de 26 de dezembro de 2003. Regulamento técnico de Porções de Alimentos Embalados para fins de Rotulagem Nutricional. Diário Oficial da União 2003. Dezembro 26: seção 1, pt 1. 2003.

BUENO, A.L., CZEPIELEWSKI, M.A. A importância do consumo dietético do cálcio e vitamina D no crescimento. Jornal de Pediatria, v. 84, n. 5, p. 386-394. 2008.

BUENO, A.L., CZEPIELEWSKI, M.A. Micronutrientes envolvidos no crescimento Revista do Hospital das Clínicas de Porto Alegre, v. 27, n. 3, p. 386-394. 2008.

CAETANO, M. C., ORTIZ, T. T. O., da SILVA, S. G. L., de SOUZA, F. I. S., SARNI, R. O. S. Alimentação complementar: práticas inadequadas em lactentes. Jornal de Pediatria, v. 86, n. 3, p. 196-201. 2010.

CARBONELL-BARRACHINA, A. A., RAMÍREZ-GANDOLFO, A., WU, X., NORTON, G. J., BURLÓ, F., DEACON, C., MEHARG, A. A. Essential and toxic elements in infant foods from Spain, UK, China and USA. Journal of Environmental Monitoring, v. 14, p. 2447-2455. 2012.

CASEY, C. E., WALRAVENS, P. A. Trace elements. In Tsang R. C. and Nichols, B. (eds). Nutrition During Infancy. Philadelphia, Hanley \& Belfus. 1988.

CEOTTO, C. S. Comparação de técnicas analíticas para determinação de elementos-traço em soluções de amostras ambientais. Universidade Federal do Espírito Santo. DIssertação de Mestrado em Química. 2009.

CHEZEM, J. C. Breastfeeding attitudes among couples planning exclusive breastfeeding or mixed feeding. Breastfeeding Medicine, v. 7, n. 3, p. 155-162. 2012.

CHUNG, Y. S., KIM, S. H., SUN, G. M., LIM, J. M., MOON, J. H., LEE. K. H., KIM, Y. J., CHOI, J. I., LEE, J. W. Comparison of elemental contents of Korean space foods using instrumental neutron activation analysis. Journal of Radioanalytical and Nuclear Chemistry, v. 291, p. 223-229. 2012.

COMINETTI, C., BORTOLI, M. C., ABDALLA, D. S. P., COZZOLINO, S. M. F. Considerações sobre estresse oxidativo, selênio e nutrigenética. Nutrire - Revista Brasileira de Alimentação e Nutrição, v. 36, n. 3, p. 131-153. 2011.

COUTINHO, J.G., RECINE, E. Experiências internacionais de regulamentação das alegações de saúde em rótulos de alimentos. Revista Pan-americana de Salud Pública, v. 22, n. 6, p. 432-437. 2007.

COZZOLINO, S. M. F. Biodisponibilidade de nutrientes. Editora Manole LTDA, $1^{\mathrm{a}}$ edição. 2005. 
CUNHA, L. R. Mercúrio em leite de mulheres residentes no Distrito Federal: concentração nos primeiros 90 dias, dieta materna e avaliação da exposição infantil. Universidade de Brasília. Dissertação de Pós Graduação em Ciências da Saúde. 2012.

CURRIE, L. A. Nomenclature in evaluation of analytical methods including detection and quantification capabilities (IUPAC Recommendations 1995). Analytica Chimica Acta, v. 391, p. 105-126. 1999.

DEEBA, F., ABBAS, N., SHAFIQUE, T., REHMAN, S., HUSSAIN, N. Chromium in various food items as regulators of different metabolic activities. Pakistan Journal of Biochemistry and Molecular Biology, v. 43, n. 1, p. 15-18. 2010.

DE SOETE, D.; GIJELS, R. e HOSTE, J. Neutron activation analysis. London. Wiley-Interscience. 1972

DIAS, M. C. A. P., FREIRE, L. M. S. (In memoriam), FRANCESCHINI, S. C. C. Recomendações para alimentação complementar de crianças menores de dois anos. Revista de Nutrição, v. 23, n. 3, p. 475-486. 2010.

DI PIERO, A., BACCHI, M. A., FERNANDES, E. A. N. INAA with gamma-gamma coincidence for selenium determination in food. Journal of Radioanalytical and Nuclear Chemistry, v. 278, n. 3, p. 761-765. 2008.

DUTTA, T. K., MUKTA, V. Trace elements. The Association of Physicians of India. Medicine update, endocrinology. 2012.

DONATI, G. L. Avaliação da viabilidade da determinação de cobalto e cromo em alimentos por espectrometria de absorção atômica com forno tubular na chama e aerossol térmico. Universidade Federal de São Carlos. Dissertação em ciências, área de concentração: Química Analítica. 2006.

FARYADI, Q. The magnificent effect of magnesium to human heatlh: a critical review. International Journal of Applied Science and Technology, v. 2, n. 3, p. 118-126. 2012.

FORDYCE, F. Selenium deficiency and toxicity in the environment. Essentials of Medical Geology, cap. 15, p. 373-415, Edinburgh. Ed. Elsevier. 2005.

GAIKWAD, R. H. Neutron Activation Analysis. A Periodical of Indian Research Scholar's Association for Promoting Science, v. 1, Issue 1, p. 26-34. 2011.

GIUGLIANI, E. R. J., VICTORA, C. G. Complementary feeding. Jornal de Pediatria, v. 76, suppl. 3, p. 253-262. 2000. 
GOMES, M. S., TREVIZAN, L. C., NÓBREGA, J. A., GOUVEIA, S. T., ROCHA, F. R. P. Integração de técnicas analíticas e proposta de experimentos para cursos de graduação em análise instrumental: uso de espectrômetro de absorção atômica para medidas de absorção molecular. Química Nova, v. 29, n. 4, p. 868-871. 2006.

GUERRA, A., REGO, C., SILVA, D., FERREIRA, G. C., MANSILHA, H., ANTUNES, H., FERREIRA, R. Alimentação e nutrição do lactente. Acta Pediátrica Portuguesa, v. 43, n. 5. P. 17-40. 2012.

HOLLER, F. J., SKOOG, D. A., CROUCH, S. R. Princípios de Análise Instrumental. ARTMED EDITORA S.A. 6” edição, p. 244 - 262. 2009.

HUNTER, C., GOTTHEIL, S., KENYON, C. Breastfeeding promotion: the NICU perspective. University of Western Ontario Medical Journal, v. 81, Issue 1, p. 31-47. 2012.

IAEA. International Atomic Energy Agency. Practical aspects of operating a nêutron activation analysis laboratory, IAEA - TECDOC - 564. 1990.

INSTITUTE OF MEDICINE. Food and Nutrition Board. Dietary references Intakes. National Academic Press, Washington D. C., 1999 - 2001. Disponível em: <http://www.iom.edu/Activities/Nutrition/SummaryDRIs/ /media/Files/Activity\%20Fi les/Nutrition/DRIs/5_Summary\%20Table\%20Tables\%201-4.pdf >. Data de acesso: $\mathrm{mar} / 2013$.

JARDIM, P. C. B. V., MONEGO, E. T., REIS, M. A. C. Potássio, cálcio, magnésio e hipertensão arterial. Revista Brasileira de Hipertensão, v. 11, n. 2, p. 109 - 111. 2004.

KAZI, T. G., JALBANI, N., BAIG, J. A., ARAIN, M. B., AFRIDI, H. I., JAMALI, M. K., SHAH, A. Q., MEMON, A. N. Evaluation of toxic elements in baby foods commercially available in Pakistan. Food Chemistry, v. 119, n. 4, p. 1313-1317. 2010.

KRAMER, M.S. e KAKUMA, R. Optimal duration of exclusive breastfeeding. Cochrane Database of Systematic Reviews, Issue 8, Art. No.: CD003517. DOI: 10.1002/14651858.CD003517.pub2. p. 1-11. 2012.

KUBOTA, N., OSHIRO, J. H., BALDUINO, M. A., de FARIA, Z. Avaliação de material educativo: adequação de quatro volantes sobre alimentação da criança de 0 a 12 meses de idade. Revista de Saúde Pública, v. 14, n. 1, p. 101-122. 1980. 
LADOMENOU, F., MOSCHANDREAS, J., KAFATOS, A., TSELENTIS, Y., GALANAKIS, E. Protective effect os exclusive breastfeeding against infections during infancy: a prospective study. Archives of Disease in Childhood, n. 95, p. 1004-1008. 2010.

LOFGREN, R. E. G. Alimentação complementar no primeiro ano de vida: as recomendações e a prática. Universidade do Estado do Rio de Janeiro. Monografia, Curso de especialização em Nutrição Materno-Infantil. 2008.

LOPEZ, F. A.; BRASIL, A. L. D. Nutrição e dietética em clínica pediátrica. São Paulo: Atheneu, cap. 14. Universidade do Estado do Rio de Janeiro. Monografia de especialista em nutrição materno-infantil. 2004.

LOZOFF, B. Iron deficiency and child development. Food and Nutrition Bulletin, v. 28, n. 4 , p. 560-571. 2007.

MARINS, B.R., JACOB, S.C., PERES, F. Avaliação qualitativa do hábito de leitura e entendimento: recepção das informações de produtos alimentícios. Ciências e Tecnologia de Alimentos, v. 28, n. 3, p. 579-585. 2008.

MELO, R., GELLEIN, K., EVJE, L., SYVERSEN, T., Minerals and trace elements in commercial infant food. Food and Chemical Toxicology, v. 46, p. 3339-3342. 2008.

MENNELLA, J. A., TRABULSI, J. C. Complementary foods and flavor experiences: setting the foundation. Annals of Nutrition and Metabolism, v. 60, suppl. 2, p. 40-50. 2012.

MICARONI R. C. C. M., BUENO M. I. M. S., JARDIM W. F. Compostos de mercúrio. Revisão de métodos de determinação, tratamento e descarte. Química Nova, v. 23, n. 4, p. 487-495. 2000.

MONTE, C. M. G, GIUGLIANI, E. R. J., Recomendações para alimentação complementar da criança em aleitamento materno. Jornal de Pediatria, v. 80, n. 5 (supl.), p. 131-141. 2004.

MONTEIRO, R. A., COUTINHO, J. G., RECINE, E. Consulta aos rótulos de alimentos e bebidas por frequentadores de supermercados em Brasília, Brasil. Revista Pan-americana de Salud Pública, v. 18, n. 3, p. 172-177. 2005.

MORAIS, S., COSTA, F. G., PEREIRA, M. L. Heavy metals and human health. Environmental health - emerging issues and practice, cap. 10, p. 227-247. Shanghai. Ed. Hard cover. 2012.

MORRIS Jr., R. C., SCHMIDLIN, O., FRASSETTO, L. A., SEBASTIAN, A. Relationship and interaction between sodium and potassium. Journal of the American College of Nutrition, v. 25, suppl. 3, p. 262-270. 2006. 
NARDI, E. P., EVANGELISTA, F. S., TORMEN, L., SAINT'PIERRE, T. D., CURTIUS, A. J., SOUZA, S. S., BARBOSA Jr, F. The use of inductively coupled plasma mass spectrometry (ICP-MS) for the determination of toxic and essential elements in different types of food samples. Food Chemistry, v. 112, Issue 3, p. 727-732. 2009.

NICKLAUS, S. Development of food variety in children. Appetite, v. 5, n. 1, p. 253255. 2009.

NICK, M. S. A importância do aleitamento materno exclusivo nos primeiros seis meses de vida para a promoção da saúde da criança. Universidade Federal de Minas Gerais. Trabalho de conclusão de curso, Curso de especialização em atenção básica em saúde da família. 2011.

NIELSEN, F. H. Manganese, Molybdenum, boron, chromium, and other trace elements. Present Knowledge in Nutrition, Tenth Edition, p. 586-589. 2012.

NOOKABKAEW, S., RANGKADILOK, N., AKIB, C. A., TUNTIWIGIT, N., SAEHUN, J., SATAYAVIVAD, J. Evaluation of trace elements in selected foods and dietary intake by young children in Thailand. Food Additives and contaminants: Part B: Surveillance, p. 1-13. 2012.

OLIVEIRA FILHO, J. N., OLIVEIRA, K. B. Análise da contaminação de cobre na água do estuário Jundiaí-Potengi. Análise de contaminação de cobre na água do estuário Jundiaí-Potengi. V Encontro da Licenciatura em Geografia do IFRN, p. 1576-1585. 2011. Disponível em: <http://dc343.4shared.com/doc/kaPTzhTT/preview.html>. Data de acesso: mar/2013.

OWINO, V., AMADI, B., SINKALA, M.,FILTEAU, S., TOMKINS, A. Complementary feeding practices and nutrient intake from habitual complementary food of infants and children aged 6-18 months old in Lusaka, Zambia. African Journal of Food Agriculture Nutrition and Development, v. 8, n. 1, p. 28-47. 2008.

PAHO/WHO. Guiding Principles for Complementary Feeding of the Breastfeed Child. Division of Health Promotion and Protection. Food and Nutrition Program. Pan American Health Organization- World Health Organization. WashingtonGeneva. 2003.

PANDELOVA, M., LOPEZ, W. L., MICHALKE, B., SCHRAMM, K. W. Ca, Cd, Cu, $\mathrm{Fe}, \mathrm{Hg}, \mathrm{Mn}, \mathrm{Ni}, \mathrm{Pb}$, Se and $\mathrm{Zn}$ contents in baby foods from the EU market: Comparison of assessed infant intakes with the present safety limits for minerals and trace elements. Journal of Food Composition and Analysis,n. 27, p. 120127. 2012. 
PARK, K., MIN, H., YIM, Y-H., YIM, Y-L., HWANG, E-J., CHO, K. Instrumental neutron activation analysis (INAA) and isotope dilution-inductively coupled plasma mass spectrometry (ID-ICP/MS) for certification of multielements in a tuna fish candidate certified reference material. Journal of Food Composition and Analysis, v. 24, n. 7, p. 1064-1068. 2011.

PEREIRA, A. G., MUNIZ, L. B. Avaliação da suplementação de cromo em pacientes diabéticos tipo II em um centro de saúde de Brasília - Distrito Federal. Revista de Divulgação Científica Sena Aires, v. 1, n. 1, p. 25 - 31. 2012.

PEREIRA, G. A. P., GENARO, P. S., PINHEIRO, M. M., SZEJNFELD, V. L., MARTINI, L. A. Cálcio dietético - estratégias para otimizar o consumo. Revista Brasileira de Reumatologia, v. 49, n. 2, p. 164-171. 2009.

PHILIPPI, S. T., CRUZ, A. T. R., COLUCCI, A. C. A. Pirâmide alimentar para crianças de 2 a 3 anos. Revista de Nutrição, v. 16, n. 1, p. 5-19. 2003.

REDERSTORFF, M., KROL, A., LESCURE, A. Understanding the importance of selenium and selenoproteins in muscle function. Cellular and Molecular Life Sciences, v. 63, p. 52-59. 2006.

RIBEIRO, A. S., ARRUDA, M. A. Z., CADORE, S. Espectrometria de absorção atômica eletrotérmica em filamento de tungstênio. Uma revisão crítica. Química Nova, v. 25, n. 3, p. $396-405.2002$.

RIELLA, M. C., PACHALY, M. A. Metabolismo do Potássio. Princípios de Nefrologia e Distúrbios Hidroeletrolíticos., cap 12, p. 129 - 142. Rio de Janeiro. Ed. Guanabara Koogan. 1996.

SANTOS, A. C., ABREU-LIMA, C. Hipertensão de difícil controle: impacto do estilo de vida. Revista Brasileira de Hipertensão, v. 16, suppl. 1, p. 5-6. 2009.

SANTOS, M. C. A. Alimentação no primeiro ano de vida: hábitos de aleitamento e de diversificação alimentar. Universidade Atlântica, Licenciatura em Ciências da Nutrição. 2010.

SARACOGLU, S., SAYGI, K. O., ULUOZLU, O. D., TUZEN, M., SOYLAK, M. Determination of trace element contents of baby foods from Turkey. Food Chemistry, v. 105, p. 280-285. 2007.

SCHIESS, S., GROTE, V., SCAGLIONI, S., LUQUE, V., MARTIN, F, STOLARCZYK, A., VECCHI, F., KOLETZKO, B. Introduction of complementary feeding in 5 European countries. Hepatology and Nutrition, v. 50, n. 1, p. 92-98, January. 2010.

SILVA, A. I. e AGUIAR, H. G. Diversificação alimentar no primeiro ano de vida. Acta Médica Portuguesa, v. 24, n. 4, p. 1035-1040. 2011. 
THOMPSON, M. Recent trends in inter-laboratory precision at ppb and sub-ppb concentrations in relation to fitness for purpose criteria in proficiency testing. Analyst, v. 125, p. $385-386.2000$.

TOLONI, M. H. A., LONGO-SILVA, G., GOULART, R. M. M., TADDEI, J. A. A. C. Introdução de alimentos industrializados e de alimentos de uso tradicional na dieta de crianças de creches públicas no município de São Paulo. Revista de Nutrição, v. 24, n. 1, p. 61-70. 2011.

TORIGOE, C. Y., ASAKURA, L., SACHS, A., da SILVA, C. V. D., ABRÃO, A. C. F. V., dos SANTOS, G. M. S., COELHO, L. C. Influence of the nutritional intervention in complementary feeding practices in infants. Revista Brasileira de Crescimento e Desenvolvimento Humano, v. 22, n. 1, p. 85-92. 2012.

VIEIRA, G. O., SILVA, L. R., VIEIRA, T, O., ALMEIDA, J. A. G., CABRAL, V. A. Hábitos alimentares de crianças menores de 1 ano amamentadas e nãoamamentadas. Jornal de Pediatria, v. 80, n. 5, p. 411-416. 2004.

VIEIRA, M. N. C. M., JAPUR, C. C., RESENDE, C. M. M., MONTEIRO, J. P. Valores de referência de ingestão de nutrientes para avaliação e planejamento de dietas de crianças de um a oito anos. Revista da Faculdade de Medicina de Ribeirão Preto, v. 41, n. 1, p. 67 - 76. 2008.

VIM, Vocabulário Internacional de Termos Fundamentais e Gerais de Metrologia. 5.14. 1aㅡ edição luso- brasileira. 2012.

WAYHS, M. L. C., de SOUZA, F. I. S., BENZECRY, S. G. Anemia ferropriva em lactentes: uma revisão com foco em prevenção. Sociedade Brasileira de Pediatria. Nutrologia. 2012.

WELZ, B; SPERLING, M. Atomic Absorption Spectrometry. $3^{\text {a }}$ edição, Weinheim, Gemany: Wiley-VCH. 1999.

ZAGATTO, E. A. G. Análise por Ativação com Nêutrons. Centro de Energia Nuclear na Agricultura. FAN 2 - Seminário 1. 9 de outubro. 2000. Disponível em: $<$ http://apostilas.cena.usp.br/Zagatto/>. Data de acesso:fev/2013.

ZAND, N., CHOWDHRY, B. Z., WRAY, D. S., PULLEN, F. S., SNOWDEN, M. J. Elemental content of commercial 'ready to-feed' poultry and fish based infant foods in the UK. Food Chemistry, v. 135, p. 2796-2801. 2012.

ZAND, N., CHOWDHRY, B. Z., ZOTOR, F. B., WRAY, D. S., AMUNA, P., PULLEN, F. S. Essential and trace elements content of commercial infant foods in the UK. Food Chemistry, v. 128, p. 123-128. 2011. 